\title{
Vegetationsgeschichtliche Untersuchungen in der westlichen Prignitz, dem östlichen Hannoverschen Wendland und der nördlichen Altmark
}

\author{
Dissertation \\ zur Erlangung des Doktorgrades \\ der Mathematisch-Naturwissenschaftlichen Fakultäten \\ der Georg-August-Universität zu Göttingen \\ vorgelegt von \\ Jörg Christiansen \\ aus Risum-Lindholm
}

Göttingen 2008 
D7

Referent: $\quad$ Prof. Dr. Hans-Jürgen Beug

Korreferent: $\quad$ Prof. Dr. Hermann Behling

Tag der mündlichen Prüfung: 30.04.08 
$\begin{array}{ll}\text { Einleitung } & 6\end{array}$ 
Literaturverzeichnis

Danksagung

Anhang

Lebenslauf 


\section{$1 \quad$ Einleitung}

Die vorgelegte Dissertation entstand im Rahmen von zwei DFG-Projekten. Zunächst begann die Arbeit als Teil eines Forschungsprojektes im Rahmen des DFG-Schwerpunktprogramms „Wandel der Geo-Biosphäre während der letzten 15.000 Jahre - Kontinentale Sedimente als Ausdruck sich verändernder Umweltbedingungen“. In der westlichen Prignitz und in der Altmark sollten durch hochauflösende vegetationsgeschichtliche Untersuchungen die Beziehungen zwischen Vegetations-, Siedlungs- und Klimageschichte bearbeitet werden, um insbesondere den Kenntnisstand für die Zeitscheibe III (3500-1500 cal. BP) auf einen mit benachbarten Landschaften vergleichbaren Stand zu bringen.

Die durchgeführten Arbeiten, am Arendsee in der nördlichen Altmark das Profil ARS 4 und im Rambower Moor in der westlichen Prignitz das Profil Boberow, brachten zwar erste Ergebnisse, eröffneten aber ebenso viele neue Fragen. Die Beschränkung auf die kurze Zeitscheibe III war für eine vegetationsgeschichtliche Arbeit aus einer Region, von der bislang keine ausführlichen Untersuchungen vorlagen, nicht ausreichend. Es erschien vielmehr wünschenswert, die begonnenen Arbeiten fortzusetzen und den betrachteten Zeitraum deutlich auszudehnen.

Das dazu notwendige Kernmaterial aus dem Arendsee war vorhanden, und so wurde die Arbeit mit den Untersuchungen am Profil ARS 1 fortgesetzt. Der Bildung der Sedimente reicht bis zum Ende der Jüngeren Dryas-Zeit zurück, und somit konnte für die nördliche Altmark die Vegetationsentwicklung vom Ende der letzten Eiszeit bis heute rekonstruiert werden.

Im Jahr 2004 begann das zur Zeit noch nicht beendete DFG-Projekt „Paläoökologische Untersuchungen über die Entwicklung der Pflanzendecke zur Slawenzeit - ein Beitrag zu den Beziehungen zwischen Umwelt und Besiedlung in der westlichen Peripherie des slawischen Siedlungsraumes.“

Als Teilprojekt eines DFG-Paket-Antrags, bei dem in enger Zusammenarbeit mit archäologischen Teilprojekten gearbeitet wird, ist das paläoökologische Untersuchungsziel die Vegetationsentwicklung der Zeit zwischen ca. 1000 v. Chr. bis 1400 n. Chr. Die Einbeziehung der vorslawenzeitlichen Abschnitte dient dabei dem Verständnis der Vorgänge, die zu der am Beginn der Slawenzeit anzutreffenden Pflanzendecke geführt haben. 
Dies ermöglichte dann abschließende Untersuchungen der jüngeren Teile aus dem Arendsee, sowie die Fortführung der Untersuchungen im Rambower Moor.

Weitere Untersuchungen im Rahmen dieses Projektes am Rudower See ebenfalls in der westlichen Prignitz und in Friedrichsruhe im südwestlichen Mecklenburg-Vorpommern laufen noch oder sind in Vorbereitung, können aber Rahmen dieser Arbeit nicht mehr mit vorgestellt werden. 


\section{Untersuchungsgebiet}

\subsection{Untersuchungspunkte}

Im Rahmen dieser Arbeit werden die Ergebnisse von drei Untersuchungspunkten vorgestellt: Ein kleines Moor im östlichen Hannoverschen Wendland am Laascher Heuweg, das Rambower Moor in der westlichen Prignitz und der Arendsee in der nördlichen Altmark (Abb. 1).

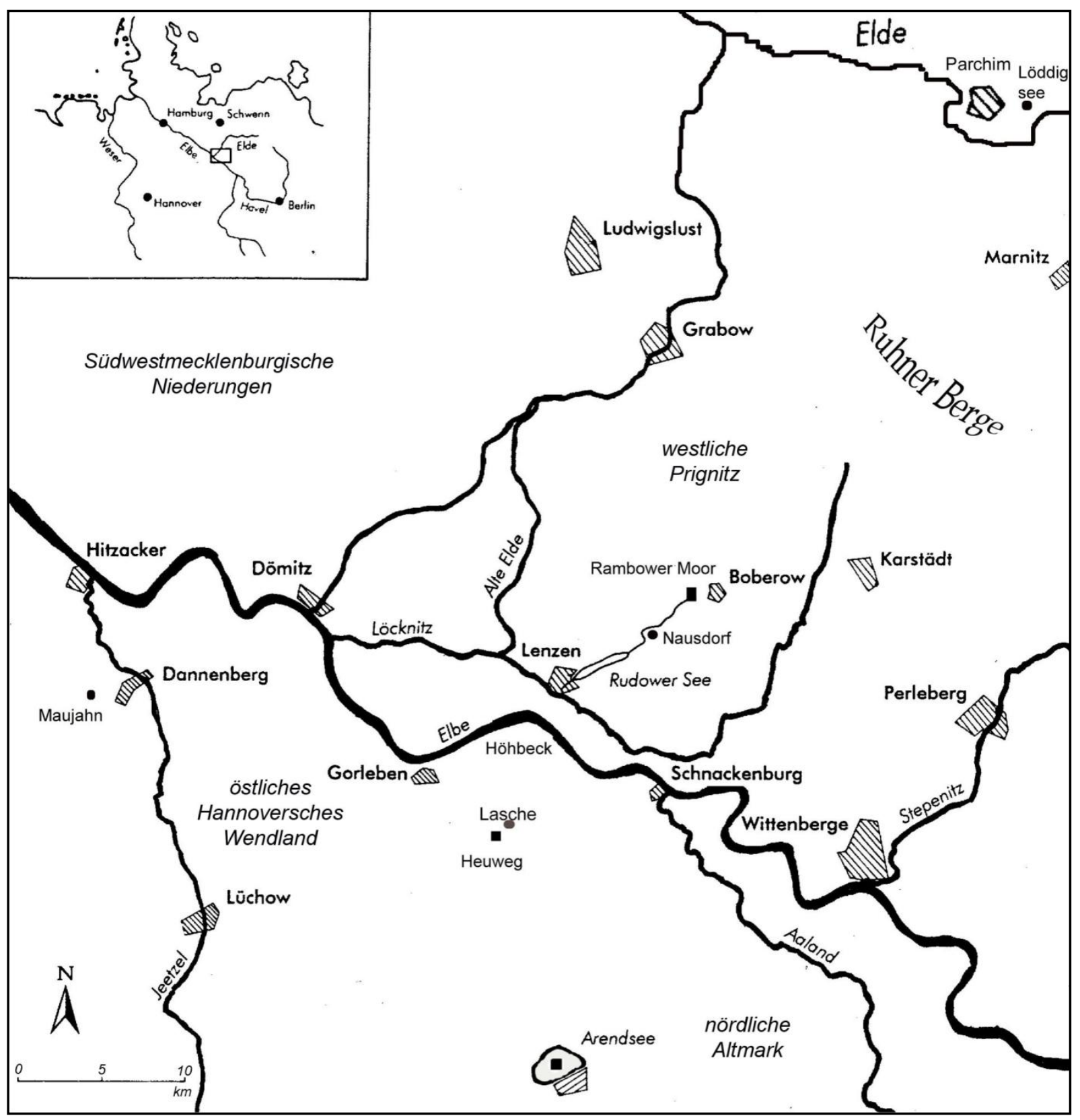

Abb. 1: Übersichtskarte des Untersuchungsgebietes, schwarze Vierecke markieren die Untersuchungspunkte.

Der Schwerpunkt der Arbeit liegt dabei auf der Untersuchung mehrerer Profilkerne aus dem Arendsee. Das Moor am Heuweg, das bereits von LeSEMANN (1969) untersucht wurde, diente 
vor allem zur Gewinnung von korrelierbaren ${ }^{14} \mathrm{C}$-Daten. Im Rambower Moor wurden neue Untersuchungen zu den im Jahr 1998 vorgestellten Diplomarbeiten (CHRISTIANSEN 1998, KIRLEIS 1998) durchgeführt. Mit diesen Untersuchungspunkten werden drei Regionen erfasst, das östliche Hannoversche Wendland mit dem Profil vom Heuweg, die westliche Prignitz mit den Profilen von Rambow und Boberow aus dem Rambower Moor und die nördliche Altmark mit drei Profilen aus dem Arendsee. Die Prignitz gehört zu Brandenburg, das Hannoversche Wendland zu Niedersachsen und die Altmark liegt in Sachsen-Anhalt. Dabei trennt die Elbe die Prignitz vom Wendland und der Altmark.

\subsection{Geologie}

Aus geologischer Sicht gehört das Untersuchungsgebiet zum einheitlichen Gebiet der Norddeutschen Senke. Der präquartäre Untergrund spielt hier nur insofern eine Rolle, als dass sowohl das Rambower Moor als auch der Arendsee über Salzstöcken liegen. Durch Subrosion bedingte Einbrüche schufen dann eine Rinne bzw. ein Becken, in denen sich heute diese Seen befinden.

Das Untersuchungsgebiet wurde in seiner quartären Entwicklung von den Eismassen der Elster- und der Saale-Eiszeit überfahren. Das Eis der Weichsel-Vereisung reichte dagegen nicht so weit und hatte nur indirekten Einfluss auf die Entwicklung der Landschaft.

Die Schmelzwässer der Elster-Eiszeit gruben sich tief in den Untergrund ein und bildeten ein System von Rinnen, die stellenweise 400 Meter tief sind. Sie wurden anschließend mit elsterzeitlichen Schmelzwassersanden und den Lauenburger Tonen wieder aufgefüllt (JäGER 2002). In der Saale-Eiszeit wurde das Gebiet mehrfach vom Inlandeis überfahren, wahrscheinlich zweimal im Drenthe-Stadium und dreimal im Warthe-Stadium (OELKE 1997). Dabei wurden Geschiebemergel und -lehme abgelagert, die in weiten Teilen des Untersuchungsgebiets, in der Regel auf Hochflächen, dominieren. In der Saale-Eiszeit wie auch in der Elster-Eiszeit, kamen Schmelzwassersande zur Ablagerung, die sich überwiegend in den Tälern und Senken akkumulierten. In der Weichsel-Eiszeit lag das Untersuchungsgebiet im Periglazialraum. Der Eisrand lag nördlich bei den bei Marnitz gelegenen $178 \mathrm{~m}$ hohen Ruhner Bergen, die als Endmoränenstaffel angesprochen werden können (LIEDTKE 1994). Während der Sommermonate kam es zu Solifluktion und Abschwemmungen an den Geesthängen. Es bildeten sich sandige Schwemmfächer, die sich in die Niederterrassensande des Elbe-Urstromtals einschalteten. Im Holozän kam es in den Elbtalauen zur Sedimentation von Flusssand, Auelehm, Mudde und Torf, was in geringerem Maß auch für die Zuflüsse der Elbe zutrifft. Außerdem wurden aus den Niederterrassen große Mengen an Sand ausgeblasen, der sich als Flugsand in 
Dünenfeldern ablagerte (JÄGER 2002). In einem solchen Dünenfeld liegt das Kleinmoor am Laascher Heuweg. Somit wird das gesamte Untersuchungsgebiet dem lößfreien Altmoränengebiet zugerechnet.

Die Oberfläche der Westlichen Prignitz ist als Grundmoränenplatte der Saale-Kaltzeit anzusprechen. Nach HURTIG (1957) ist sie zum Teil von weichselzeitlichen Sanderflächen überdeckt (Abb. 2). Das Rambower Moor liegt im Bereich der Grundmoränenplatte, aber außerhalb der Sanderflächen. Der Arendsee liegt im Übergangsbereich zwischen den Sanderflächen im Norden und der als Altmarkplatte bezeichneten Grundmoränenplatte im Süden.

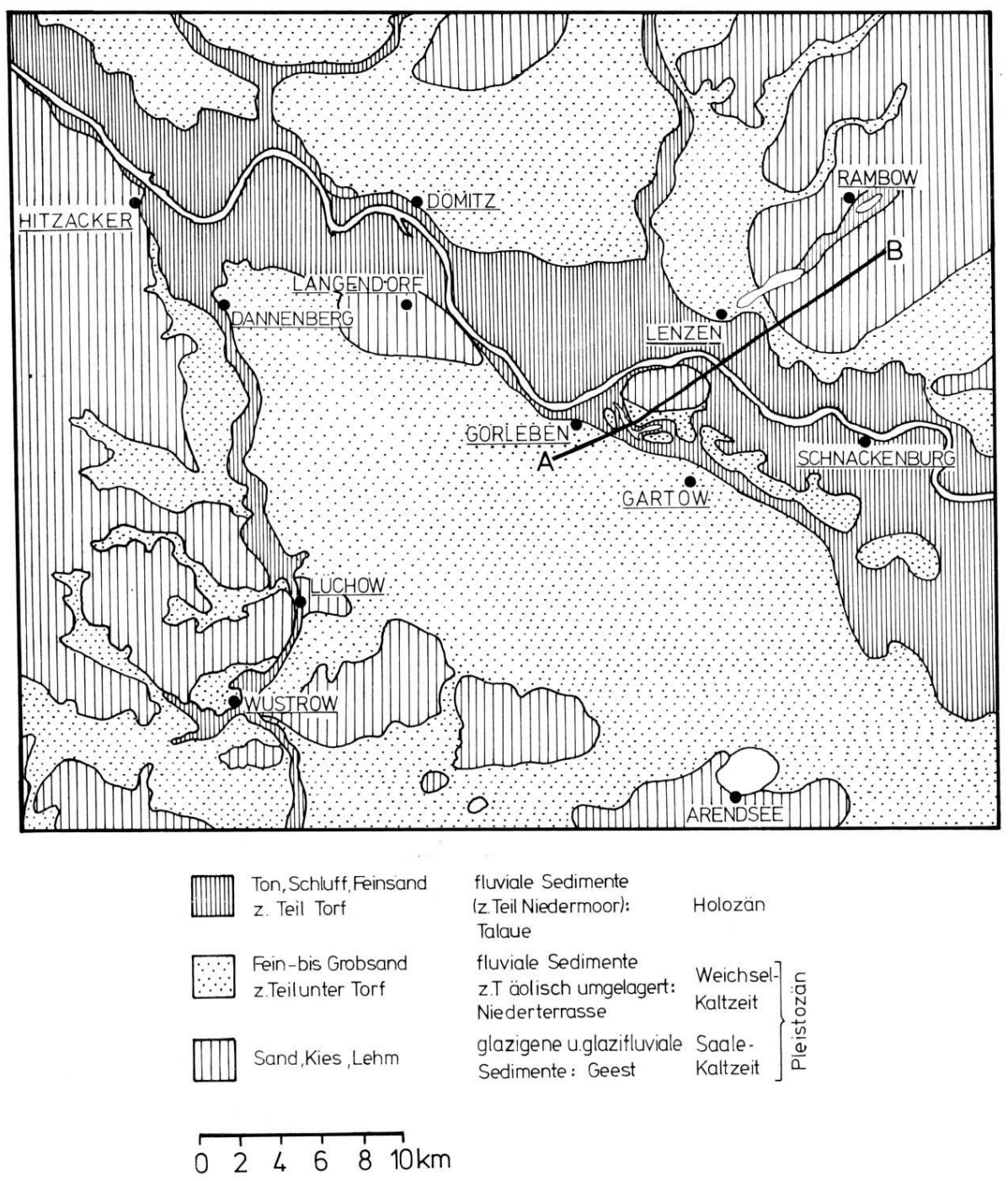

Abb. 2: Quartärgeologische Übersichtskarte des Untersuchungsgebietes, (GRIMMEL 1980), verändert. Die Strecke A-B gibt die Lage des Schnittes in Abb. 3 an.

Abb. 3 zeigt ein quartärgeologisches Profil durch das Elbtal (Holozän bis Saale-Kaltzeit), die Lage des Profils ergibt sich aus Abb. 2 (GRIMMEL 1980). Das Rambower Moor und der Rudower See liegen in einer Subrosionsrinne, die teilweise über $20 \mathrm{~m}$ tiefer als das umgebende 
Gelände liegt. Deutlich erkennt man, dass der Höhbeck (als Insel), der Gorlebener/Gartower Forst und der Damrower Forst außerhalb des Hochwasserbereiches der Elbe liegen.

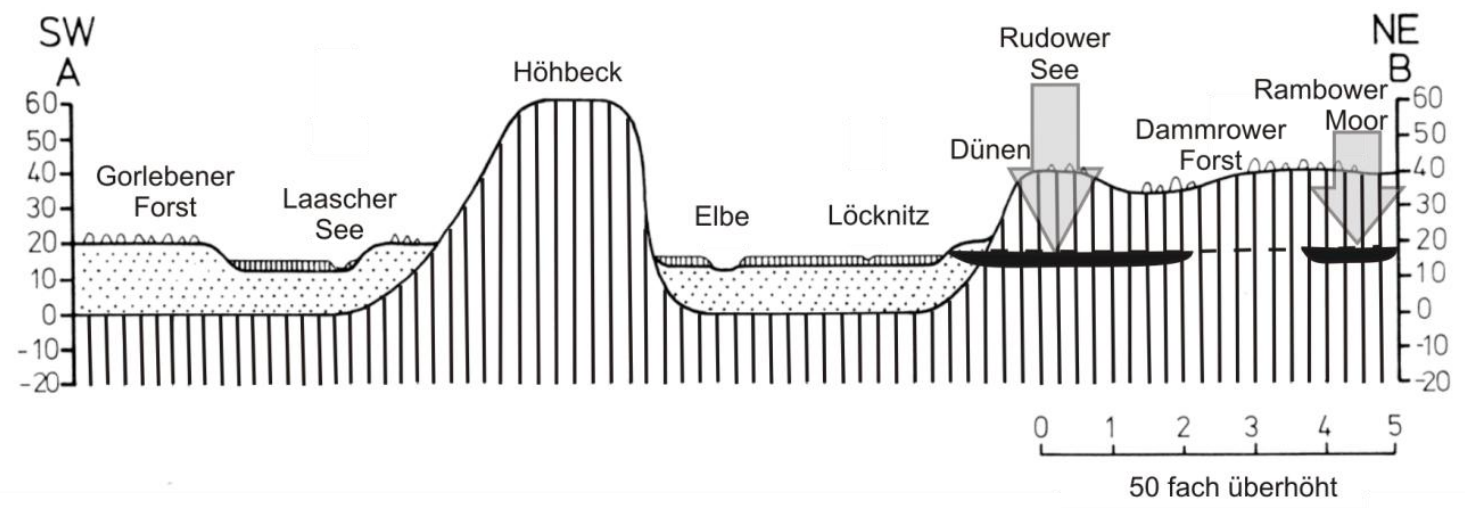

Abb. 3: Quartärgeologisches Profil durch das Elbtal, Holozän bis Saale-Kaltzeit (GRIMMEL 1980), verändert, Lage des Profils und Legende vgl. Abb. 2.

\subsubsection{Böden}

In der Prignitz herrschen im Bereich der Grundmoränenplatten lehmige Böden vor, die Braunerden mittlerer Güte gebildet haben. Im Bereich der Sanderflächen sind die Sandböden podsoliert, so dass sie nur von geringem landwirtschaftlichem Nutzen sind. In den Tälern sind die Böden häufig vergleyt (FINCK 2002).

Da der Arendsee im Übergangsbereich zwischen den Sanderflächen im Norden und der Altmarkplatte im Süden liegt, gibt es hier im Nordosten Regosole bis Podsole aus Dünensand, im Nordwesten herrschen Gleye bis Humusgleye aus Niederungssand vor. Im Süden liegen lehmige Böden vor, die Braunerde- Fahlerden aus lehmigem Geschiebedecksand über Geschiebelehm gebildet haben, aber auch podsolige Sauerbraunerden bis Braunerde-Podsole und Rosterden aus Geschiebedecksand über Schmelzwassersand sowie Gleye aus lehmigem Sand über Niederungssand oder -lehm (Übersichtskarte der Böden, BÜK400d, Geologisches Landesamt Sachsen-Anhalt 1994). Das Moor am Laascher Heuweg liegt inmitten der Sanderflächen in einem Bereich, dem Gartower Forst, in dem sich ausgedehnte Dünen gebildet haben (LESEMANN 1969).

\subsection{Klima}

Das Untersuchungsgebiet liegt klimageographisch im Übergangsbereich vom einem subatlantisch zum einem subkontinental getönten Klima. Für die Zeit von 1961-1990 waren nur für die Station Lüchow sowohl mittlerer monatlicher Niederschlag und die durchschnittliche monatliche Tagestemperatur verfügbar (Tabelle 1). 
Tabelle 1: Klimadaten: Niederschläge in $\mathrm{mm}$, für Lüchow auch die durchschnittlichen Tagestemperaturen (Daten vom Deutschen Wetter Dienst 1961-1990)

\begin{tabular}{|c|c|c|c|c|c|c|c|c|c|c|c|c|c|}
\hline Station & Jan & Feb & Mrz & Apr & Mai & Jun & Jul & Aug & Sep & Okt & Nov & Dez & Jahr \\
\hline Arendsee & 45,4 & 34,5 & 39,1 & 44,0 & 49,9 & 63,6 & 57,4 & 52,7 & 46,7 & 35,8 & 47,2 & 49,8 & $566,1 \mathrm{~mm}$ \\
\hline \hline Lenzen & 48,8 & 34,7 & 42,6 & 45,3 & 51,2 & 67,7 & 74,3 & 63,8 & 50,3 & 37,7 & 49,5 & 51,1 & $617,1 \mathrm{~mm}$ \\
\hline Lüchow & 41,4 & 32,2 & 36,3 & 41,3 & 48,1 & 61,5 & 66,0 & 54,7 & 41,3 & 34,0 & 42,5 & 45,8 & $545,2 \mathrm{~mm}$ \\
\hline \hline Lüchow & $-0,1$ & 0,5 & 3,7 & 7,6 & 12,7 & 15,9 & 17,2 & 16,9 & 13,5 & 9,3 & 4,6 & 1,4 & $8,6^{\circ} \mathrm{C}$ \\
\hline
\end{tabular}

In Abb. 4 ist der Jahresverlauf für Lüchow dargestellt. Deutlich erkennt man, dass die Hauptmenge des Niederschlages während der Vegetationsperiode fällt. Für die Stationen Arendsee und Lenzen waren aus diesem Zeitraum nur die Niederschlagsdaten verfügbar, die Niederschlagsverteilung übers Jahr gesehen ist dabei den Werten auch Lüchow recht ähnlich. Für die Region um den Arendsee geben WOLFF et al. (2003) 8,5 $5^{\circ} \mathrm{C}$ mittlere Lufttemperatur im Jahr an, dies deckt sich gut mit den Werten aus Lüchow und man darf wohl davon ausgehen, das im gesamten Untersuchungsgebiet keine gravierende Abweichungen zu erwarten sind.

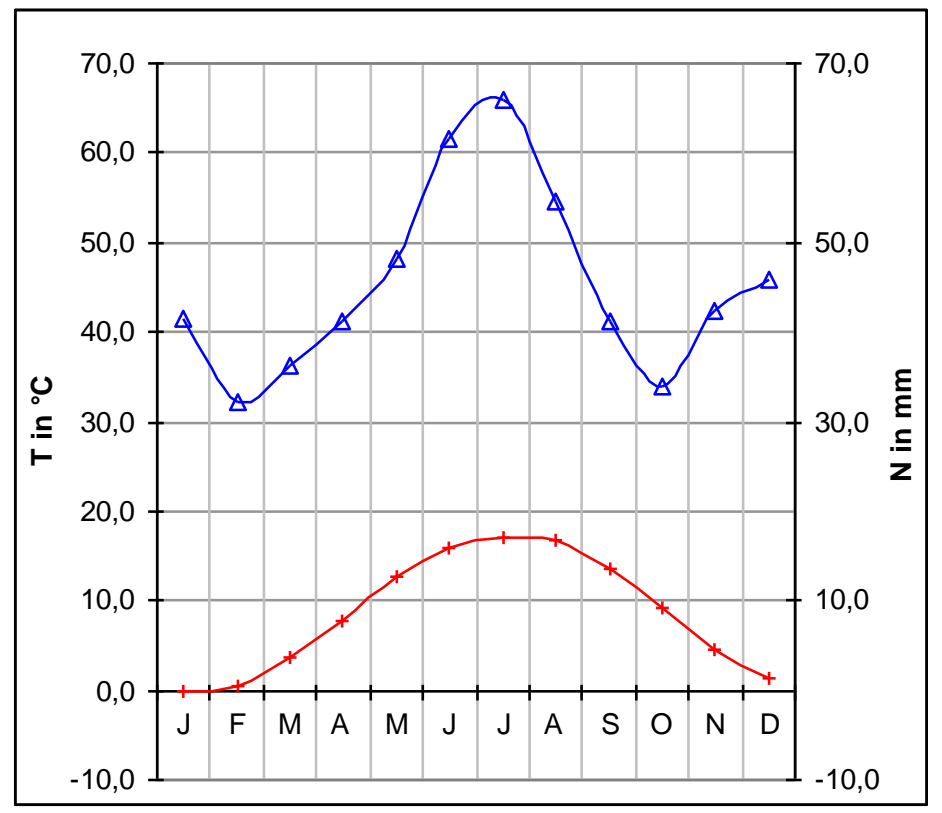

Abb. 4: Mittlerer monatlicher Niederschlag (Dreiecke) und die durchschnittliche monatliche Tagestemperatur (Kreuze) für die Station Lüchow (Daten vom Deutschen Wetter Dienst 19611990) 


\subsection{Naturräumliche Gliederung und Vegetation}

\subsubsection{Arendsee und Umgebung}

Der Arendsee liegt nordwestlich der direkt an den See grenzenden gleichnamigen Stadt in der Altmark (Abb. 1). Die Altmark geht im Norden und Westen eher unmerklich in die LüchowDannenberger Niederung und in das Vorland der Lüneburger Heide über. Im Nordosten und Osten liegen die Elbeniederung und die Wische, zum Süden und Südwesten begrenzen die Ohreniederung und der Drömling die Altmark. Geologie und Oberflächenformen werden von warthestadialen Bildungen dominiert. Charakteristisch ist eine enge Verzahnung von pleistozänen Endmoränenlagen, Grundmoränenlagen, Sanderflächen, Talsandebenen und holozän überprägten Niederungen (OELKE 1997).

Beim Arendsee handelt sich um einen natürlich entstandenen, mittelgroßen Subrosionssee. Zwei in schriftlichen Quellen angeführte Einstürze, in den Jahren 822 und 1685, führten zu der heutigen Gestalt (HalbFASS 1896). In der Chronik der Stadt Arendsee (FELCKE 1891) wird über den „Wendischen See“ berichtet, der nördlich des heutigen Arendsees gelegen haben soll (vgl. Abb. 9).

Der Arendsee wird durch ein 29,8 $\mathrm{km}^{2}$ großes Einzugsgebiet, einen insgesamt geringen oberirdischen Zufluss, und ohne natürlichen Abfluss und eine lange Verweilzeit des Wassers (> 100 Jahre) charakterisiert (NIXDORF et al. 2003). Neuere Berechnungen haben aber ergeben, dass die Verweilzeit wohl doch nur 68 Jahre beträgt (HUPFER, pers. Mittl.). Die Höhe des mittleren Wasserspiegels liegt bei $23 \mathrm{~m}$ über NN. Die genaue Lage der untersuchten Profile findet sich in Abb. 9 und in der 3. Der Arendsee kann mit ca. 514 ha als mittelgroßer bis groBer See angesehen werden. Er ist der größte natürliche See in Sachsen-Anhalt.

Der Arendsee besitzt wegen der Steilheit der Ufer nur einen schmalen Röhrichtgürtel. Das Einzugsgebiet des Sees besteht zu 37,6 \% aus Wald/Forst, zu 34,6 \% aus Grünland, zu 18,4 \% aus Acker/Grünland und zu 9,4\% aus urbanisierter Fläche (NIXDORF et al. 2003). Als potentielle natürliche Vegetation gibt FINCK (2002) für die bodensauren Standorte EichenBuchenwälder und Buchenwälder an, die im Gebiet der Altmarkplatten an feuchte EichenHainbuchenwälder angrenzen. In den versumpften Niederungen würden Schwarzerlen- und Moorbirkenbruchwälder wachsen, an den Fließgewässern Erlen-Eschenwälder. Nur auf Sanddünen und stellenweise in Sandergebieten gäbe es trockene Eichenwälder mit einzelnen natürlichen Kiefernvorkommen und einem starken Flechten-Unterwuchs. 


\subsubsection{Rambower See und Umgebung}

Das Rambower Moor mit dem Rambower See im Zentrum liegt östlich der Elbe in der westlichen Prignitz (Abb. 1). Die Prignitz wird im Nordwesten vom Meyn Bach und der Elde sowie im Norden durch die Ruhner Bergen von Mecklenburg abgegrenzt. Im Osten fehlt eine natürliche Grenze gegen die Uckermark, im Südosten begrenzt das Haveltal die Prignitz. Im Süden und Südwesten bildet die Elbe eine natürliche Grenze zur Altmark und dem Hannoverschen Wendland (FISCHER 1958). Das Rambower Moor ist ein ausgewiesenes Naturschutzgebiet mit einer Fläche von ca. 330 ha und Teil des Naturparks „Brandenburgische Elbtalaue“. Das Rambower Moor liegt über dem Gorleben-Rambower Salzstock. Der Rambower See befindet in einer Subrosionssenke und liegt ca. 1,4 km vor dem nordöstlichen Ende der Senke, die sich in südwestlicher Richtung noch ca. $12 \mathrm{~km}$ bis zur Elbe erstreckt. Außer dem Rambower Moor liegt auch der Rudower See in dieser Rinne. Der Rambower See liegt $16 \mathrm{~m}$ über NN und hat eine Fläche von ca. 14 ha bei einer Tiefe von $50 \mathrm{~cm}$. Er befindet sich nach verschiedenen wasserbaulichen Maßnahmen in den letzten 100 Jahren in einem starken Verlandungsprozess (KöLLN 2001). Es ist ein eutropher Flachwassersee, der von einem ausgedehnten Schilfgürtel, von Seggenriedern sowie von Weidengebüschen und Erlenbruchwäldern umgeben ist (Abb. 5). An die Verlandungszone schließen sich ausgedehnte Feuchtwiesen an, die extensiv bewirtschaftet werden. Am Rand der Subrosionssenke und auf einer kleinen Erhebung, dem Werl, gibt es nordwestlich des Sees eine größere Anzahl von Sandtrockenrasen und Kiefernforsten (GöTZMANN 1996). Neben Ackerbau und Grünlandwirtschaft bestimmen vor allem Kiefernforste, die zum Teil auf Binnendünen stocken, das Landschaftsbild außerhalb der Seensenke. Das umgebende Gelände entwässert zur Elbe. 


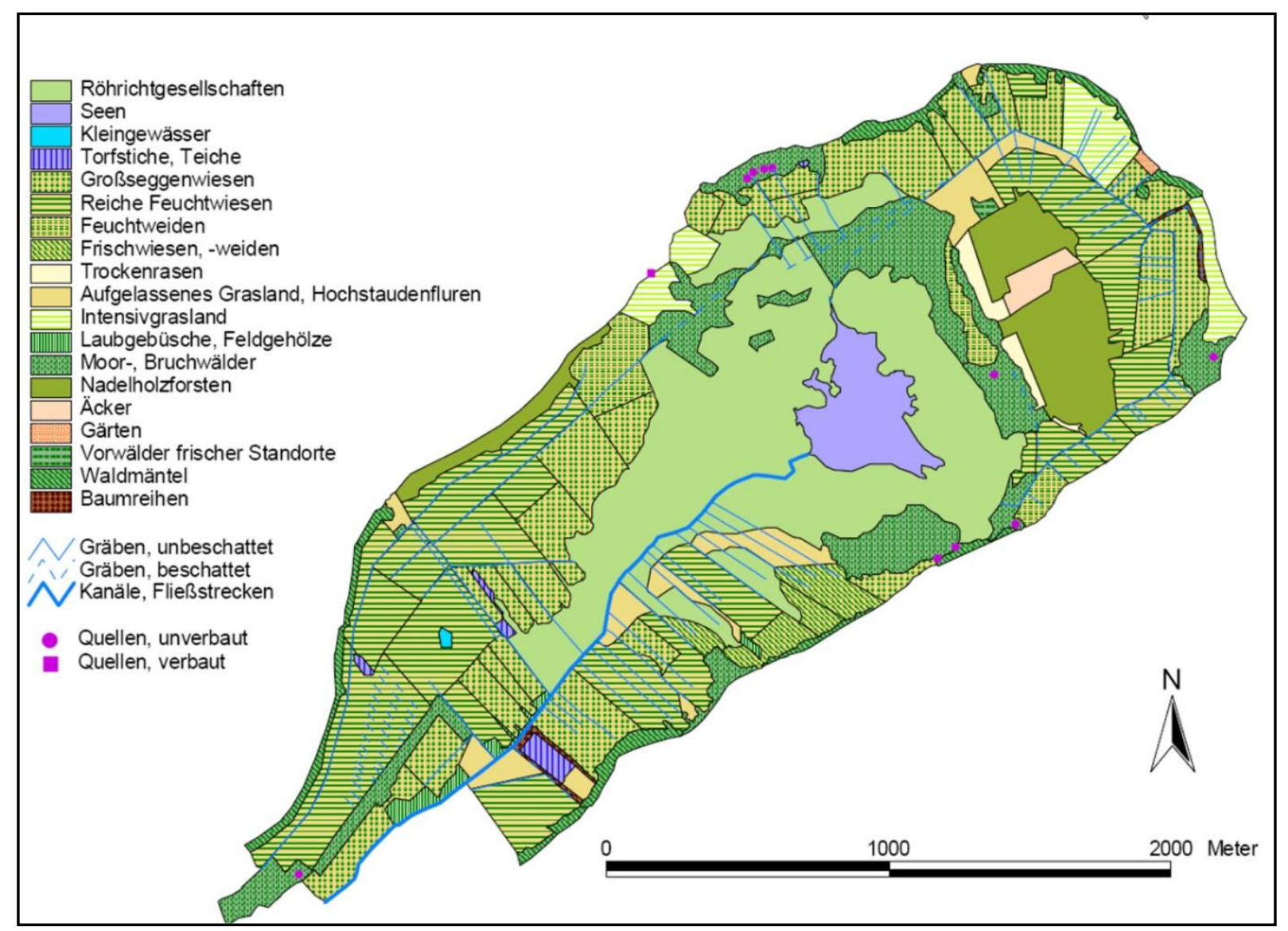

Abb. 5: Übersichtskarte über die Biotoptypen im Rambower Moor (KÖLLN 2001, mit frdl. Genehmigung der Autorin)

FISCHER (1958) nimmt für dieses Gebiet Buchen-Mischwälder und Eichen-Hainbuchenwälder als „ursprüngliche Vegetation“ an. Dagegen erwarten FugMANN \& JANOTTA (1995, zitiert nach GÖTZMANN 1996) für die entkalkten Sandlehmstandorte bodensaure Buchenwälder und für die reicheren Sandstandorte Buchen-Eichenwälder als potentiell natürliche Vegetation.

\subsubsection{Heuweg}

Das von LESEMANN (1969) untersuchte Kleinmoor am Laascher Heuweg ist eines von mehreren kleinen Dünentalmooren im östlichen Teil des Hanoverschen Wendlandes. Das Moor hat nur einen Durchmesser von etwa 200 m.

Der Ostteil des Hannoverschen Wendlandes gehört zur Lüchower Niederung, die im Urstromtalbereich der Elbe liegt. Sie wird von der Altmark durch die von Westen nach Osten zum Arendsee verlaufende, vielfach von Flachmooren bedeckte Bergener Dumme- und Landgrabenniederung getrennt. Die nördlich dieser Bruchniederung gelegene Grundmoränenplatte wurde durch Erosion und Denudation stark aufgelöst und von Talsanden der Elbe überschüttet. Zwischen den saalezeitlichen Durchragungen, dem Öring (CAPELLE et al. 1962) und dem Lemgow im Süden und der Langendorfer Diluvialinsel (GIESE 1970) im Norden liegt die Lu- 
cie, eine Niederung aus weichseleiszeitlichen fluvialen Sanden und Kiesen mit sehr hohem Grundwasserstand und aufgesetzten Flugsanddecken. Heute erfolgt ihre Entwässerung durch den Luciekanal. Weichselkaltzeitlich wurden auch die Talsandflächen des Gartower Forsts gebildet, die in weiten Bereichen durch holozäne Dünen überdeckt werden (PYRITZ 1972).

Für das Wendland nimmt LESEMANN (1969) als potentielle natürliche Vegetation, ähnlich wie FISCHER (1958) für die Prignitz, buchenreiche Eichen-Hainbuchengesellschaften an, für die ärmeren Standorte Eichen-Birken-Gesellschaften. Vorherrschende Waldform sind zurzeit aber Kiefernforste, die die Probenentnahmestelle vollständig umgeben. Das stark abgetorfte Moor hat einen hochmoorartigen Charakter. Erwähnenswert ist das Vorkommen von Ledum palustre.

\subsection{Siedlungsgeschichte}

\subsubsection{Steinzeit}

Vom Mesolithikum liegt aus dem Untersuchungsgebiet eine Reihe von Einzelfunden vor, die die Anwesenheit des Menschen schon kurz nach dem Ende der letzten Eiszeit belegen. Es überwiegen bislang Streufunde. Flache, sandige Anhöhen in Gewässernähe sind bevorzugte Fundstellen und waren damit zumindest saisonale Siedlungsplätze. Mehr als 100 solcher Plätze konnten mittlerweile festgestellt werden (u.a. BREEST 1997).

Für das Untersuchungsgebiet ist die Trichterbecherkultur die erste sicher nachgewiesene neolithische Kultur. Während weiter südlich das Neolithikum mit der Linienbandkeramischen Kultur deutlich früher beginnt (STEINMETZ 1986), werden im Untersuchungsgebiet erst mit dem Mittelneolithikum die Funde zahlreicher und auch auffälliger, denn mit der altmärkischen Gruppe (PREUSS 1980) hielt die Megalithkultur Einzug. Zwar trennt BEIER (1991) die Prignitz-Gruppe von der altmärkischen Gruppe ab, aber nur, weil hier sichere Befunde fehlen. Das Grab von Mellen, direkt am Rambower Moor gelegen, sieht er jedoch als Indiz dafür an, dass hier eine Kolonisierung aus dem altmärkisch-lüneburgischen Raum vorliegt. Die Trichterbecherkultur könnte aus dem Westen bzw. Nordwesten ins Gebiet eingedrungen sein (PREUSS 1980, BEIER 1991). RICHTER weist hingegen auf die starken Baalberger Einflüsse hin (RICHTER et al. 2002).

Im Hannoversches Wendland und der Altmark folgte auf die Trichterbecherkultur die Kugelamphorenkultur (STEINMETZ 1986, KEILING 1982, BEIER 1991). Inwieweit dies auch für die westliche Prignitz gilt, ist unklar. SPROCKHOFF (1926) wies zwar auf das Fehlen der Kugelamphorenkultur in der Prignitz hin, was aufgrund der geringen Funddichte jedoch nicht gesi- 
chert sein kann. Neben der Kugelamphorenkultur gibt es insbesondere im Hannoverschen Wendland auch deutliche Einflüsse der Bernberger Kultur. Dies zeigt sich besonders deutlich an den Fundplätzen Pevestorf 19 (Voss 1965) am Höhbeck und in Kapern (PUDELKO \& Voss 1966), einem Ortsteil von Schnackenburg.

Im Spätneolithikum finden sich Einflüsse der Einzelgrabkultur aus dem Norden, der Schnurkeramischen Kultur aus dem Osten, der Schönfelder Kultur aus dem Südosten (WETZEL 1979) und der Glockenbecherkultur aus dem Westen. Eine umfassende Darstellung vom Mesolithikum bis zur Bronzezeit für das Hannoversche Wendland erfolgt derzeit im Rahmen einer Dissertation an der Universität Göttingen (WITTORF pers. Mitt.).

\subsubsection{Bronzezeit}

In der Frühbronzezeit (ab ca. 2200 v. Chr.) lag das Untersuchungsgebiet im Bereich der Nordwestgrenze der Aunjetitzer Kultur. Dies belegen Hortfunde im Hannoverschen Wendland und in der Altmark (BRUNN 1959; VOELKEL 1981; WACHTER 1988), sowie Gräber (SPROCKHOFF 1963; VOSS 1970) und Einzelfunde (LAUX 1996; VOELKEL 1965). Es zeigt sich aber, dass das Untersuchungsgebiet, wie bereits im Neolithikum, ein Kontaktgebiet verschiedener Kulturen war: Im Westen die Lüneburger Gruppe, im Norden die Mecklenburger und im Osten die Lausitzsche Gruppe und die Elbe-Havel-Gruppe. Während die wissenschaftlich untersuchten Funde (z.B. SPROCKHOFF 1963, PudELKO \& VoelKel 1970) aus der älteren und mittleren Bronzezeit eher spärlich sind und in der Altmark Siedlungsfunde ganz fehlen (BERAN 2002), nehmen in jüngeren Bronzezeit die Fundplätze dann deutlich zu. Hierzu gehört die Siedlung von Zedau (HORST 1985), für die allerdings die Interpretation der Ergebnisse umstritten ist (BERAN 2002). Insbesondere die große Zahl der Grabhügel (derzeit sind im Hannoverschen Wendland 80 Grabhügel von der Landesdenkmalpflege lokalisiert worden) und Gräberfelder lässt auf eine bedeutende Bevölkerungsdichte schließen.

\subsubsection{Vorrömische Eisenzeit}

In der Eisenzeit (ab ca. 600 v. Chr.) gehörte das Untersuchungsgebiet zur Jastorfkultur (MÜLLER 1985) und war dicht besiedelt (SEYER 2002). Insbesondere das Hannoversche Wendland und die Altmark gehörten zum Kerngebiet dieser Kultur. Während die Grabkomplexe in der Altmark relativ gut erforscht sind (MITTAG 2002), gibt es noch deutliche Defizite bei den Siedlungen (NÜSSE 2002). Die Siedlung von Zedau (HORST 1985) bildet hier wieder eine Ausnahme; das zugehörige Gräberfeld war durchgängig von der jüngeren Bronzezeit bis zur Eisenzeit belegt. Für das Hannoversche Wendland hat NÜSSE (2002) eine umfassende Zu- 
sammenstellung vorgelegt. Seine Zusammenstellung der Funde schließt die wichtigsten Funde des übrigen Untersuchungsgebietes mit ein (Abb. 6).

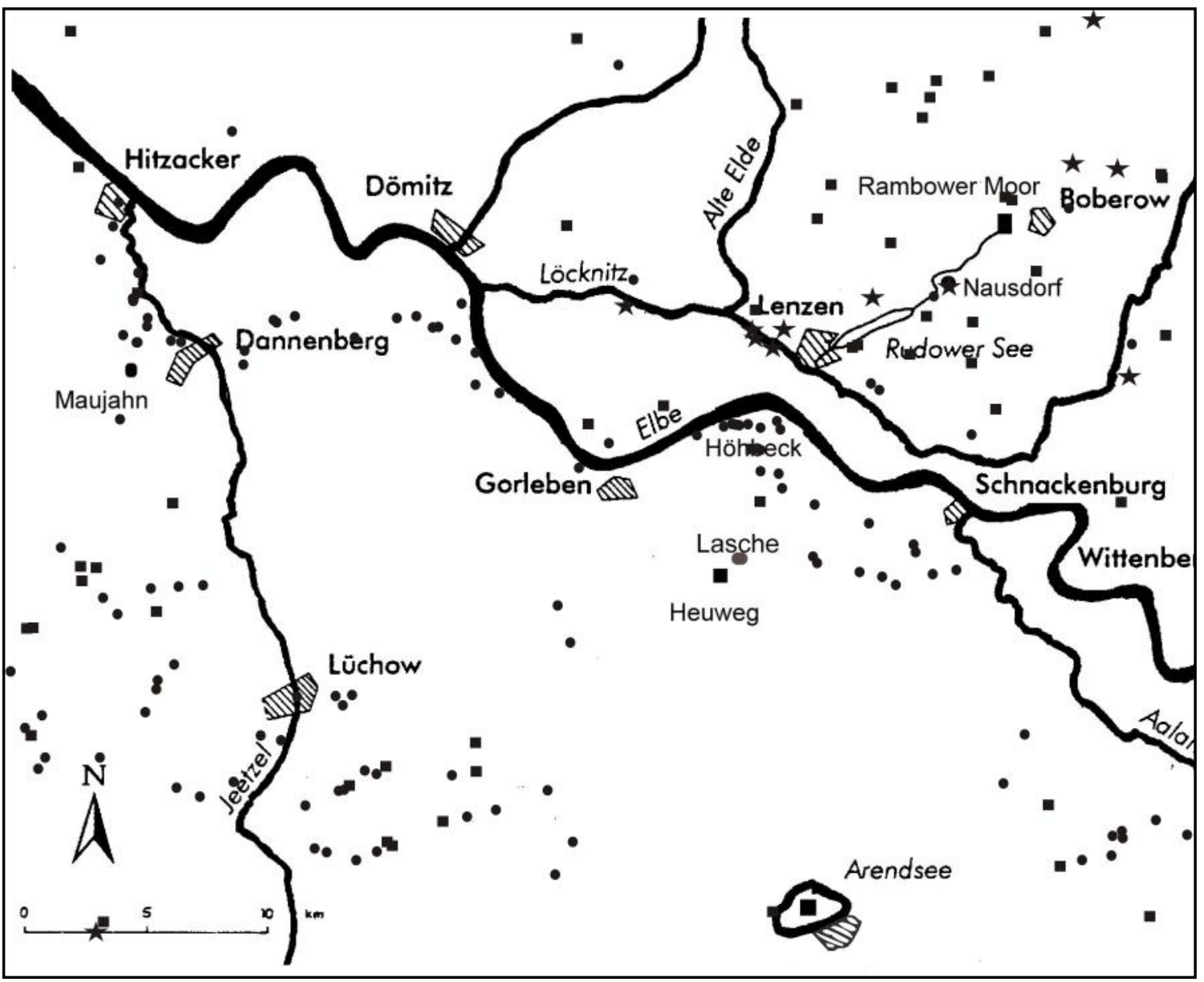

Abb. 6: Fundstellenübersicht von der jüngeren vorrömischen Eisenzeit bis zur Völkerwanderungszeit, Kreise geben Siedlungsfunde an, Vierecke Grabfunde, beim Stern sind die Zuordnungen unsicher (NÜSSE 2002, verändert).

\subsubsection{Römische Kaiserzeit und Völkerwanderungszeit}

Funde aus der römischen Kaiserzeit und der Völkerwanderungszeit (0 bis 200 - 600 AD) wurden für das Hannoversche Wendland ebenfalls von NÜSSE (2002) umfassend bearbeitet. Zusammen mit den publizierten Funden für die nördliche Altmark und die westliche Prignitz ist die Fundlage in Abb. 6 dargestellt. Während wiederum die Gräberfelder in der Altmark für die römische Kaiserzeit gut erforscht sind, ist der Kenntnisstand über die Siedlungen noch schlecht (LEINEWEBER 2002), genau wie in der Prignitz (NüSSE 2002). Aus der Völkerwanderungszeit sind die Funde äußerst spärlich, wie es zu erwarten wäre, wenn man annimmt, dass wohl ein großer Teil der ansässigen Bevölkerung das Untersuchungsgebiet verlassen hat. 


\subsubsection{Besiedlung im frühen Mittelalter}

Das frühe Mittelalter wird hier gefasst vom Ende der Völkerwanderungszeit bis zum Beginn des Hochmittelalterlichen Landesausbaus (600 - 1100 AD). In das nur noch dünn besiedelte Land wandern im 7. Jahrhundert Slawen ein. Der genaue Zeitpunkt dieser Einwanderung sowie Art und Weise der slawischen Landnahme in Wendland, Prignitz und Altmark sind momentan Gegenstand aktueller Untersuchungen des in der Einleitung beschriebenen DFGProjektes. Eine Übersicht (Abb. 7) zeigt die Verteilung bekannter slawischer Siedlungen und Burgwälle.

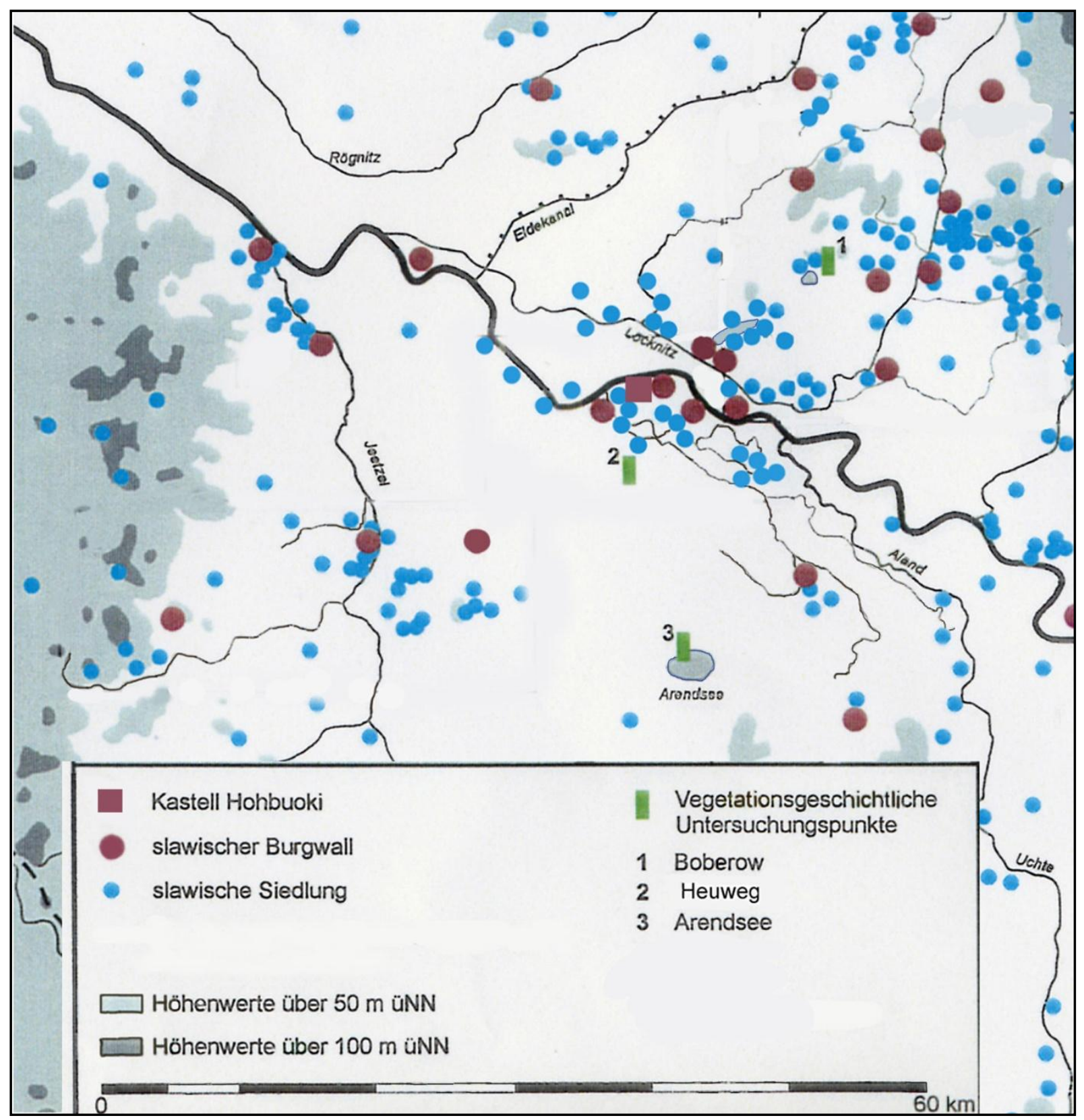

Abb. 7: Funde slawischer Siedlungen und Burgwälle im Untersuchungsgebiet, (SAILE, DFGProjektantrag ,Slawen an der unteren Mittelelbe“, verändert) 
Das Ausmaß germanisch-slawischer Kontakte zu Beginn der Neubesiedlung lässt sich nur schwer abschätzen. Das zeitliche Verhältnis zwischen slawischem Vordringen über die Elbe und fränkischem Vorstoß an die Elbe unter Karl dem Großen ist noch unklar. Ebenso unsicher ist der Beginn des slawischen Burgenbaus und ob es möglicherweise eine burgenlose erste Phase slawischer Besiedlung gegeben hat (SAILE 2004). Einen ausführlichen Überblick über den derzeitigen Kenntnisstand und die Forschungsgeschichte gibt es von SAILE (2007).

\subsubsection{Hochmittelalterlicher Landesausbau}

Der hochmittelalterliche Landesausbau (1100 - 1500 AD) war eine Zeit des Umbruchs. Im Jahre 1134 waren die Askanier mit der Nordmark belehnt worden, um das Land zu kolonisieren. Albrecht der Bär wurde Markgraf und eroberte unter anderem die Prignitz. Er rief unter Gewährung günstiger Siedlerrechte Rheinländer, Holländer und Flamen ins Land (SAILE 2007). Auf ihre Anwesenheit sind wohl erste Deichbauten an der Elbe zurückzuführen (BENDIXEN 1937). Mit dem herrschaftlich geplanten Landesausbau begann die Zeit der Trockenlegung von Sümpfen und Rodungen (BоHм 1937). Im Jahr 1183 gründete Markgraf Otto I. von Brandenburg dann ein Kloster am Arendsee, das sicher nicht unwesentlich zur Festigung der Machtverhältnisse beigetragen haben dürfte. Die Chronik berichtet, dass der Bau des Klosters eine stark zunehmende Einwohnerzahl zur Folge hatte, was zur Gründung der Neustadt führte (FELCKE 1891).

\subsubsection{Neuzeit}

In der Neuzeit (1500 - heute) ist eines der wichtigsten Ereignisse für das Untersuchungsgebiet der 30-jährige Krieg, der schwere Verwüstungen hinterließ. Der brandenburgisch-schwedische Krieg von 1675-1679 setzte die Verwüstungen fort. Im 18. Jahrhundert wurde das Untersuchungsgebiet von Napoleon besetzt, nach dem II. Weltkrieg wurde es Zonenrandbezirk. 


\section{Material und Methoden}

\subsection{Geländearbeiten}

\subsubsection{Profilentnahme am Rambower Moor}

Im Rambower Moor wurden mehrfach Geländearbeiten durchgeführt. Bereits im Oktober 1996 wurde der Kern Rambow erbohrt, dessen Ergebnisse bislang unveröffentlicht waren (Christiansen 1998, Kirleis 1998). Die Profilentnahme erfolgte bis zu einer Tiefe von $9 \mathrm{~m}$ mit einem Russenbohrer mit einer $50 \mathrm{~cm}$ langen Bohrkammer, die einen Durchmesser von 4,5 cm hatte. Dabei wurde jeweils $5 \mathrm{~cm}$ überlappend gebohrt. Die tiefer liegenden Sedimente mussten mit einer Dachnowski-Sonde (25 cm Länge, 1,5 cm Durchmesser) erbohrt werden. Bei einer Tiefe von 10,28 m war ein tieferes Vordringen mit einfachem Handbohrgerät nicht mehr möglich. Die Kerne wurden in Plastikfolie verpackt und bis zu ihrer Aufbereitung kühl und dunkel gelagert. Die Sedimentansprache erfolgte direkt beim Bohren im Gelände und findet sich im Anhang in Tabelle 13.

Im Jahr 1998 wurde das Profil Boberow 1, ein 3,50 m langer Kern, im Rambower Moor, nahe bei Boberow mit dem Russenbohrer genommen. Die Entnahme des Profils erfolgte ca. $650 \mathrm{~m}$ nordwestlich des Ortes Boberow und ca. $1 \mathrm{~km}$ nordöstlich der Seemitte (Abb. 8) am Rande des Röhrichtgürtels.

Weitere Bohrungen mit dem Russenbohrer, wurden gemäß Tabelle 2 durchgeführt, die Hälfte der geborgenen Profile war jedoch aufgrund der schlechten Pollenerhaltung für pollenanalytische Untersuchungen nicht geeignet. Proben aus den Torfen wurden ${ }^{14} \mathrm{C}$ datiert, um zur Aufklärung der Genese des Seebeckens beizutragen. 
Tabelle 2: Verzeichnis der Profilentnahmestellen im Rambower Moor.

\begin{tabular}{|c|c|c|}
\hline Kern & Abkürzung in Abb. 8 & Bemerkung \\
\hline Rambow & Ra & Diagramm: Beilage 5 \\
\hline Boberow 1 & Bo & Diagramm: Beilage 4 \\
\hline Boberow 2 & B2 $\mathrm{C}$ \\
\hline Nausdorf & $\mathrm{Na}$ & ${ }^{14} \mathrm{C}$ \\
\hline Torfstich & To & ${ }^{14} \mathrm{C}$ \\
\hline Werl & $\mathrm{We}$ & ${ }^{14} \mathrm{C}$ \\
\hline Boberow & $\mathrm{Ki}$ & KIRLEIS 1998 \\
\hline
\end{tabular}

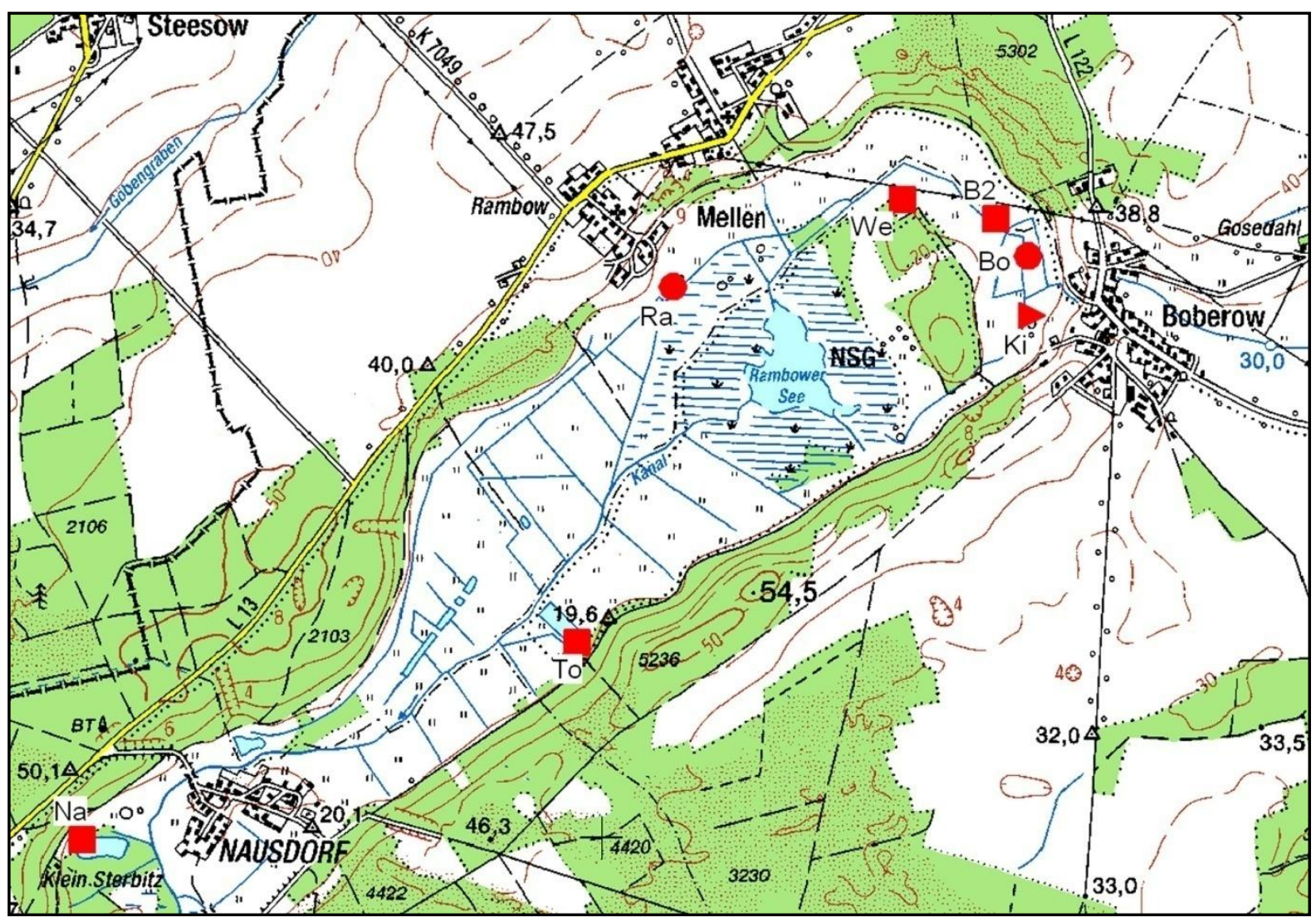

Abb. 8: Das Rambower Moor mit umgebenden Ortschaften und den Profilentnahmestellen. Legende in Tabelle 2. (Mecklenburg-Vorpommern/Landesvermessungsamt, TK 1:50.000, 2003, verändert)

\subsubsection{Profilentnahme am Arendsee}

Die Kerne ARS 1, ARS 4, ARS 5 und ein Freeze-Core wurden von Prof. Dr. Burkhard Scharf und seinem Team vom Umwelt-Forschungs-Zentrum (UFZ) - Magdeburg im Rahmen des DFG-Programms „Wandel der Geo - Biosphäre der letzten 15.000 Jahre“ erbohrt. Im Rahmen dieses DFG-Schwerpunktprogrammes wurde die Zeitscheibe III, die den Zeitraum 1500 cal. 
BC bis 500 cal. AD umfasst, am Kern ARS 4 pollenanalytisch untersucht. Nach Abschluss des Projektes stand das noch vorhandene Kernmaterial dann für die weiteren palynologischen Untersuchungen in Göttingen zur Verfügung.

Wassertiefe, Koordinaten und verwendete Bohrtechnik der Probestellen des Arendsees sind in 3 aufgeführt, eine Übersicht über die Lage der Bohrpunkte gibt Abb. 9. Der in der Abbildung dargestellte „Wendische See“ bezeichnet eine Seekreidebank, die sich in einem Flachwasserbereich gebildet hat. Nach Berichten aus der Chronik der Stadt Arendsee (FELCKE 1891) sollte sich hier der älteste Teil des Arendsees befunden haben, was aber auch durch die vorliegende Untersuchung widerlegt werden konnte.

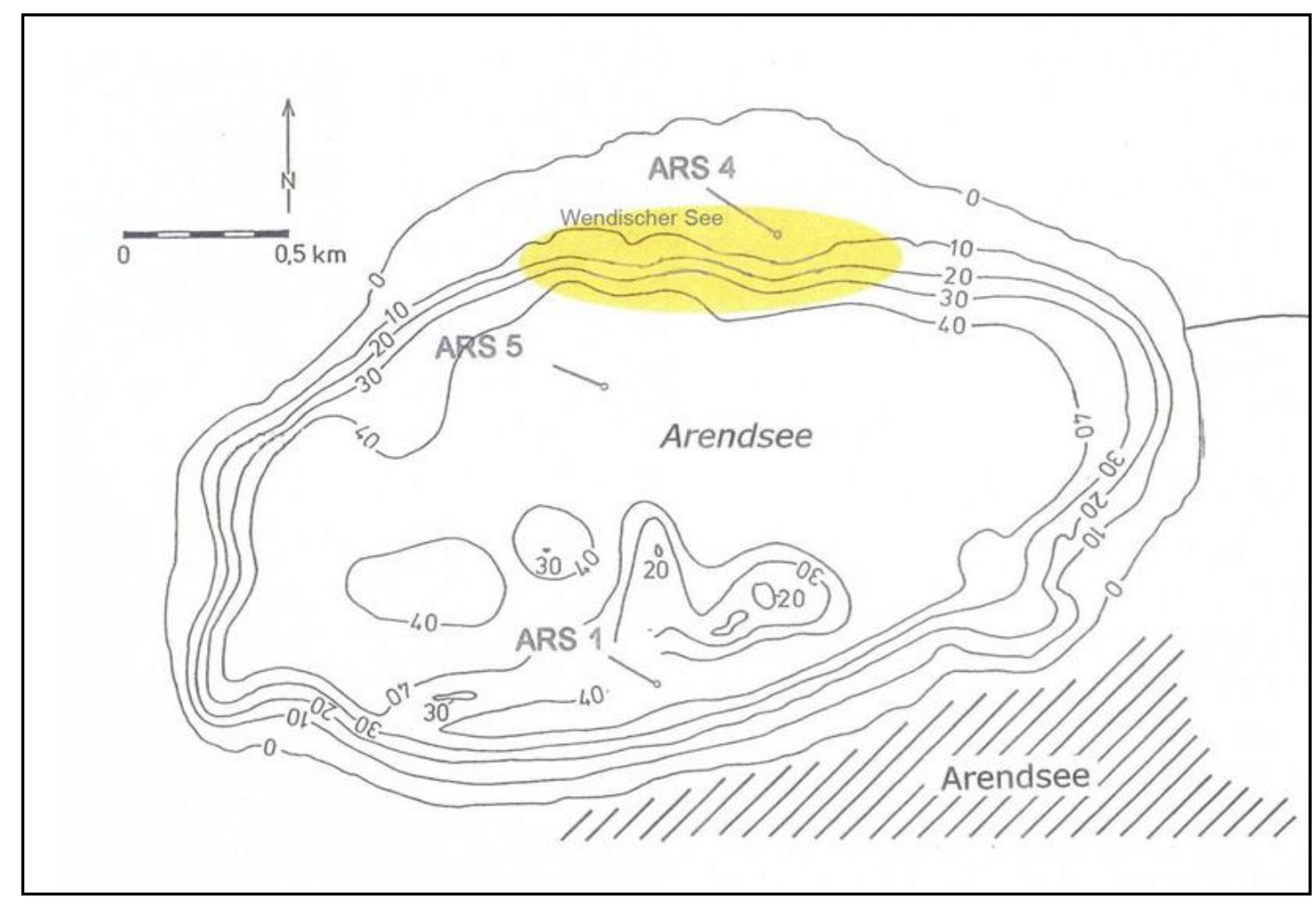

Abb. 9: Arendsee mit Lage der paläoökologisch untersuchten Bohrungen. Nach SCHARF (1998), verändert, der „Wendische See“ bezeichnet eine Seekreidebank, die sich in einem Flachwasserbereich gebildet hat. 
Tabelle 3: Wassertiefe, Koordinaten und verwendete Bohrtechnik der Probestellen des Arendsees.

\begin{tabular}{|c|c|c|c|c|}
\hline Probestelle & Wassertiefe [m] & \multicolumn{2}{|c|}{ Position } & Bohrtechnik \\
\hline ARS 1 & 48 & N $52^{\circ} 53.15^{\prime}$ & $\mathrm{E} 11^{\circ} 28.55^{\prime}$ & Kolbenlot \\
\hline ARS 1 & 48 & N $52^{\circ} 53.15^{\prime}$ & E $11^{\circ} 28.55^{\prime}$ & Mondsee \\
\hline ARS 1A & 47 & N 52 $53.092^{\prime}$ & E $11^{\circ} 28.583^{\prime}$ & Kolbenlot \\
\hline ARS 1A & 47 & N 52॰53.092' & E $11^{\circ} 28.583^{\prime}$ & Mondsee \\
\hline ARS 4 & 6,30 & N 52॰53.81' & E $11^{\circ} 28.81^{\prime}$ & Kolbenlot \\
\hline Freeze-Core & 6,10 & N 52॰53.81', & E $11^{\circ} 28.81^{\prime}$ & Freeze-Corer \\
\hline ARS 5 & 41 & N 5253.60’ & E $11^{\circ} 28.43^{\prime}$ & Kolbenlot \\
\hline
\end{tabular}

Bedauerlicherweise fehlten vom Kern ARS 1 die obersten 2 m. Da vom Kern ARS 5 aber die obersten 2 m vorlagen, wurde dies zunächst nicht als Problem angesehen. Es zeigte sich aber, dass im Kern ARS 5 die Sedimentationsrate deutlich niedriger war als im Kern ARS 1, so dass dieser Kern nicht die erforderliche zeitliche Auflösung ermöglichte. Nachdem sich herausgestellt hatte, dass gerade die obersten $2 \mathrm{~m}$ von ARS 1 für die Untersuchung besonders wichtig waren, hatte Prof. Scharf sich bereit erklärt, noch ein weiteres Bohrvorhaben durchzuführen. Die Probenentnahme erfolgte im Mai 2006 von einem Floß aus, das mit 4 Seilen am Grund des Sees verankert wurde. Die Bohrung erfolgte an der Stelle des Arendsees, wo bereits 1995 der Kern ARS 1 erbohrt worden war. Am Bohrpunkt betrug die Wassertiefe 47 m. Die Bohrung erfolgte mit einem Kolbenlot der Firma UWITEC (NIEDERREITER). Die obersten Sedimente wurden mit einem sogenannten Mondsee-Corer erbohrt, der die Gewinnung der obersten noch nicht konsolidierten Sedimente ermöglicht. Direkt nach der Entnahme wurden die Stechrohre, die einen Durchmesser von $60 \mathrm{~mm}$ und eine Länge von $200 \mathrm{~cm}$ hatten, ausgedrückt und geteilt. Das neue Profil erhielt die Bezeichnung ARS 1A. Es wurden Kerne von 0 - 2 m und von 2 - 3 m erbohrt, sowie ein Kern mit dem Mondsee-Corer von 0-36 cm.

\subsubsection{Profilentnahme am Heuweg}

In dem bereits von LESEMANN (1969) untersuchten Moor am Laascher Heuweg wurde mit dem russischen Kammerbohrer Profile für palynologische Untersuchungen und ${ }^{14} \mathrm{C}$ Datierungen entnommen. Die Stratigraphie-Ansprache erfolgte im Gelände und findet sich im Anhang in Tabelle 12. Um Verwechslungen zu vermeiden, wird das in dieser Arbeit vorgestellte Profil mit Heuweg 1 bezeichnet. 


\subsection{Laborarbeiten}

Mit Ausnahme einiger Übersichtsproben und der Proben aus dem Profil Heuweg 1 wurden alle Proben mit $5 \mathrm{ml}$ Einwegspritzen, deren Spitze abgeschnitten worden war, genommen, um eine genaue Volumenbestimmung der einzelnen Proben durchführen zu können. Die Torfproben aus dem Heuweg 1 waren zu faserig, um sie mit den Spritzen ausstechen zu können, sie mussten mit einem Skalpell ausgeschnitten werden.

Zur Bestimmung der Pollendichte wurde den Proben Lycopodium-Tabletten zugefügt (STOCKMARR 1971). Da diese Lycopodium-Tabletten sich am besten in Salzsäure lösen wurden Proben, bei deren Carbonatgehalt eigentlich keine Salzsäurebehandlung erforderlich gewesen wäre, mit HCL behandelt. Allerdings wurde hier die Salzsäuremenge reduziert. Die weitere Aufbereitung erfolgte nach dem üblichen Acetolyseverfahren (BEUG 1957), wobei die Proben zunächst mit 10 \%iger KOH gekocht wurden. Um die Proben von gröberen Sedimentbestandteilen zu reinigen, wurden sie durch ein $200 \mu \mathrm{m}$-Sieb gegeben. Eine HF-Behandlung zur Entfernung von Silikaten wurde nur durchgeführt, wenn sie notwendig war. Die meisten Proben wurden aufgrund des hohen Gehaltes feiner organischer Detritus-Partikel zusätzlich mit einem $6 \mu \mathrm{m}$-Sieb im Ultraschall-Wasserbad behandelt.

\subsubsection{Die Profile aus dem Arendsee}

Die Kerne ARS 1 und ARS 1A wurde alle $10 \mathrm{~cm}$ beprobt. In einigen Bereichen wurden auch in $5 \mathrm{~cm}$ Abständen Zwischenproben entnommen. Das Profil ARS 4 und der Freeze-Core stammen aus dem nördlichen Uferbereich des Arendsees und wurden in 6,10 m Wassertiefe erbohrt. Der Freeze-Core wurde für die Pollenanalyse nur alle $10 \mathrm{~cm}$ beprobt. Es war später nicht mehr möglich, Zwischenproben zu erhalten. Daher wurden die Proben aus dem FreezeCore nur auf eine Summe von 200 Baumpollen ausgezählt, um jedenfalls eine Konnektierung der hier durchgeführten ${ }^{14} \mathrm{C}$-Datierungen mit den übrigen Kernen zu ermöglichen. Vom Kern ARS 4 wurde die Kernstrecke von 0 - 178,5 cm alle $2 \mathrm{~cm}$ beprobt und auf 1000 Baumpollen ausgezählt.

Vom Kern ARS 5 wurden zwei Abschnitte untersucht: Aus dem Kernabschnitt 0 - 2 m wurde der Abschnitt 0 - $1 \mathrm{~m}$ alle $2 \mathrm{~cm}$ beprobt. Der 1-3 m Kernabschnitt mit einer Profillänge von $144 \mathrm{~cm}$ (abzüglich Kernverlust) wurde alle $5 \mathrm{~cm}$ beprobt, in jüngeren Abschnitten wurden später dann noch Zwischenproben genommen. Die jeweils obersten Proben der Teilstücke stellten sich als stark verunreinigt heraus und wurden daher im Pollendiagramm nicht verwertet. Die Kernabschnitte 2-3 m und 3 - $4 \mathrm{~m}$ fehlten für die palynologische Untersuchung, in 
Tabelle 19 (Anhang) sind jedoch zwei Datierungen aufgeführt, die an diesen Kernabschnitten durchgeführt wurden. Die Kernabschnitte 4 - 5 m und 5 - 6 m enthielten nur Sand und wurden nicht beprobt. Die Pollenanalysen zeigten schließlich, dass der Kernabschnitt 0 - 1 m sich um ca. $35 \mathrm{~cm}$ mit dem Abschnitt 1 - 1,78 m überlappt.

\subsubsection{Die Profile aus dem Rambower Moor}

Der oberste Abschnitt vom Profil Rambow, 0-3,60 m wurde seinerzeit von KIRLEIS (1998) bearbeitet. Der untere, von mir bearbeitete Abschnitt, wurde von 3,60 m bis $5,50 \mathrm{~m}$ alle $5 \mathrm{~cm}$ beprobt, im darunter liegenden Teil, bis 10,28 m, wurden Proben in Abständen von $10 \mathrm{~cm}$ entnommen und auf 500 Baumpollen ausgezählt.

Das Profil Boberow wurde unter ungünstigen Bedingungen nach starken Regenfällen im $34 \mathrm{~cm}$ tiefen Wasser erbohrt. Da es wie das Profil ARS 4 für die Zeitscheibe III, die den Zeitraum 1500 cal. BC bis 500 cal. AD umfasst, im Rahmen des DFG-Programms „Wandel der Geo - Biosphäre der letzten 15.000 Jahre“ untersucht werden sollte, wurden zunächst nur die Bereiche eng beprobt, von denen vermutet wurde, dass sie in diesen Zeitbereich fallen.

\subsubsection{Das Profil vom Heuweg 1}

Die obersten $34 \mathrm{~cm}$ des Profils vom Heuweg 1 wurden nicht untersucht, da die Neuzeit nicht Ziel der Untersuchung war und die stark durchwurzelten Seggentorfe für ${ }^{14} \mathrm{C}$-Datierungen ohnehin nicht geeignet waren. Im Bereich bis $120 \mathrm{~cm}$ wurde alle $5 \mathrm{~cm}$ eine Probe für die Pollenanalysen genommen, im Bereich darunter alle $10 \mathrm{~cm}$.

\subsection{Mikroskopische Arbeiten}

Die Bestimmung der Pollenkörner erfolgte mit einem Zeiss-Standard-Mikroskop bei 500facher Vergrößerung. Zur Bestimmung wurden die Arbeiten von FÆGRI \& IVERSEN (1989), Moore, Webb \& Collinson (1991), Beug (2004), und die von Punt (1976), Punt \& Clarke (1980, 1981, 1984), Punt, Blackmore U. Clarke (1988) und Punt \& Blackmore (1991) herausgegebenen Bände der 'Northwest European Pollen Flora', sowie die Vergleichssammlung der Abteilung für Palynologie und Klimadynamik der Universität Göttingen herangezogen. 


\subsection{Darstellung der Pollendiagramme}

Die Berechnung der Daten erfolgte mit dem Programm TILIA, die graphische Darstellung mit dem Programm TGVIEW (GRIMM 1990). Die Ergebnisse der Pollenanalysen sind als Schattenriss-Kurven dargestellt, die extra Linien geben zehnfach überhöhte Werte -an. Als Bezugssumme für die Pollendiagramme, Beilage 1-4, diente die Summe der Baumpollen (=100\%) ohne Alnus und Corylus (vgl. Kapitel 3.6). Die Summenbildungen enthalten folgende Pollentypen:

Kulturpflanzen-Summe: Secale cereale, Hordeum-Typ, Triticum-Typ, Avena-Typ, Cerealia indeterminata, Fagopyrum esculentum.

Summe der sekundären Siedlungszeiger (SZ): Plantago lanceolata, Rumex acetosa-Typ, Artemisia, Centaurea cyanus, Polygonum aviculare-Typ.

Nichtbaumpollen (NBP)-Summe: alle krautigen und staudigen Sippen mit den Siedlungszeigern und den Poaceae, ohne Wasser- und Uferpflanzen, zu denen auch die Cyperaceae gerechnet wurden.

Summe übrige NBP: alle krautigen und staudigen Sippen ohne die Kulturpflanzen, Siedlungszeiger, Poaceae, Wasser- und Uferpflanzen.

Unter „Polypodiaceae p.p.“ sind monolete Farnsporen ohne Perispor, unter „Indeterminata“ nicht bestimmbare Pollenkörner und unter „Varia“ unbekannte Pollenkörner zusammengefasst.

Die Gliederung der Diagramme erfolgt in Zonen nach FIRBAS (1949), die mit durchgezogenen Linien getrennt werden und mit römischen Ziffern von I-X bezeichnet werden. Für eine übersichtlichere Gliederung der einzelnen Siedlungsphasen wurde jede zweite Phase grau unterlegt. Die Phasen sind mit Kleinbuchstaben von a-n bezeichnet.

Abweichend davon wurde für das Profil Rambow als Bezugsgrundlage die Baumpollensumme ohne Corylus (=100 \%) gewählt. Die Summenbildungen enthalten folgende Pollentypen:

EMW-Summe: Quercus, Ulmus, Fraxinus, Tilia cordata-Typ, Acer

NBP-Summe: alle Kräuter und Stauden

SZ-Summe: Getreide-Summe, Artemisia, Plantago lanceolata, Chenopodiaceae, Polygonum aviculare-Typ, Fallopia, Rumex acetosa-Typ

Getreide-Summe: alle PK vom Getreide-Typ 
Die Gliederung des Diagramms in Beilage 5 erfolgte ebenfalls nach FIRBAS (1949), es wurden aber zusätzliche Diagrammabschnitte (DA), die mit Grossbuchstaben von A-I bezeichnet wurden, ausgewiesen.

Die verschiedenen Siedlungsphasen des Diagramms wurden mit Kleinbuchstaben von a bis e bezeichnet.

\subsection{Datierungen}

\subsubsection{Arendsee}

Die ersten Probenserien wurden von der Arbeitsgruppe von Prof. Dr. Scharf am UFZMagdeburg entnommen und zur Datierung in das Leibniz Labor für Altersbestimmung und Isotopenforschung der Christian-Albrechts-Universität Kiel geschickt. Da hier das gesamte Sediment datiert wurde, waren die Datierungen mehr oder weniger stark vom Hartwasseroder Reservoireffekt betroffen. Dieser Effekt tritt auf, wenn im Wasser gelöster Kohlenstoff nicht direkt aus der Atmosphäre stammt, sondern schon lange Zeit gebunden war. Das Problem ist, dass die Stärke des Effektes sehr variabel ist und es keine bestimmbaren Korrekturfaktoren gibt. Je nachdem wie hoch der Anteil der Wasserpflanzen und Algen am Sediment ist, wie viel „,alter“ Kohlenstoff im Wasser gelöst ist, variiert die Stärke des Effektes. Da der Arendsee aber zumindest in der Gegenwart eine sehr lange Verweilzeit hat (ca. 100 Jahre), sollte die Variabilität des Effektes aber gering sein, wenn auch der Effekt selber relativ hoch sein dürfte.

Nachdem sich herausgestellt hatte, dass die ersten Probenserien vom Hartwassereffekt betroffen waren und die Datierungen nicht verwendet werden konnten, wurde eine weitere Probenserie in das AMS C ${ }^{14}$-Labor (KORA) der Friedrich-Alexander-Universität Erlangen-Nürnberg geschickt. Hier wurden die Proben so aufbereitet, dass nur der Kohlenstoff der Pollenfraktion datiert wurde. Dies scheint wenigstens teilweise gelungen zu sein (s. Kapitel 6).

\subsubsection{Heuweg}

Am Laascher Heuweg wurden zwei parallele Profile für ${ }^{14} \mathrm{C}$-Datierungen entnommen, die Datierungen wurden in Hannover vom Niedersächsischen Landesinstitut für Bodenforschung durchgeführt. Die Ergebnisse sind in Tabelle 5 zusammengestellt.

\subsubsection{Rambower Moor}

An den Torfen aus dem Rambower Moor wurden mehrere ${ }^{14} \mathrm{C}$-Datierungen durchgeführt (Tabelle 6 und Tabelle 7). Die Torfe hatten aber durchweg eine so schlechte Pollenführung 
und -erhaltung, dass keine Pollenanalysen durchgeführt werden konnten. Die Proben können aber dennoch zumindest über das Alter der Torfe und somit über die Moorentwicklung Auskunft geben.

\subsection{Ergebnisse der Radiokohlenstoff-Datierungen}

Wie im vorherigen Abschnitt schon beschrieben, gab es bei den Radiokohlenstoffdatierungen einige Schwierigkeiten. Der am Arendsee auftretende Hartwassereffekt führte dazu, dass nur die in Tabelle 4 mit einem * markierten Datierungen Verwendung finden konnten. Alle übrigen Datierungen, die am Arendsee durchgeführt wurden, können zum Teil um mehrere Jahrtausende von den erwarteten Altern abweichen und werden daher nicht verwendet.

Tabelle 4: Messdaten der Radiokohlenstoffanalysen des Bohrkernes Arendsee ARS 1A

\begin{tabular}{|c|c|c|c|c|}
\hline $\begin{array}{l}\text { Tiefe } \\
\text { in } \mathrm{cm}\end{array}$ & $\begin{array}{l}\text { Lab.-Nr. } \\
\text { Erl- }\end{array}$ & $\begin{array}{l}\delta^{13} \mathrm{C} \\
(\%)\end{array}$ & $\begin{array}{l}\text { Konventionelles } \\
{ }^{14} \text { C-Alter B.P. }\end{array}$ & $\begin{array}{l}\text { Alter in kalibrierten Jahren } \\
\text { (angegeben ist der Datierungsabschnitt mit der } \\
\text { höchsten Wahrscheinlichkeit im } 1 \sigma \text { - Bereich) }\end{array}$ \\
\hline $47,5-52,5$ & 10694 & $-27,0$ & $3574 \pm 51$ & 1982 - 1879 B.C. \\
\hline $102,5-107$ & 10691 & $-26,9$ & $1553 \pm 46$ & $432-494 \mathrm{AD}$ \\
\hline $127,5-132,5$ & 10692 & $-27,7$ & $3155 \pm 73$ & 1513 - 1374 B.C. \\
\hline $157,5-162,5$ & 10693 & $-27,3$ & $2508 \pm 49$ & 652 - 543 B.C. \\
\hline $182,5-187,5$ & 10689 & $-27,2$ & $2642 \pm 39$ & 832 - 793 B.C. \\
\hline $208,5-213,5$ & 10695 & $-28,0$ & $3529 \pm 52$ & 1851 - 1772 B.C. \\
\hline $285-290$ & 10696 & $-27,8$ & $3808 \pm 53$ & $\begin{array}{c}2311 \text { - } 2143 \text { B.C. } * \\
2267 \pm 93 \text { (CalPal online) }\end{array}$ \\
\hline $335-345$ & 10697 & $-28,0$ & $4660 \pm 36$ & $\begin{array}{c}3512 \text { - 3426 B.C.** } \\
3448 \pm 56 \text { (CalPal online) }\end{array}$ \\
\hline 357,5 - 362,5 & 10690 & $-28,4$ & $\mathbf{5 3 7 4} \pm \mathbf{5 8}$ & $\begin{array}{c}\text { 4274 - } 4227 \text { B.C. } * \\
4205 \pm 98 \text { (CalPal online) }\end{array}$ \\
\hline $505-534410$ & 10698 & $-27,3$ & $9982 \pm 75$ & 9553 - 9338 B.C. \\
\hline
\end{tabular}

Die Kalibrierung der Daten erfolgte in Erlangen mit dem Kalibrierungsdatensatz aus Reimer et al. (2004). Aus Gründen der Übersichtlichkeit ist nur der Datierungsabschnitt mit der höchsten Wahrscheinlichkeit im $1 \sigma$ - Bereich angegeben. Für die einfachere Verwendung im Text wurden die drei verwendeten Daten mit CalPal-2007online noch mal kalibriert.

Die Ergebnisse der mit dem Hartwassereffekt belasteten Datierungen, die vom UFZMagdeburg durchgeführt wurden finden sich, da sie nicht berücksichtigt werden konnten im Anhang. In Tabelle 18 die Ergebnisse von ARS 4 und in Tabelle 19 die Ergebnisse von ARS 5. 
Die Ergebnisse der am Heuweg 1 durchgeführten Datierungen sind in Tabelle 5 zusammengefasst. Die Kalibrierung erfolgte hier nach STUIVER et al. (1993).

Tabelle 5: Messdaten der Radiokohlenstoffanalysen des Bohrkernes Heuweg 1

\begin{tabular}{|c|c|c|c|c|}
\hline $\begin{array}{c}\text { Tiefe } \\
\text { in cm }\end{array}$ & $\begin{array}{c}\text { Lab.-Nr. } \\
\text { Hv- }\end{array}$ & $\begin{array}{c}\delta 13 \mathrm{C} \\
(\%)\end{array}$ & $\begin{array}{c}\text { Konventionelles } \\
14 \text { C-Alter B.P. }\end{array}$ & $\begin{array}{c}\text { Alter in kalibrierten Jahren } \\
\text { (angegeben ist der Datierungsabschnitt mit der } \\
\text { höchsten Wahrscheinlichkeit im } 1 \sigma-\text { Bereich) }\end{array}$ \\
\hline $53-56$ & 23270 & $-25,5$ & $1285 \pm 80$ & $665-865$ A.D. \\
\hline $70-75$ & 23271 & $-25,4$ & $1795 \pm 65$ & $140-335$ A.D. \\
\hline $85-90$ & 23272 & $-26,9$ & $2770 \pm 60$ & $990-830$ B.C. \\
\hline $93-96$ & 23273 & $-26,8$ & $3435 \pm 75$ & $1875-1635$ B.C. \\
\hline
\end{tabular}

In Tabelle 6 sind die Ergebnisse der konventionellen und in Tabelle 7 die Ergebnisse der AMS-Datierungen aus dem Rambower Moor zusammengestellt, ein Überblick über die Lage der Probenentnahmestellen ist in Abb. 8 ersichtlich. Bemerkenswert ist die Übereinstimmung der Datierungen aus „gleicher“ Tiefe, relativ zur heutigen Oberfläche gesehen. Die Datierungen B2 und To aus $119 \mathrm{~cm}$ liegen nur 30 Radiokohlenstoffjahre auseinander und die Datierungen To $267 \mathrm{~cm}$ und Nau $270 \mathrm{~cm}$ nur $3 \mathrm{~cm}$ und 5 Radiokohlenstoffjahre. Dies kann als Hinweis gewertet werden, dass das Aufwachsen des Torfkörpers über Große Teile des Moores relativ gleichmäßig erfolgte.

Tabelle 6: Messdaten der Radiokohlenstoffanalysen Profils „Werl“, aus dem Rambower Moor.

\begin{tabular}{|l|l|l|l|ll|}
\hline $\begin{array}{l}\text { Tiefe } \\
\text { in cm }\end{array}$ & $\begin{array}{l}\text { Lab.-Nr. } \\
\text { KI- }\end{array}$ & $\begin{array}{l}\delta^{13} \mathrm{C} \\
(\%)\end{array}$ & $\begin{array}{l}\text { Konventionelles } \\
14\end{array}$-Alter B.P. & $\begin{array}{l}\text { Kalender-Alter } \\
\pm 1,65 \mathrm{~s} ; \mathrm{P}=90 \%\end{array}$ \\
\hline $140-148$ & 4934,02 & $-28,78$ & $3790 \pm 45$ & $2355 \mathrm{BC}<\mathrm{J}<2045 \mathrm{BC}$ & \\
\hline $211-219$ & 4934,01 & $-28,61$ & $6210 \pm 70$ & $5305 \mathrm{BC}<\mathrm{J}<4995 \mathrm{BC}$ & \\
\hline
\end{tabular}


Tabelle 7: Messdaten der Radiokohlenstoffanalysen (AMS) im Rambower Moor Die Übersetzung in das „Calibrated age” erfolgte mit „CALIB rev 4.3” (Datensatz 2), STUIVER et al. (1998).

\begin{tabular}{|c|c|c|c|c|c|}
\hline Profil & $\begin{array}{c}\text { Tiefe } \\
\text { in cm }\end{array}$ & $\begin{array}{c}\text { Lab.- } \\
\text { Nr. } \\
\text { KIA- }\end{array}$ & $\begin{array}{c}\delta^{13} \mathrm{C} \\
(\%)\end{array}$ & ${ }^{14}$ C-Alter B.P. & $\begin{array}{c}\text { Kalender-Alter } \\
\text { (angegeben ist der Datierungsabschnitt } \\
\text { mit der höchsten Wahrscheinlichkeit im } \\
1 \sigma \text { - Bereich): }\end{array}$ \\
\hline B2 05 & 44 & 30390 & $-28,44 \pm 0.09$ & $1205 \pm 20 \mathrm{BP}$ & cal AD $797-830$ \\
\hline B2 05 & 119 & 30391 & $-26.82 \pm 0.25$ & $2930 \pm 25 \mathrm{BP}$ & cal BC $1102-1068$ \\
\hline To & 119 & 30392 & $-26.76 \pm 0.32$ & $2965 \pm 30 \mathrm{BP}$ & cal BC $1182-1146$ \\
\hline To & 267 & 30393 & $-28.20 \pm 0.21$ & $9545 \pm 50 \mathrm{BP}$ & cal BC $9119-8990$ \\
\hline Nau & 240 & 30394 & $-28.04 \pm 0.16$ & $9310 \pm 70 \mathrm{BP}$ & cal BC $8631-8451$ \\
\hline Nau & 270 & 30395 & $-26.87 \pm 0.14$ & $9540 \pm 45 \mathrm{BP}$ & cal BC 9117-8991 \\
\hline
\end{tabular}




\section{Bemerkungen zur Vergleichbarkeit von Pollendiag- rammen}

Da diese Arbeit vermutlich auch von siedlungsgeschichtlich interessierten Archäologen gelesen wird, seien hier einige Anmerkungen zur Interpretation der Pollendiagramme gestattet. Die Bezugsgrundlage der Pollenkurven ist bedauerlicherweise einem Wandel unterzogen. In den Anfängen der pollenanalytischen Arbeiten wurden zunächst oft nur die Baumpollen (BP) erfasst und ausgewertet. Mit seiner Arbeit "Über die Bestimmung der Walddichte und der Vegetation waldloser Gebiete mit Hilfe der Pollenanalyse" führte FIRBAS (1934) die Zählung und Auswertung der Nichtbaumpollen (NBP) ein. Die Höhe der NBP-Anteile ist ein wichtiges Kriterium für Aussagen über die Bewaldung eines Gebietes. Bezugssumme waren aber weiterhin die Baumpollen. Aufgrund der im Boreal vor allem in den Lössgebieten und Gebirgen auftretenden enorm hohen Hasel-Werte (bis über $600 \%$, bezogen auf die übrigen BP) wurde die Hasel aus der Baumpollensumme ausgenommen. Aus anderen Landschaften gibt es Pollendiagramme, bei denen die Hasel-Anteile mit in die BP-Summe einbezogen wurden.

Da bei der Beurteilung der Bewaldung immer das Verhältnis von BP zu NBP eine wichtige Rolle spielt, ging eine Reihe von Autoren dazu über, den Pollen der Landpflanzen in die Grundsumme der Diagramme einzubeziehen. Wasserpflanzen wurden weiterhin aus der Summe ausgenommen, weil es hier lokal zu stark überhöhten Werten kommen kann und ihre Anteile nicht zur Beurteilung der Bewaldungsdichte beitragen können. Neben den Wasserpflanzen können die lokal auftretenden Bruchwaldarten, namentlich die Birke und die Erle, als starke Pollenproduzenten so sehr überrepräsentiert sein, dass sie aus der Summe ausgenommen werden müssen, wie bei LESEMANN (1969) in den Diagrammen von Siemen und Laase. Es ergibt sich somit eine Vielzahl von mittlerweile verwendeten Grundsummen. So verwendet DÖRFLER (im Druck) am Rugensee als Bezugssumme für die Pollendiagramme die Summe der Pflanzen trockener Standorte (Landpflanzen), während am Löddigsee JAHNS (2007) ebenfalls die Landpflanzen als Summe verwendet, jedoch dabei die Poaceae und Cyperaceae ausnimmt. In der Döberitzer Heide bezieht WOLTERS (2002) die Baumpollen-Anteile auf die Summe der Gehölze und die Anteile der übrigen Sippen auf eine Gesamtpollensumme mit speziellen Ausnahmen.

Diese wenigen Beispiele führen deutlich vor Augen, dass ein unmittelbarer Vergleich der in den Diagrammen angegebenen Prozentwerte erschwert sein kann. Die unterschiedlichen Bezugssummen sind aber nicht die einzige Schwierigkeit, die sich bei der Interpretation von 
Pollendiagrammen ergibt. Dazu zählt die spezifische Pollenproduktion der einzelnen Baumarten. Während die windblütigen Arten generell mehr Pollen produzieren als die von Insekten bestäubten Arten, gibt es aber noch weitere artspezifische Unterschiede. So gelten Betula und Pinus als starke Pollenproduzenten. Fagus und Carpinus werden als mittelstarke und Acer und Tilia als schwache Produzenten eingestuft (FIRBAS 1949). Andere Autoren kommen zu anderen Ergebnissen (u. a. LANG 1994).

Um diese unterschiedliche Pollenproduktion zu berücksichtigen, sind seit langem Korrekturfaktoren im Gespräch (ANDERSEN 1970, 1980), und es gibt immer wieder neue Ansätze wie zum Beispiel die „Eichung“ durch Vergleiche mit dem rezenten Pollenniederschlag und der aktuell vor Ort aufgenommenen Vegetation (WOLTERS 2002). Es werden auch Versuche unternommen, die Korrekturfaktoren in Modellrechnungen zur Vegetationsbedeckung einzusetzen (SoEPBOER et al. 2007). Die Ergebnisse werden von den Autoren als viel versprechend gewertet, da sie zumindest statistisch gesehen eine gute Annäherung an die Realität ergeben.

Eine weitere Schwierigkeit bei der Interpretation von Pollendiagrammen ist, dass das Einzugsgebiet einer „Pollenfalle“, sei es nun ein See oder ein Moor, in einem engen Bezug zu der Flächengröße steht, welche die in der Luft befindlichen Pollen ,einfängt“ (u. a. JACOBSEN \& BRADSHAW 1981). Für die Interpretation der hier vorgelegten Diagramme, ARS 1, ARS 5 , Boberow, Rambow und Heuweg 1 muss dabei die Größe der See- bzw. Mooroberfläche, als auch der Abstand des Bohrpunktes vom Rand der als Pollenfalle wirkenden Fläche berücksichtigt werden. In Abb. 10 ist vereinfacht dargestellt, wie sich die Pollenanteile der einzelnen Profile in etwa zusammensetzen. Wenn sich die Oberflächengröße oder die Entfernung zum Rand ändert, verändern sich die entsprechenden Anteile, die aus der Region, der näheren Umgebung oder dem lokalen Einzugsbereich stammen. Beim Profil ARS 4 zeigt sich die zeitweise Ufernähe durch lokale Alnus-Werte von bis zu 150\%. Im Profil Heuweg 1 lässt sich ein deutlicher Wechsel vom Beginn der Vermoorung (HWa), als kleinere Vermoorungen noch dicht vom Wald umgeben waren, zu der der heutigen Situation (HWb), wo das gewachsene Moor eine offene Oberfläche von ca. $300 \mathrm{~m}$ hat, nachweisen. Die Profile von ARS 1 und ARS 5 unterscheiden sich nur geringfügig durch ihre Entfernung vom Ufer.

Eine weitere Schwierigkeit können wechselnde Sedimentationsraten sein. So sind im Spätglazial, in den Zeiten offener Landschaften, die Sedimentationsraten durchweg hoch. Wenn in Zeiten stärkerer Besiedlung großflächige Rodungen erfolgen, tritt dieser Effekt ebenfalls auf. In Phasen mit geringeren Niederschlägen kann es zur Verringerung der Sedimentationsraten 
kommen, speziell in Mooren, wie zum Beispiel am Heuweg kann es zur Verlangsamung oder Einstellung des Torfwachstums kommen.

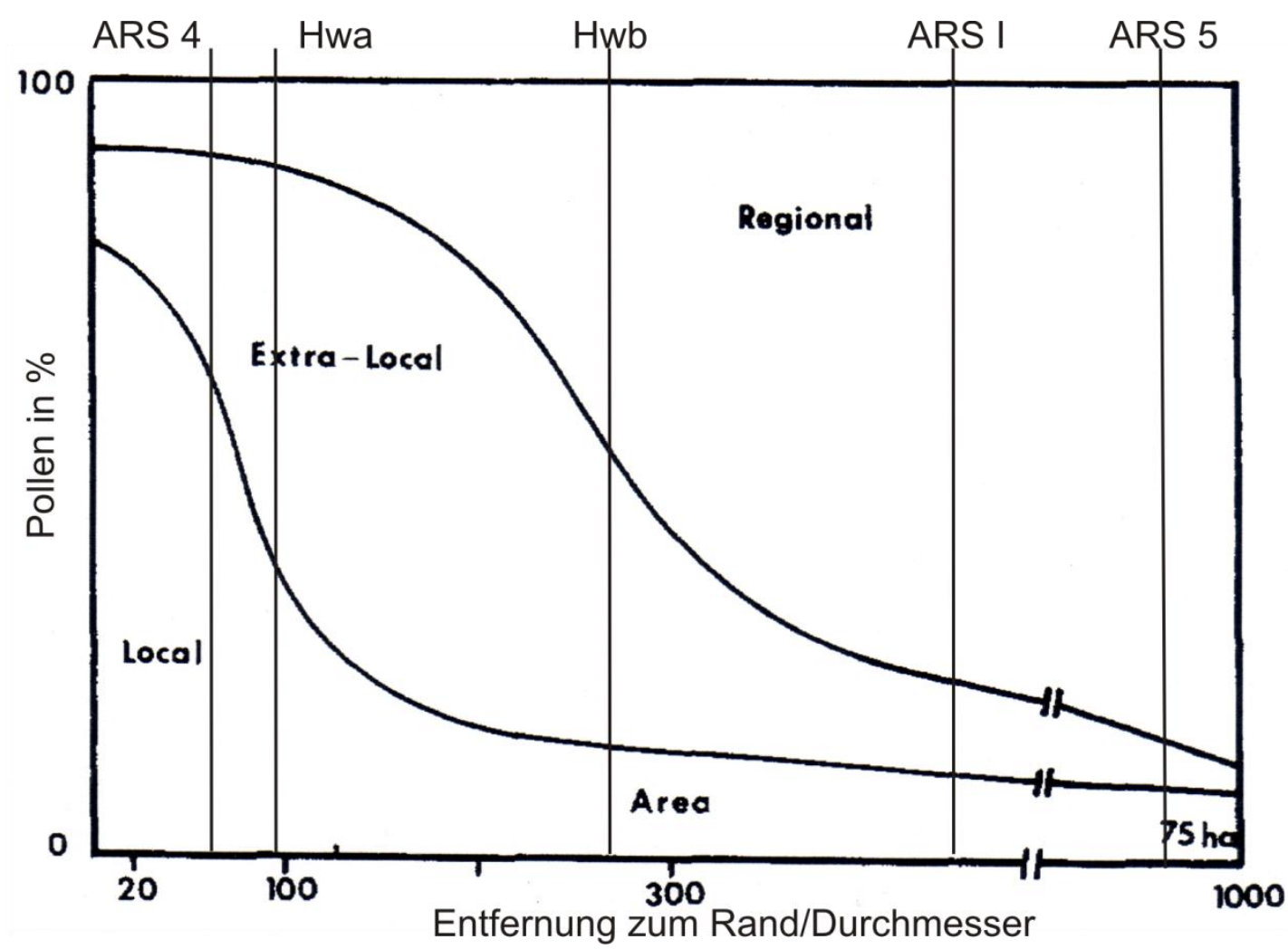

Abb. 10: Einfluss der Oberflächengröße auf den Ursprung der Pollenwerte (JACOBSEN \& BRADSHAW 1981), verändert. Weitere Erläuterung im Text. 


\section{Ergebnisse}

\subsection{Der Arendsee}

\subsubsection{Profil ARS 1}

Das Profil ARS 1 entstand aus 3 Kernen, dem Kern ARS 1, dem Kern ARS 1A und einem Mondseecore (vgl. 3.1.2). Die Stratigraphie der einzelnen Kernabschnitte ist in Tabelle 8 zusammengestellt. Nur die oberen Zentimeter weisen eine deutliche Laminierung auf, die auf helle Sommer- und dunklen Winterlagen beruht. Im Jahr 1995 wurde am Arendsee eine Seekreideaufspülung durchgeführt, um durch Phosphatbindung eine Verringerung der sommerlichen Algenblüte zu erreichen. Ein dauerhafter Erfolg blieb jedoch aus, wie in Abb. 11 deutlich zu sehen ist. Auch nach der Seekreideaufspülung setzt sich die Laminierung fort.

Die jährliche helle Sommerlage wird gebildet, wenn es durch Bindung des im Wasser gelösten $\mathrm{CO}_{2}$ zur Ausfällung von relativ großen Mengen von Kalziumcarbonat kommt. Daher lässt sich das Ausbleiben der hellen Sommerlagen als Hinweis auf eine deutlich geringere Biomasseproduktion durch die Algen werten. Was als Zeiger einer geringeren Eutrophierung des Arendsees gesehen werden darf.

Um das Profil ARS 1 in einem durchgehenden Diagramm (Beilage 1) darzustellen, mussten die Ergebnisse von mehreren Kernen, zum Teil nicht überlappend gebohrt, zusammengefügt werden. Um die Bereiche hervorzuheben, in denen Kernverluste auftraten oder Stauchungen korrigiert werden mussten, wurden gestrichelte Trennlinien eingefügt. In der Diagrammbeschreibung werden die Tiefen angegeben, die die Abschnitte im zusammengestellten Kern haben. Im Anhang in Tabelle 10 sind die Angaben im Diagramm den tatsächlichen Tiefen im Kern gegenübergestellt. In Tabelle 4 sind die 14C-Datierungen zusammengestellt, die angegebenen Tiefen beziehen sich auf die tatsächlichen Kerntiefen und weichen daher von denen im Diagramm ab. Die im Diagramm verwendeten Daten sind Fett gedruckt. Warum die anderen als vom Hartwassereffekt betroffen und als zu alt eingestuft wurden, ist in Kapitel 6 erläutert. 
Tabelle 8: Stratigraphie des Profils ARS 1

\begin{tabular}{|c|c|c|}
\hline Kern in $\mathrm{m}$ & Tiefe in $\mathrm{cm}$ & Stratigraphie \\
\hline \multicolumn{3}{|c|}{$\begin{array}{l}\text { Kern ARS } 1 \\
\text { Mondseecore (nicht der selbe wie in Abb. 11) }\end{array}$} \\
\hline \multirow[t]{2}{*}{$0-0,37$} & $0-13$ & Laminierte Algenmudde \\
\hline & $13-37$ & Dunkelbraune Algenmudde \\
\hline \multicolumn{3}{|c|}{ Kern ARS 1A } \\
\hline \multirow[t]{5}{*}{$0-2$} & $0-45$ & Dunkelbraune Algenmudde \\
\hline & $45-50$ & Helles Band \\
\hline & $50-131$ & Dunkelbraune Algenmudde \\
\hline & $131-132$ & Helles Band \\
\hline & $132-200$ & Dunkelbraune Algenmudde \\
\hline \multicolumn{2}{|c|}{ Kern ARS 1} & \\
\hline \multirow[t]{2}{*}{$2-3$} & $200-292$ & Hellbraune Algenmudde \\
\hline & $292-300$ & Kernverlust \\
\hline \multirow[t]{3}{*}{$3-4$} & $300-308$ & Kernverlust \\
\hline & $308-396$ & Hellbraune Algenmudde \\
\hline & $396-400$ & Kernverlust \\
\hline $4-5$ & $400-500$ & Hellbraune Algenmudde \\
\hline \multirow[t]{2}{*}{$5-6$} & $500-506$ & Kernverlust \\
\hline & $506-600$ & Hellbraune Algenmudde \\
\hline \multirow[t]{5}{*}{$6-7$} & $600-643$ & $\begin{array}{l}\text { Hellbraune Algenmudde, } \\
\text { LST bei 612-614 }\end{array}$ \\
\hline & $643-658$ & Dunkle Feindetritusmudde \\
\hline & $658-668$ & hellbraune Feindetritusmudde \\
\hline & $688-673$ & $\begin{array}{l}\text { hellbraune Feindetritusmudde, } \\
\text { zunehmend sandig }\end{array}$ \\
\hline & $673-683$ & Sand \\
\hline
\end{tabular}

Abb. 11: Der Mondseecore ARS 1A

Man erkennt deutlich die Schicht (2,5 $5 \mathrm{~cm}$ ) der Seekreideaufspülung im Jahr 1995

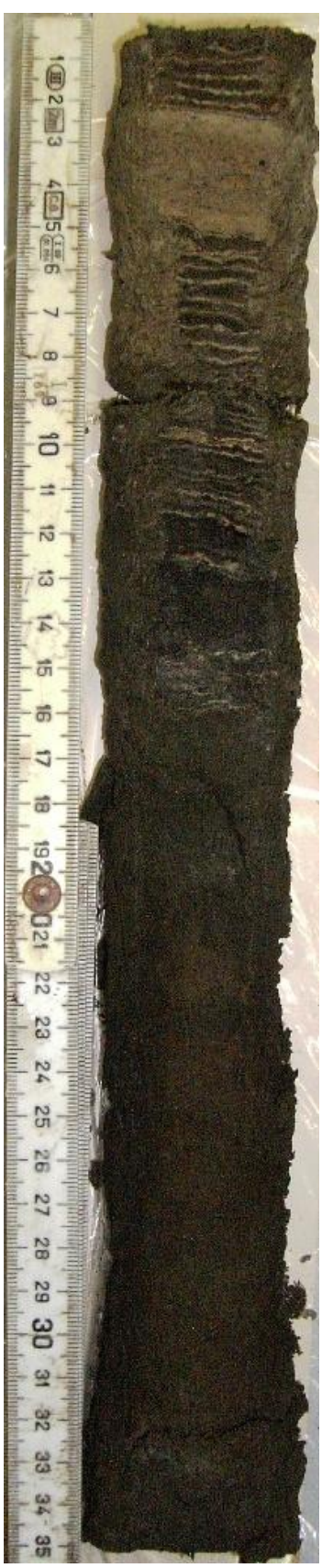




\section{Diagrammbeschreibung Profil ARS 1:}

661,5-680 cm, Ältere Dryas-Zeit, Pollenzone I, Hoher Anteil NBP von $26 \%$, die BetulaWerte erreichen $80 \%$ und die Pinus -Werte ein Maximum von $28 \%$, Juniperus-Werte fallen von $10 \%$ auf $1 \%$, die Artemisia-Kurve sinkt von $10 \%$ auf $4 \%$.

Grenze I/II: Rückgang der Betula-Werte. Überschneidung der Kurven von Betula und Pinus.

612,5-661,5 cm, Allerød-Zeit, Pollenzone II, es erfolgt ein starker Rückgang der NBP-Kurve auf Werte um $8 \%$ und der Betula-Werte auf $24 \%$, bei gleichzeitig starken Anstieg der PinusKurve auf maximal 73\%, die Juniperus-Kurve erreicht nur noch 1\%, die Artemisia-Werte erreichen noch 2\%. Die Laacher See-Tephra (LST) ist im Diagramm mit einer gestrichelten Linie eingezeichnet $(632 \mathrm{~cm})$.

Grenze II/III: Erneuter Anstieg der Betula-Kurve, sowie der Juniperus- und der NBP-Werte.

567,5-612,5cm, Jüngere Dryas-Zeit, Pollenzone III, die Pinus-Werte liegen bei 50\%, die Betula-Werte steigen über $40 \%$, Anstieg der Juniperus-Werte auf maximal $4 \%$ und die der NBP-Werte auf 40\%, die Kurve von Empetrum setzt ein und erreicht 8\%. Am Ende der Zone gibt es ein Betula-Maximum von 58\%, die Artemisia-Kurve erreicht Werte von 7\%.

Grenze III/IV: Starker Rückgang der NBP-Werte, Anstieg der Pinus-Werte.

532,5-567,5 cm, Präboreal, Pollenzone IV, ein starker Rückgang der NBP-Werte unter 10\%, Anstieg der Pinus-Werte, die Juniperus-Kurve endet, die Artemisia-Werte setzen aus.

Grenze IV/V: Beginn des Corylus-Anstiegs.

505-532,5 cm, Boreal, Pollenzone V, der boreale Haselgipfel erreicht 39\%, der Beginn der Zone fällt jedoch mit einem Kernverlust (gestrichelte Linie $524,5 \mathrm{~cm}$ ) zusammen und wurde nicht vollständig erfasst, daher sei hier auf das Profil ARS 5 verwiesen, Einwanderung der Eichenmischwald- (EMW) Arten, bei stark zurückgehenden Pinus-Werten.

Grenze V/VI: Abfall der Corylus-Kurve auf unter $30 \%$ und Beginn des Steilanstieges der Alnus-Kurve.

445,5-505 cm, Älteres Atlantikum, Pollenzone VI, es erfolgt die Massenausbreitung von Alnus und der EMW-Arten, deutlicher Rückgang der Betula-Werte von 25\% auf weniger als $10 \%$.

Grenze VI/VII: Der Anstieg der Fraxinus-Kurve über $2 \%$.

352,5-445,5 cm, Jüngeres Atlantikum, Pollenzone VII, deutlicher Rückgang der PinusKurve von $64 \%$ auf $40 \%$, stetiger Anstieg der Quercus-Werte von $12 \%$ auf $20 \%$, übrige 
EMW-Arten relativ konstant, am Ende der Zone ein deutlicher Rückgang der Ulmus-Kurve von $6 \%$ auf $3 \%$.

Grenze VII/VIII: Der Ulmenfall, Fagus- und Carpinus-Kurve geschlossen.

257,5 -352,5 cm, Subboreal, Pollenzone VIII, in dieser Zone beginnen die geschlossenen Fagus- und Carpinus-Kurven, Quercus-Werte bleiben relativ konstant (im Mittel 34\%), die Pinus-Kurve sinkt stetig von 55\% auf 30\%, die Kurve der SZ hat nahezu durchgängig Werte über 2\%, die am Ende der Zone auf $8 \%$ steigen. Es gibt erste vereinzelte Funde vom GetreideTyp.

Grenze VIII/IXa: Fagus-Werte $>5 \%$.

197,5-257,5 cm, Älteres Subatlantikum, Pollenzone IXa, weiter stetiger Rückgang der Pinus-Werte bis auf 9\%, die Fagus-Kurve liegt durchgängig über 5\%, die Carpinus-Werte steigen stetig von $4 \%$ auf 12\%, die SZ-Kurve geht von einem Maximum mit 17\% am Beginn der Zone deutlich zurück, auf Werte von $5 \%$.

Grenze IXa/IXb: Anstieg der Fagus-Werte über 10\% und der Carpinus-Kurve über 10\%, Beginn der Secale-Kurve.

197,5-132,5 cm, Älteres Subatlantikum, Pollenzone IXb, die Massenausbreitung von $F a$ gus, mit maximal 21\% und Carpinus, mit maximal 20\% erfolgt, die Secale-Werte liegen um $1 \%$, die SZ-Werte liegen bei 5\%, mit einem deutlichem Minimum von 2\%.

Grenze IXb/X: Starker Anstieg der SZ-Werte und der Secale-Kurve.

0-132,5cm, Jüngeres Subatlantikum, Pollenzone X, die Fagus-Kurve fällt deutlich ab, auf Werte um die 5\%, ebenso die Carpinus-Kurve, die Secale-Werte steigen über 20\%, die SZWerte steigen auf ein Maximum von 64\%.

\subsubsection{Profil ARS 4}

Das Diagramm (Beilage 2) umfasst die Zeit vom Ende des Subboreals (Zone VIII) bis in den älteren Teil des älteren Subatlantikums (Zone IXb). Aufgrund der Ufernähe des Bohrpunktes und der hohen Sedimentationsrate, die etwa dreimal so hoch liegt wie im Profil ARS 5, ist die zeitliche Auflösung des Diagramms deutlich höher. Allerdings endet das Profil am Beginn der römischen Kaiserzeit. Vermutlich mit dem See-Einbruch von 882 kam es zu einer Absenkung des Seegrundes im Bereich des Bohrpunktes ARS 4 (Abb. 9). Heute liegt der Bohrpunkt im Bereich eines relativ steilen Hanges und jüngere Sedimente sind abgerutscht bzw. wurden nicht mehr abgelagert. 


\section{Diagrammbeschreibung Profil ARS 4:}

176-127 cm, Subboreal, Pollenzone VIII, in dieser Zone hat Fagus Werte um $2 \%$ und die Carpinus-Kurve ist geschlossen, Quercus-Werte schwanken (im Mittel 20\%), die PinusKurve liegt um die $21 \%$, die Kurve der SZ hat durchgängig Werte über 2\%, die in Phase b auf $8 \%$ steigen. Es gibt vereinzelte Funde von Pollenkörnern vom Getreide-Typ.

Grenze VIII/IXa: Fagus-Werte $>5 \%$.

127-67 cm, Älteres Subatlantikum, Pollenzone IXa, die Pinus-Werte liegen bei weiter um die 20\%, die Fagus-Kurve überschreitet die 5\%-Grenze erstmals, fällt aber zeitweise wieder darunter zurück. Die Carpinus-Werte liegen über 1\%, die SZ-Kurve schwankt um Werte von $5 \%$ und erreicht in dieser Zone maximal $11 \%$.

Grenze IXa/IXb: Anstieg der Fagus-Werte über 10\% und der Carpinus-Kurve im Mittel über $5 \%$, beginn der geschlossenen Secale-Kurve.

67- 0 cm, Älteres Subatlantikum, Pollenzone IXb, die Fagus-Werte liegen über 10\% und die Carpinus-Kurve liegt im Mittel über 5\%, deutlicher Rückgang der Pinus-Kurve auf Werte um 10\%. Beginn der geschlossenen Secale-Kurve.

\subsubsection{Profil ARS 5}

Wie bei ARS 1 sind im Diagramm von ARS 5 (Beilage 3) mehrere Kernabschnitte zusammengefügt. Daher entsprechen die Tiefen im Diagramm nicht den Tiefen im Kern, eine Gegenübergestellung befindet sich im Anhang in Tabelle 11.

\section{Diagrammbeschreibung Profil ARS 5:}

205-207,5 cm, Präboreal, Pollenzone IV, Niedrige NBP-Werte, Anstieg der Pinus-Werte, Beginn des Corylus-Anstiegs.

Grenze IV/Va: Beginn des Corylus-Anstiegs.

195-205 cm, Boreal, Pollenzone Va, Beginn des starken Haselanstiegs, beginnende Einwanderung der EMW-Arten bei stark zurückgehenden Pinus-Werten.

Grenze Va/Vb: EMW-Werte > 5\%.

170-195 cm, Boreal, Pollenzone Vb, borealer Haselgipfel, beginnende Einwanderung von Alnus bei stark zurückgehenden Pinus-Werten. 
Grenze Vb/VI: Abfall der Corylus-Kurve unter $30 \%$ und Beginn des Steilanstieges der Alnus-Kurve.

145-170 cm, Älteres Atlantikum, Pollenzone VI, deutlicher Rückgang von Betula und Corylus, Ausbreitung der EMW-Arten und Alnus.

Grenze VI/VII: Der Anstieg der Fraxinus-Kurve über $1 \%$.

97-145 cm, Jüngeres Atlantikum, Pollenzone VII, deutlicher Rückgang der Pinus-Kurve, stetiger Anstieg der Quercus-Werte, übrige EMW-Arten relativ konstant.

Grenze VII/VIII: Der Ulmenfall, Fagus-Kurve geschlossen.

75-97 cm, Subboreal, Pollenzone VIII, deutlicher Rückgang der Ulmus-Werte, geschlossene Fagus-Kurve, Quercus-Werte bleiben relativ konstant, Rückgang der Pinus-Werte.

Grenze VIII/IXa: Fagus-Werte durchgängig >2\%.

39-75 cm, Älteres Subatlantikum, Pollenzone IXa, Fagus-Werte übersteigen 2\%, die Carpinus-Kurve ist geschlossen

Grenze IXa/IXb: Anstieg der Fagus-Werte über 5\% und der Carpinus-Kurve über 4\%, Beginn der Secale-Kurve.

13-39 cm, Älteres Subatlantikum, Pollenzone IXb, Fagus-Werte erreichen ein Maximum. Am Beginn der Zone ist die Carpinus-Kurve geschlossen und erreicht dann im weiteren Verlauf ebenfalls ein Maximum. Weiter stetiger Rückgang der Pinus-Werte. Es lassen sich mehrere Phasen unterschiedlicher Besiedlungsintensität erkennen.

Grenze IXb/X: Starker Anstieg der SZ-Werte und der Secale-Kurve.

0-13 cm, Jüngeres Subatlantikum, Pollenzone Xa, ein sehr starker Anstieg der SZ-Kurve, gefolgt von einem deutlichen Anstieg der Pinus- und der Quercus-Werte. 


\subsection{Rambower Moor}

Im Rambower Moor wurden mehrere Profile erbohrt (Abb. 8). Einige aus den verlandeten Bereichen des Sees, deren Auswertung ergab, dass sie für pollenanalytische Untersuchungen nicht geeignet waren, da die Torfe im oberen Teil der Profile allgemein schlechte Erhaltungsbedingungen für Pollenkörner boten. Warum dies so ist, konnte bislang nicht schlüssig geklärt werden, möglicherweise spielt die Stellung des Rambower Moores als basenreiches Durchströmungsmoor eine gewisse Rolle. Anderseits konnte in den Kalkmudden, immer eine gute Pollenerhaltung festgestellt werden.

\subsubsection{Profil Boberow}

Die Stratigraphie-Ansprache (Tabelle 13) erfolgte im Gelände.

\section{Diagrammbeschreibung Profil Boberow:}

273-335 cm, Subboreal, Pollenzone VIII, die Pinus-Werte sinken von $40 \%$ auf $10 \%$, die Quercus-Kurve liegt bei $20 \%$. Bei insgesamt niedrigen Werten der SZ deutet sich nur in Phase a eine Zeit stärkerer Besiedlung an.

205-273 cm, Älteres Subatlantikum, Pollenzone IXa, die Fagus-Kurve übersteigt die 2\% Marke und die Carpinus-Kurve ist nun geschlossen. Im weiteren Verlauf gehen die PinusWerte deutlich zurück. Es sind mehrere Phasen (c-f) wechselnder Besiedlungsintensität zu erkennen.

148-205 cm, Älteres Subatlantikum, Pollenzone IXb, die Fagus-Kurve und die CarpinusKurve steigen über die 10\% Marke. Die Pinus-Werte gehen deutlich zurück während die Buchenkurven ihre Maxima erreichen. Es sind mehrere Phasen (g-i) wechselnder Besiedlungsintensität zu erkennen.

130-148 cm, Jüngeres Subatlantikum, Pollenzone Xa, starker Anstieg der SZ-Kurve, Beginn des Rückgangs der Buchen-Werte.

\subsubsection{Profil Rambow}

Die Stratigraphie-Ansprache (Tabelle 14) erfolgte im Gelände.

\section{Diagramm-Abschnitt (DA) A, Präboreal (10,28 - 9,98 m)}

Die Pinus-Kurve weist zu Beginn Werte um $55 \%$ auf und steigt auf ein Maximum von $76 \%$. Die Betula-Werte liegen bei $42 \%$ und gehen auf $20 \%$ zurück. Die Populus-Kurve setzt mit $0,7 \%$ ein und steigt auf $2,6 \%$ an. 
Die EMW-Summe erreicht nur in einer Probe Werte über $1 \%$. Die Salix-Werte liegen zwischen 0,2 und 0,7\%. Die Corylus-Kurve setzt mit 1,6\% ein und steigt auf 6,6\%.

Die NBP-Werte liegen bei $11 \%$ und sinken auf 7,3\%. Den größten Anteil haben daran die Poaceae. Die Kurve der Cyperaceae fällt von 4,1 auf 2,2 \% ab. Es findet sich bereits ein erstes PK vom Triticum-Typ.

Calluna tritt mit Werten von maximal 0,3\% auf.

Unter den Sumpf- und Wasserpflanzen sind nur Filipendula (max. 0,7 \%) und der Sparganium-Typ (0,1-0,4\%) etwas häufiger. Thelypteris ist mit ansteigenden Anteilen zwischen 0,1 und $0,7 \%$ vertreten.

Die Anteile von Pediastrum liegen anfangs bei 6,1\% und gehen dann auf 0,6\% zurück.

Grenze DA A/B: Anstieg der Corylus-Kurve auf über $10 \%$ und Rückgang der Pinus-Werte auf weniger als $75 \%$.

\section{Diagrammabschnitt B, älteres Boreal (9,90 - 9,22m)}

Die Pinus-Kurve fällt von 73 auf $66 \%$. Betula ist mit Anteilen von $26 \%$, vorübergehend sogar $39 \%$, etwas stärker als zuvor vertreten. Die Populus-Kurve erreicht ihr Maximum von 3,2 $\%$ und sinkt anschließend wieder etwas ab.

Die Anteile vom EMW steigen von 2,5 auf 4,6\% an. Hauptbestandteile sind Quercus und Ulmus. Während am Beginn vom DA B Pollen von Ulmus häufiger als Quercus ist, ist das Verhältnis am Ende vom DA B umgekehrt. Fraxinus ist mit Werten bis maximal 0,5 \% vertreten.

Die Alnus-Kurve setzt in der Mitte des DA B ein und erreicht maximal 0,9\%. Die CorylusKurve steigt von 19 auf $43 \%$ an.

Der Anteil der NBP liegt um $12 \%$.

Die Werte der SZ-Summe liegen um $1 \%$. Pollen vom Getreide-Typ ist in zwei Proben der jüngeren Abschnittshälfte mit maximalen Anteilen von 0,5\% vorhanden (Zur Bewertung dieser Funde beachte man Kapitel 6.2.1).

Die Calluna-Kurve steigt allmählich auf 1,5\% und fällt dann wieder auf 0,6\% ab.

Unter den Sumpf- und Wasserpflanzen haben Filipendula und der Sparganium-Typ nahezu geschlossene Kurven mit Höchstwerten von jeweils 0,4\%. 
Bei den Polypodiaceae indet. liegen die Anteile weiterhin um $1 \%$. Hier beginnt die Pteridium-Kurve. Die Sphagnum-Kurve setzt am Anfang vom DA B ein, erreicht aber nur 0,2 \%.

Die Kurve von Pediastrum steigt auf $8 \%$ und sinkt dann auf $1 \%$ ab.

Grenze DA B/C: Anstieg der EMW-Kurve auf über $10 \%$, beginn der geschlossenen Tilia cordata-Kurve und Abfall der NBP-Kurve.

\section{Diagrammabschnitt C, jüngeres Boreal (9,10 - 8,70 m)}

Die Pinus-Kurve sinkt weiter auf $47 \%$ ab. Die Betula-Werte gehen von 32 auf $23 \%$ zurück. Die Populus-Werte sinken weiter ab und liegen nun bei $1 \%$.

Die EMW-Summe steigt weiter von 13,5 bis auf $21 \%$ an. Während die Quercus-Werte von 9 auf $16 \%$ ansteigen, zeigt Ulmus mit Anteilen zwischen 2,5 und 4,1\% nur relativ geringe Veränderungen. Die Kurve vom Tilia cordata-Typ setzt ein. Gleichzeitig mit dem Tilia cordataTyp tritt Viscum auf, gefolgt von Hedera. Bis zum Abschnittsende ist Hedera mit einzelnen PK in mehreren Spektren vertreten.

Die Alnus-Kurve steigt in der zweiten Hälfte des DA C rasch auf 7,3\%. Die Corylus-Kurve erreicht zu Beginn des DA C ihr Maximum von $51 \%$ und fällt anschließend wieder auf $39 \%$ ab.

NBP ist nur noch mit Werten zwischen 8,6 und 7,6\% vertreten.

Mit geringen Werten kommt Calluna durchgehend vor.

Von den Sumpf- und Wasserpflanzen sind Filipendula und der Sparganium-Typ weiterhin durchgehend mit geringen Werten vertreten.

Grenze DA C/D: Abfall der Corylus-Kurve von 39 auf $20 \%$ und Beginn des Steilanstieges der Alnus-Kurve.

\section{Diagrammabschnitt D, älteres Atlantikum älterer Teil (8,60 - 7,80m)}

Die Pinus-Kurve sinkt von $58 \%$ unter starken Schwankungen (Minimum 26\%) auf $47 \%$ ab. Die Betula-Kurve sinkt von 18 auf $14 \%$ ab; nur im Bereich vom Pinus Minimum erreicht sie $29 \%$. Die Populus-Kurve liegt bei 0,6\%.

Die Anteile vom EMW bewegen sich zwischen 14 und $23 \%$. Den größten Anteil daran hat Quercus mit etwa zwei Dritteln. Die Ulmus-Werte liegen im Mittel bei 4 \%. Die FraxinusKurve schließt sich, die Anteile sind weiter nur gering (max. 0,4\%). Am Beginn des DA D steigt die Kurve vom Tilia cordata-Typ auf ein Niveau von 1,3\%. Viscum ist mit einzelnen 
PK regelmäßig vertreten. Hedera ist nun in fast jedem Pollenspektrum vorhanden. Daneben finden sich vereinzelte PK von Picea sowie das erste PK von Fagus.

Die Alnus-Werte steigen zunächst auf ein Maximum von $30 \%$ an und schwanken dann um $21 \%$.

Die Corylus-Kurve fällt auf $13 \%$ ab.

Die Werte der NBP schwanken um 6,8 \%. Der Anteil der Poaceae liegt um 3,6 \%, der der Cyperaceae bei $1,3 \%$. SZ sind mit Werten um $0,3 \%$ vertreten. In der Mitte des DA tritt zum ersten Mal ein PK vom Plantago lanceolata-Typ auf.

Die Calluna-Kurve liegt mit ihren Werten um 0,8\%.

Unter den Sumpf- und Wasserpflanzen ist Filipendula nun nicht mehr durchgängig (max. 0,6 $\%$ ) vertreten. Pollen vom Sparganium-Typ kommt nahezu durchgehend vor.

Bei den Polypodiaceae indet. liegen die Anteile weiter um $1 \%$. Thelypteris erreicht Werte bis maximal 0,8\% und ist in diesem und den folgenden Abschnitten nicht mehr durchgehend vertreten.

Grenze DA D/E: Anstieg der Ulmus-Kurve auf 7,5 \% und Anstieg der EMW-Kurve auf über $20 \%$.

\section{Diagrammabschnitt E, älteres Atlantikum jüngere Teil (7,70 - 7,00m)}

Die Pinus-Werte liegen um $39 \%$. Die Betula -Werte steigen allmählich auf $17 \%$ an. Populus ist mit Anteilen von ca. $0,7 \%$ weiter nur gering vertreten.

Die EMW-Summe erreicht durchgehend Anteile von über $20 \%$ und bis zum Ende des DA steigen sie auf $27 \%$ an. Die Quercus -Werte machen den Hauptanteil aus; sie liegen bei $14 \%$ und steigen am Abschnittsende auf $19 \%$ an. Ulmus ist mit Anteilen zwischen 3,6 und 7,5\% etwas stärker als zuvor vertreten. Die Fraxinus-Kurve beginnt anzusteigen, erreicht 2,4\% und geht am Ende des DA E auf 0,6 \% zurück.

Ein Pollenkorn von Hedera, Pollenkörner von Viscum fehlen, sie treten erst in DA H wieder auf. Die Picea-Kurve schließt sich und erreicht maximal 0,6 \%. Je ein PK von Fagus und von Carpinus.

Die Alnus-Kurve schwankt um $24 \%$. Salix -Werten von 0,4\% vertreten, kommt dann jedoch am Ende des DA E nicht mehr vor. Die Anteile von Corylus bewegen sich um $13 \%$ und sinken am Ende des DA auf 8,5\% ab. 
Der NBP erreicht nur noch Werte um 5,5\%. Weiterhin am häufigsten sind Poaceae (um 2,5 $\%$ ), Cyperaceae (um $1 \%$ ) und Calluna (um 1,1\%). Unter den SZ (maximal 1,3\%) ist Artemisia mit max. 0,4\% vertreten. Am Beginn vom DA gibt es ein PK vom Avena-Typ, in der zweiten Abschnittshälfte sind Plantago lanceolata, Chenopodiaceae und der Rumex acetosaTyp mit einzelnen PK vertreten.

Am Beginn des DA E steigt die Pteridium-Kurve auf 1,1\%. Von Sphagnum, Thelypteris und Equisetum sowie von Dryopteris filix mas finden sich nur einzelne Sporen.

Grenze DA E/F: Anstieg der Fraxinus-Kurve auf dauerhaft über $2 \%$, und Anstieg der $U l$ mus-Werte auf ihr höchstes Niveau (5,7\%).

\section{Diagrammabschnitt F, jüngeres Atlantikum (6,90 - 6,20m)}

Die Pinus-Werte unterliegen Schwankungen zwischen 51 und $26 \%$. Die Kurve von Betula geht auf von 20 auf $12 \%$ zurück. Keine Veränderungen zeigen sich in der Populus-Kurve.

Die EMW-Anteile sinken zunächst wieder auf $19 \%$ ab; in der zweiten Abschnittshälfte liegen sie bei ca. $26 \%$. Quercus ist mit Werten zwischen 11 und $19 \%$ wieder am stärksten an der EMW-Summe beteiligt. Die Ulmus-Kurve steigt von 5,2 \% auf ihr Maximum im Diagramm $(8 \%)$ an und sinkt dann wieder auf 6,9\% ab. Die Fraxinus-Kurve erreicht am Beginn des DA F ebenfalls ihren Höchstwert von 4,9 \%, danach schwankt sie um 2,7 \%. Die Anteile vom Tilia cordata-Typ sinken ab auf ca. 1,1\%. PK von Hedera sind nur in zwei Spektren vorhanden. Die Picea-Kurve ist mit Werten um 0,3 \% nun geschlossen. Es treten vereinzelte PK von Fagus und Carpinus auf.

Die Alnus-Kurve bewegt sich zwischen 15 und $25 \%$. Salix kommt nun wieder regelmäßig mit Werten um 0,3\% vor. Die Corylus-Werte liegen um $11 \%$.

Nur geringfügige Veränderungen zeigen sich beim Anteil $(5,4 \%)$ und der Zusammensetzung der NBP. Weiterhin liegt der Anteil der Poaceae bei 2,3\%, der der Cyperaceae bei 1,1 \%. Die Calluna-Kurve schwankt zwischen 0,2 und 1,7\%. Die SZ erreichen nur noch Anteile von max. 0,9\%. Am Ende des DA F findet sich ein PK vom Hordeum-Typ außerhalb der Zählung. PK von Plantago lanceolata fehlen.

Die Werte der Polypodiaceae indet. erreichen maximal 2,5\%. Die Pteridium-Kurve geht von 2 auf $0,4 \%$ zurück. Thelypteris und Sphagnum treten nur vereinzelt auf.

Grenze DA F/G: Rückgang der Ulmus Werte und Rückgang der Werte vom Tilia cordataTyp. 


\section{Diagrammabschnitt G, älteres Subboreal (6,10 - 5,50m)}

Die Pinus-Kurve sinkt von 41 auf $22 \%$ ab und steigt in der zweiten Abschnittshälfte wieder auf $36 \%$ an. Die Betula-Werte steigen von 13 auf $18 \%$ an. Die Populus-Kurve ist nicht mehr geschlossen und liegt um $0,5 \%$.

Die Werte für die EMW-Summe gehen auf $22 \%$ zurück, steigen dann auf $30 \%$ in der Mitte des DA G an und sinken auf $23 \%$ ab. Die Quercus-Werte liegen zwischen 15 und $22 \%$. Die Ulmus-Werte fallen an der Grenze DA F/G auf 1,9\% ab (1. Ulmenabfall). Nur vorübergehend steigen sie nochmals auf 5,4\% an und liegen dann am Ende des DA G bei 2,1 \%. Die Anteile von Fraxinus liegen relativ konstant bei 2,5 \%. Nachdem die Werte vom Tilia cordata-Typ am Beginn des DA G aussetzen, steigen sie wieder auf etwa 1,2\% an. Es treten erstmals vereinzelt PK von Acer auf. Hedera ist mit einzelnen PK repräsentiert. PK von Fagus und Carpinus sind weiterhin nur vereinzelt vertreten.

Die Alnus-Kurve liegt zwischen 18 und $31 \%$. Die Corylus-Kurve steigt an auf ca. $14 \%$.

Die Werte der NBP steigen auf 7,3\% an und gehen dann wieder auf 3,4 \% zurück. Der Anteil der Poaceae sinkt auf 1,5\%, die Werte der Cyperaceae liegen fast unverändert bei ca. 1,2 \%. Calluna wird in der Mitte vom DA mit Werten von 2,3 \% etwas häufiger; anschließend gehen die Anteile auf 1,3\% zurück. Die SZ erreichen weiterhin nur Werte um 0,3\%. PK vom Getreide-Typ und von Plantago lanceolata fehlen.

Rotatorien-Cysten sind durchgehend mit Anteilen von maximal $1 \%$ vertreten.

Grenze DA G/H: Beginn der geschlossenen Fagus-Kurve und Anstieg der Picea-Kurve. Diagrammabschnitt H, älteres Subboreal (5,40-4,65m)

Die Pinus-Werte liegen zunächst um $31 \%$, erreichen dann ein Maximum von $56 \%$ und gehen anschließend auf $35 \%$ zurück. Die Kurve von Betula geht auf $8 \%$ zurück, am Ende des DA H steigt sie dann wieder auf $17 \%$ an.

Die Kurve vom EMW unterliegt stärkeren Schwankungen von 18 bis 36 \%. Die Ulmus-Werte liegen um 3,2\%, steigen vor dem Ende des DA H bis auf 5,4\% an und sinken dann bei Beginn eines zweiten Ulmen-Rückgangs, der die Grenze zu DA I bildet, auf 4,4\%. Die PiceaKurve erreicht am Anfang des DA ihren Höchstwert im Diagramm mit 2,5 \%; anschließend liegen die Werte um $1 \%$. Die Fagus-Kurve ist nun geschlossen und steigt zum Ende des DA $\mathrm{H}$ auf $0,7 \%$.

Alnus wird in der ersten Hälfte des DA H mit Werten bis zu 30 \% etwas häufiger; es folgt ein Rückgang auf 16 bis $24 \%$. Die Corylus-Kurve geht zunächst bis auf $8 \%$ zurück und steigt dann am Ende des DA H auf $18 \%$ an. 
Die NBP-Kurve schwankt stark und hat in der Mitte des DA H ein Maximum von $12 \%$. Die Werte von Cyperaceae und Calluna sind mit ca. 1,3\% weiterhin nahezu unverändert. Die Anteile der SZ steigen bis zur Mitte des DAH auf 3,6\% an und sinken dann wieder bis auf 0,2 \% ab. In der ersten Hälfte des DA H treten PK vom Getreide-Typ auf. Artemisia erreicht maximal Werte von 0,4\%. Dagegen steigen die Anteile von Plantago lanceolata bis auf 2,5\%, die vom Rumex acetosa-Typ bis auf $0,8 \%$ an.

Die Rotatorien-Cysten erreichen Werte von maximal $3 \%$.

Grenze DA H/I: Rückgang der Ulmus-Werte auf 1,8\% und Anstieg der Corylus-Werte.

\section{Diagrammabschnitt I, älteres Subboreal (4,60 - 3,65m)}

Die Pinus-Kurve fällt bis zur Mitte des DA auf $23 \%$ ab, steigt dann auf $44 \%$ an und fällt auf $19 \%$ ab. Die Betula-Werte liegen um $14 \%$, sinken am Ende vom DA auf 8,4 \% und steigen zu einem kleinen Gipfel von $19 \%$ an.

Die Anteile vom EMW liegen zwischen 21 und $35 \%$. Quercus ist mit Werten zwischen 19 und $26 \%$ etwas stärker als zuvor vertreten. Die Ulmus-Werte erreichen einen Tiefstwert von $0,7 \%$, danach liegen sie bei ca. $2 \%$. Auch die Fraxinus-Anteile sind mit ca. $2 \%$ geringer als zuvor vertreten. Die Kurve vom Tilia cordata-Typ sinkt am Ende des DA I von Werten um 1,4 auf $0,5 \%$ ab. Am Anfang des DA I steigen die Fagus-Werte zum ersten Mal über $1 \%$, anschließend gehen sie bis auf 0,1\% zurück. Maximal werden $3 \%$ erreicht. Die CarpinusKurve ist nahezu geschlossen und erreicht max. $1,1 \%$.

Die Alnus Anteile liegen zunächst zwischen 19 und $32 \%$; sie steigen in der zweiten Hälfte des DA auf ihren Höchstwert von $41 \%$ an. Die Corylus-Werte liegen um $18 \%$.

Die NBP-Werte liegen am Beginn des DA I bei 7,5\%, sie schwanken stark und steigen in der zweiten Hälfte des DA zu einem Gipfel von $24 \%$ an, von dem sie auf $10 \%$ abfallen. Die Calluna-Kurve schwankt zwischen 0,1 und 2,7\%.

Die SZ sind deutlich stärker als zuvor vertreten und erreichen am Ende des DA I Anteile von 8,4 \%. PK vom Getreide-Typ erreichen am Ende des DA I einen Höchstwert von 1,3 \%. Erstmals kommt Secale vor. Die Kurven von Plantago lanceolata und dem Rumex acetosa-Typ steigen bis auf 2,8 bzw. $3,7 \%$ an.

In der zweiten Hälfte vom DA I ist Pediastrum erstmals seit DA C wieder stärker mit Anteilen von maximal $11 \%$ vertreten.

Die Rotatorien-Cysten erreichen Werte von maximal 2,1\%.

Bei 3,65 m endet der hier bearbeitete Profilteil, der obere Abschnitt wurde von KIRLEIS (1998) untersucht. 


\subsubsection{Profil Heuweg 1}

Das Moor am Heuweg wurde bereits von LESEMAnN (1969) untersucht. Die hier vorliegende neue Untersuchung diente in erster Linie der Gewinnung von ${ }^{14} \mathrm{C}$-Datierungen, die frei vom Hartwassereffekt sind und deren Ergebnisse in Tabelle 5 zusammengestellt sind. Die Stratigraphie des Profils ist in Tabelle 12 (Anhang) beschrieben. Abweichend von den übrigen Diagrammen ist im Profil Heuweg 1 neben Alnus und Corylus auch Betula aus der Baumpollensumme ausgeschlossen (Abb. 12), da hier aufgrund des Kleinmoorcharakters die lokale Anwesenheit der Birke ebenfalls zu einer Überrepresentation führt.

\section{Diagrammbeschreibung Profil Heuweg 1:}

147-123,5 cm, Jüngeres Atlantikum, Pollenzone VII, die Pinus-Werte liegen um die 30\%, Anstieg der Quercus-Werte von 9\% auf 17\%, Rückgang der Corylus-Kurve von 300 auf 125\%, am Ende der Zone ein deutlicher Rückgang der Ulmus-Kurve von 45 auf $20 \%$.

Grenze VII/VIII: Der Ulmenfall.

123,5-87,5 cm, Subboreal, Pollenzone VIII, in dieser Zone beginnt die geschlossene FagusKurve, Quercus-Werte bleiben relativ konstant (im Mittel 29\%), die Ulmus-Werte schwanken um die 19\% und fallen am Ende der Zone unter 5\%,

Grenze VIII/IXa: Fagus-Werte > 2\%, Beginn der geschlossenen Carpinus-Kurve.

87,5-62,5 cm, Älteres Subatlantikum, Pollenzone IXa, Rückgang der Pinus-Werte von 62 auf $13 \%$, die Fagus-Kurve steigt von $4 \%$ auf $15 \%$, die Carpinus-Werte steigen stetig von $4 \%$ auf 12\%, die SZ-Kurve geht von einem Maximum mit 17\% am Beginn der Zone deutlich zurück, auf Werte von $5 \%$.

Grenze IXa/IXb: Anstieg der Fagus-Werte über 15\% und der Carpinus-Kurve über 5\%.

62,5-37,5 cm, Älteres Subatlantikum, Pollenzone IXb, die Massenausbreitung von Fagus, mit maximal 36\% und Carpinus, mit maximal 35\% erfolgt.

Grenze IXb/X: Starker Anstieg der SZ-Werte und Einsetzen der Secale-Kurve.

37,5-30 cm, Jüngeres Subatlantikum, Pollenzone Xa, die Fagus-Kurve fällt deutlich ab, ebenso die Carpinus-Kurve, die Secale-Werte setzen ein, die SZ-Werte steigen von 8 auf über $30 \%$. 


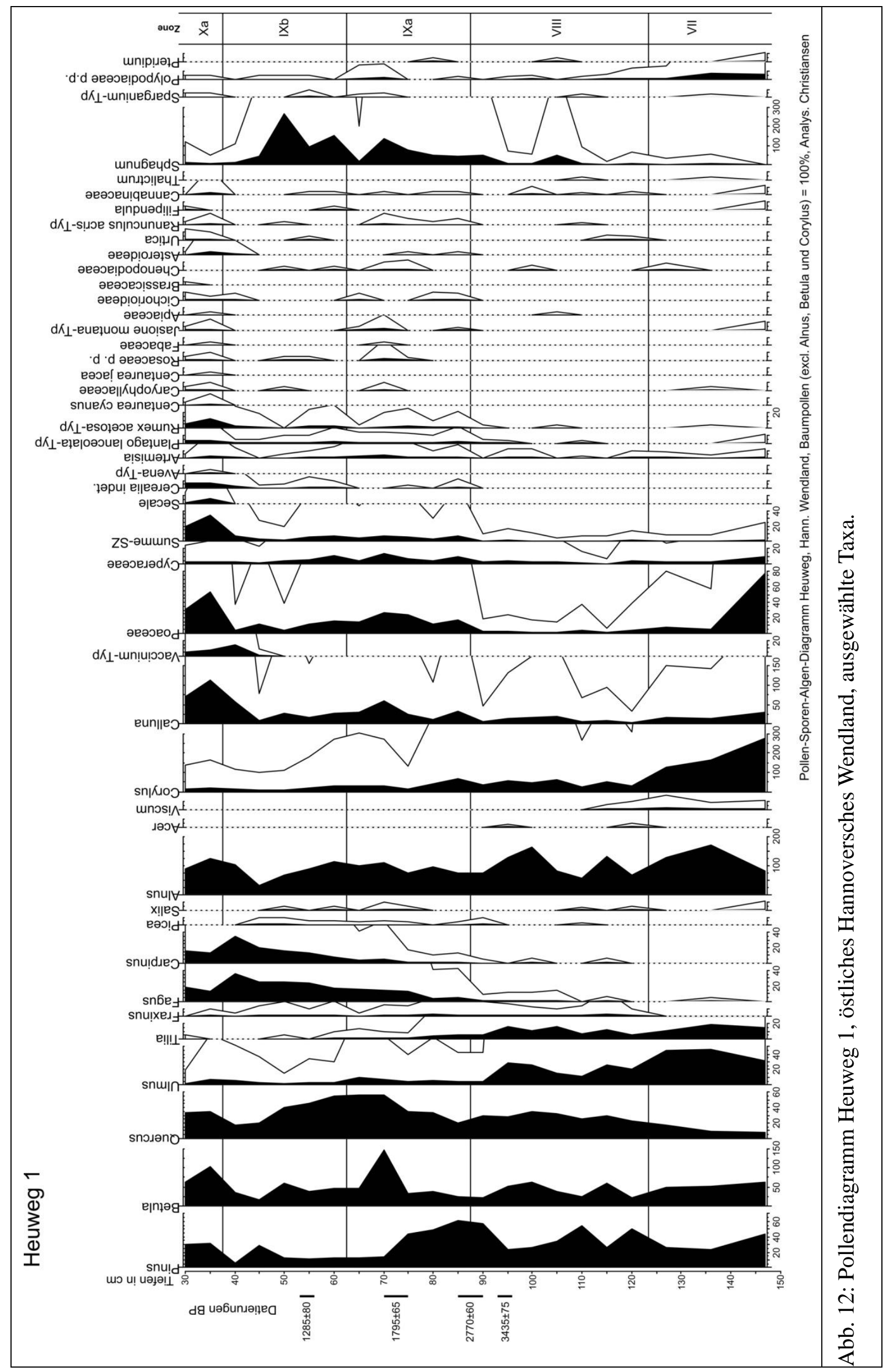




\section{Diskussion}

\subsection{Bemerkungen zu den Radiokohlenstoff-Datierungen}

Bei den Datierungen des Arendsees gab es einige Schwierigkeiten durch den Hartwassereffekt, wie bereits in Kapitel 3.5.1 angeführt wurde. Im Rambower Moor gab es Probleme aufgrund der schlechten Pollenerhaltung in den Torfen. Die Korrelierung der ${ }^{14} \mathrm{C}$-Datierungen vom Heuweg 1 mit den pollenanalytischen Ergebnissen vom Arendsee und dem Rambower Moor wurde dadurch erschwert, dass es sich beim Heuweg 1 um ein sehr kleines Moor handelt, welches noch dazu inmitten einer Sanddünenfläche liegt. Dies wirkt sich auf die Vegetationsentwicklung aus und kann so zu Unterschieden beim Vergleich mit den Ergebnissen vom Arendsee und dem Rambower Moor führen.

Dennoch ist am Arendsee eine relative Datierung gelungen (Abb. 14). Erster Datierungspunkt ist die Laacher See Tephra, die mit cal. 10930 v. Chr. datiert wird (LITT und STEBICH 1999). Für die Datierung des Ablaufs der spätglazialen und früholozänen Vegetationsentwicklung wurde auf die Synopse von 27 Pollendiagrammen aus Brandenburg zurückgegriffen (Abb. 13, WOLTERS 2002). Die Werte vom Arendsee lassen sich dabei problemlos in den Gliederungsvorschlag für Brandenburg einfügen. Allerdings beginnt am Arendsee das Diagramm erst am Ende der älteren Dryas-Zeit. Im Bereich des Boreals gab es in ARS 1 einen Kernverlust, so dass in Abb. 13 auf eine Untergliederung verzichtet wurde (vgl. Kapitel 6.1.3 und 6.1.5). 


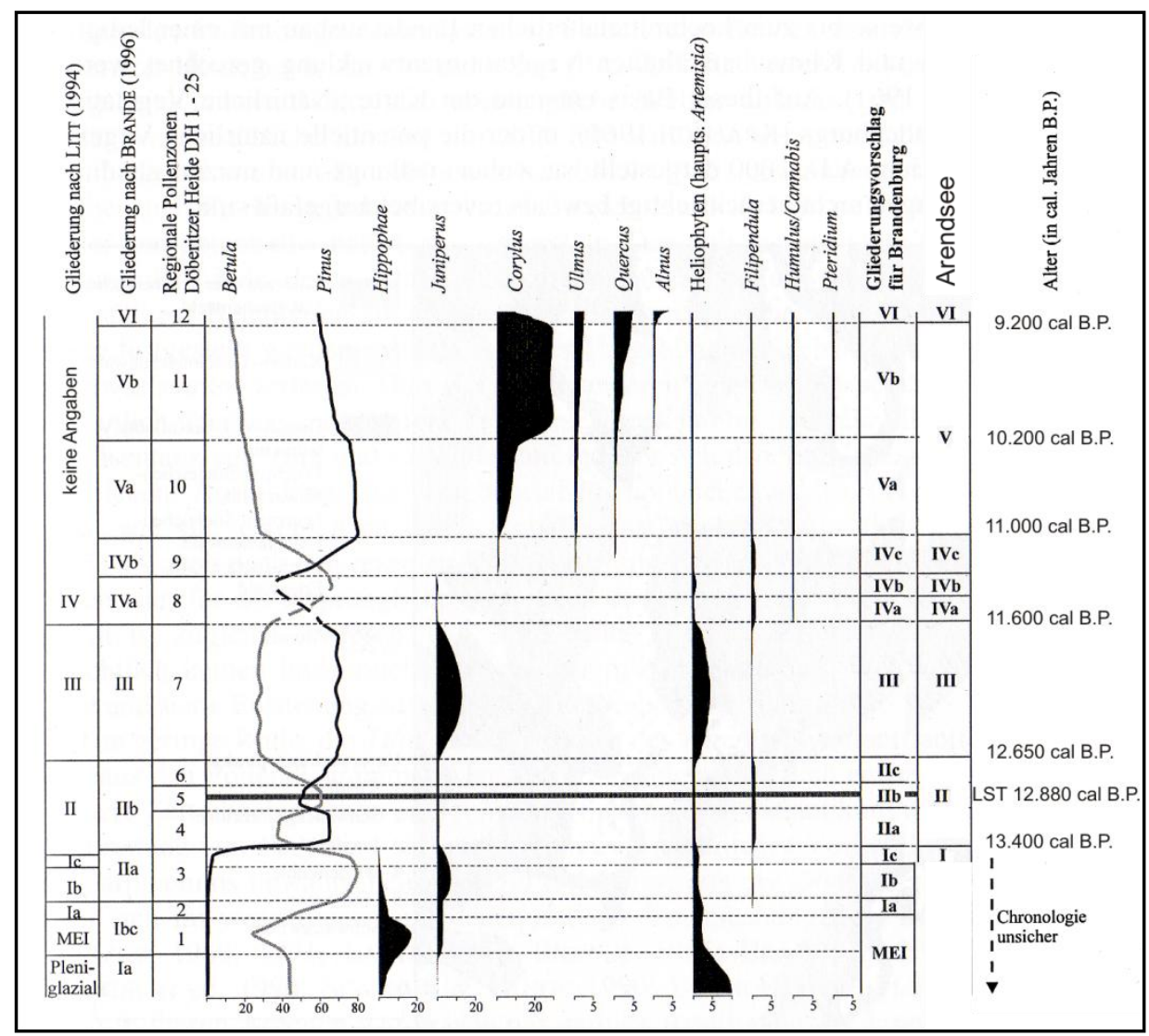

Abb. 13: Pollenstratigraphisches Gliederungsprinzip und Ablauf der spätglazialen und frühholozänen Vegetationsentwicklung in Brandenburg auf Grundlage von 27 Pollendiagrammen, (WOLTERS 2002), verändert.

Beim Vergleich wurden auch die Datierungen von JAHNS (2007) am Löddigsee und von LESEMANN (1969) in Siemen berücksichtigt. Die aus dem Arendsee vorliegende Datierung für den Beginn des Boreals fällt mit $9982 \pm 75$ BP (11503 cal. BP) deutlich zu alt aus.

Für den Beginn des Atlantikums liegen vom Löddigsee (JAHNS 2007) und aus der Döberitzer Heide (Wolters 2002) Datierungen vor. Aus dem Atlantikum liegen keine Datierungen vor, die sich übertragen lassen, was an der aus waldgeschichtlicher Sicht relativ ereignislosen Zeit liegen kann. Die drei ${ }^{14} \mathrm{C}$-AMS-Datierung (vgl. Tabelle 4), die aus dem Arendsee vorliegen, scheinen im Vergleich mit erwarteten Werten gut überein zu stimmen und werden daher verwendet.

Bei den folgenden Proben, die nach den pollenanalytischen Ergebnissen alle ins Subatlantikum fallen, tritt der Hartwasser-Effekt deutlich zutage. Eine der Proben erreicht ein Alter von 463 n. Chr., was ca. 700 Jahre zu alt ist, da hier der Beginn des mittelalterlichen Landesausbaus datiert werden sollte. Die Probe, die eigentlich ein Siedlungsminimum der Völkerwanderungszeit genau datieren sollte, wurde mit $1443 \mathrm{v}$. Chr. datiert, und ist beinahe 2000 Jahre zu alt. Am auffälligsten ist aber eine Datierung, die klären sollte, ob ein Minimum der Siedlungszeiger Folge des 30jährigen Krieges war oder doch der Pest im 14. Jahrhundert zugerechnet 
werden musste. Mit 1811 v. Chr. liegt sie 3496 Jahre zu alt. Diese Abweichungen lassen sich allein mit dem Hartwassereffekt nicht erklären, zumal die Datierung an der Pollenfraktion durchgeführt wurde. Zumindest für die beiden zuletzt angeführten Datierungen bietet sich eine andere Erklärung an: es sind die Folgen der Salzstockeinbrüche der Jahre 815/820 und 1685. Das infolge der Einbrüche aufgewirbelte Sediment, das im Kern als helleres Band zu erkennen ist, insbesondere für den Einbruch, bei dem die Mühle im See versank, enthielt einen großen Teil älterer Ablagerungen. Als Folge wurden natürlich auch die Pollen älterer Sedimente aufgewirbelt und abgelagert, dadurch werden die Minima in den SiedlungszeigerWerten nochmals verstärkt.

\section{Zeit-Tiefen-Diagramm}

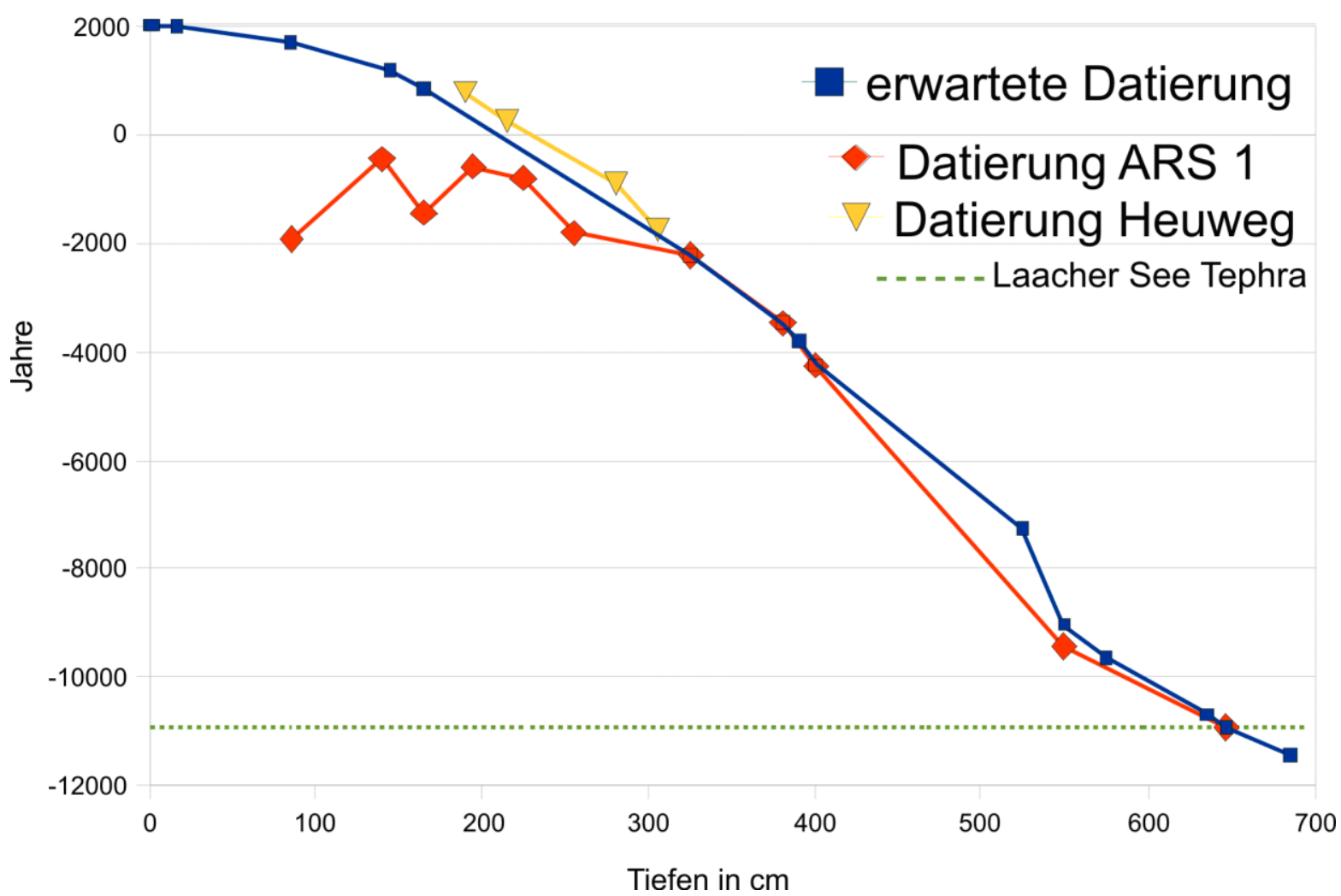

Abb. 14: Zeit-Tiefen-Diagramm für den Arendsee (Profil ARS 1). Zeiten v. Chr. sind mit negativen Werten angegeben, Tiefenangabe in cm, Erläuterungen im Text.

\subsubsection{Die regionale vegetationsgeschichtliche Entwicklung}

Die Vegetationsentwicklung stimmt in allen untersuchten Profilen soweit überein, dass sie hier exemplarisch am Kern ARS 1 vorgestellt werden kann. Gibt es deutliche Abweichungen bei den anderen untersuchten Profilen, so wird darauf hingewiesen. Allgemein gilt, dass die 
Profile Heuweg 1 und ARS 4 aufgrund ihrer deutlichen lokalen Überrepräsentation der Erle (vgl. Kapitel 4) anders bewertet werden müssen als die übrigen Profile.

$\mathrm{Zu}$ den eigenen Untersuchungen werden zum Vergleich einige der am nächsten gelegenen, modernen Ansprüchen genügenden pollenanalytischen Untersuchungen herangezogen. In einer Reihenfolge von Nord nach Süd sind das der Rugensee (DöRFLERim Druck), der Löddigsee (JAHNS 2007), die Untersuchungen am Maujahn, dem Niehnhofer Forst, in Laase, Siemen und dem Heuweg (Lesemann 1969)), der Döberitzer Heide (Wolters 2002) und der Drömling (GOLOMBEK 1980).

Das Spätglazial wurde nur im Kern ARS 1 nahezu vollständig erfasst, für die Darstellung (Abb. 15) wurde abweichend zu den übrigen Diagrammen die Summe auf die gleiche Weise gebildet wie bei BEHRE (1966).

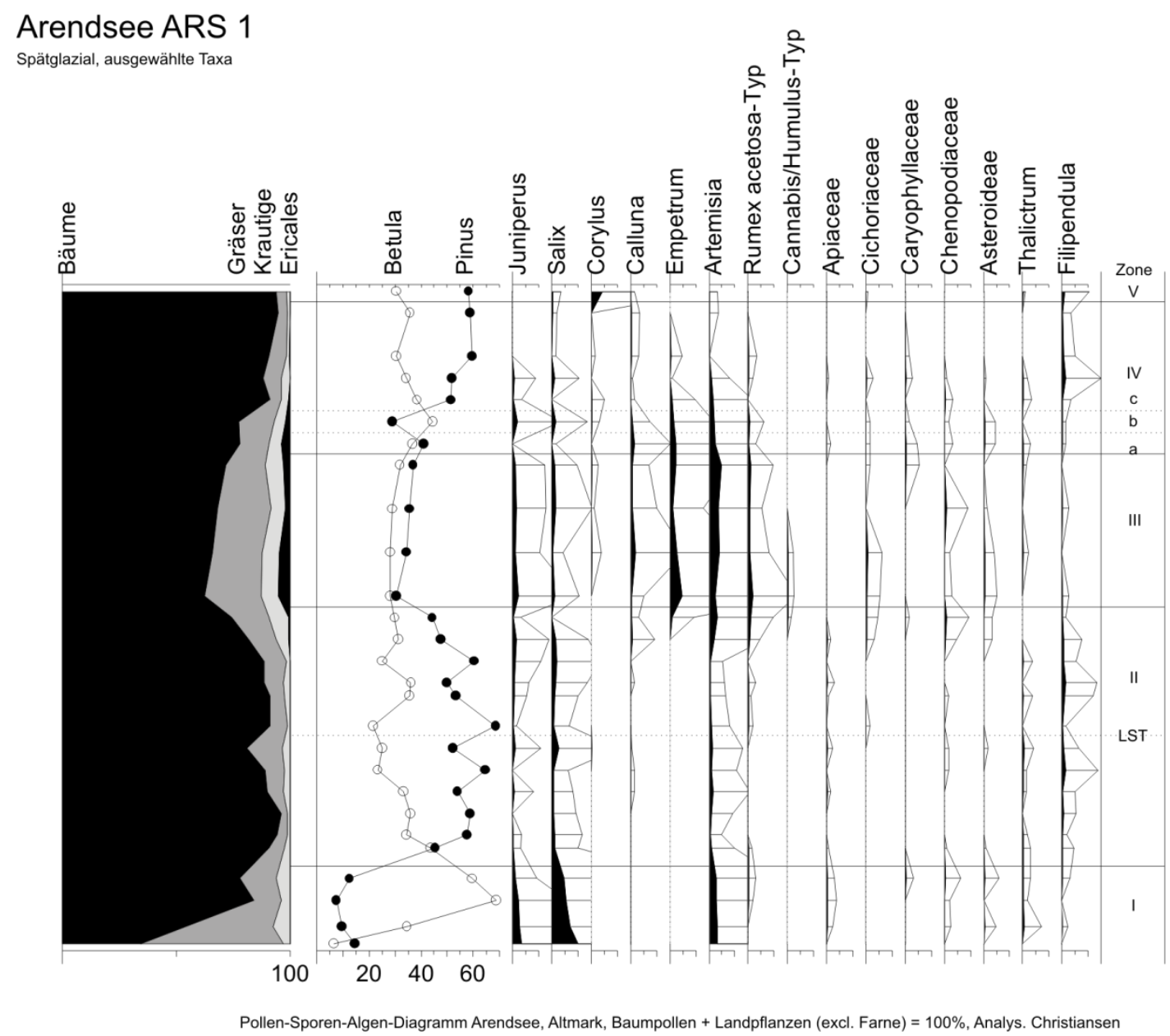

Abb. 15: Pollendiagramm des Spätglazials und Übergangs zum Holozän am Arendsee, Profil ARS 1, Baumpollen + Landpflanzen $=100 \%$, Zonen nach FIRBAS (1949), weitere Erläuterungen im Text. 


\subsection{2 Ältere Dryas-Zeit (Pollenzone I)}

Nur im Diagramm ARS 1 ist das Ende der älteren Dryas-Zeit mit wenigen Proben erfasst, böllingzeitliche Bildungen sind nicht vorhanden. Die hohen NBP-Werte zeigen eine waldfreie Landschaft an, in der allenfalls Strauchbirken und Weidengebüsche, sowie Juniperus als Gehölze im Gebiet des Arendsee wuchsen. Es gab eine offene Tundren-Vegetation, die von $A r$ temisia und Gräsern geprägt war. Am Übergang zur Allerød-Zeit wurde diese offene Tundra, mit ihren Strauchbirken und Weiden, dann abgelöst von Baumbirken und schließlich durch lichte Kiefer-Birkenwälder ersetzt. Erkennbar ist dies am starken Rückgang der NBP-Werte und den hohen Betula-Anteilen, gefolgt von hohen Pinus-Werten. Im benachbarten Faulen See, der pollenanalytisch von BEUG (RÖHRIG et al. 2004) untersucht wurde, zeigt sich dies noch etwas deutlicher. Hohe NBP-Werte zeigen eine offene Tundra an, die von Weidengebüschen und Strauchbirken abgelöst wurde. In Siemen wurde diese Phase von LESEMANN (1969) erfasst.

Am Rugensee wurde das Spätglazial nicht untersucht, am Löddigsee und in der Döberitzer Heide konnte nicht nur das Ende dieser Phase erfasst werden sondern noch ältere Abschnitte, wie sie in Tabelle 9 aufgeführt sind. 


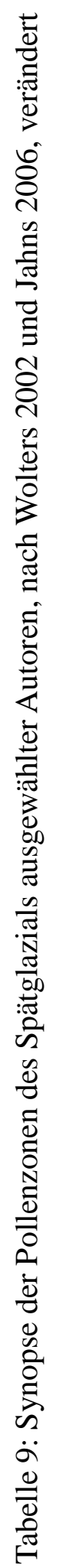

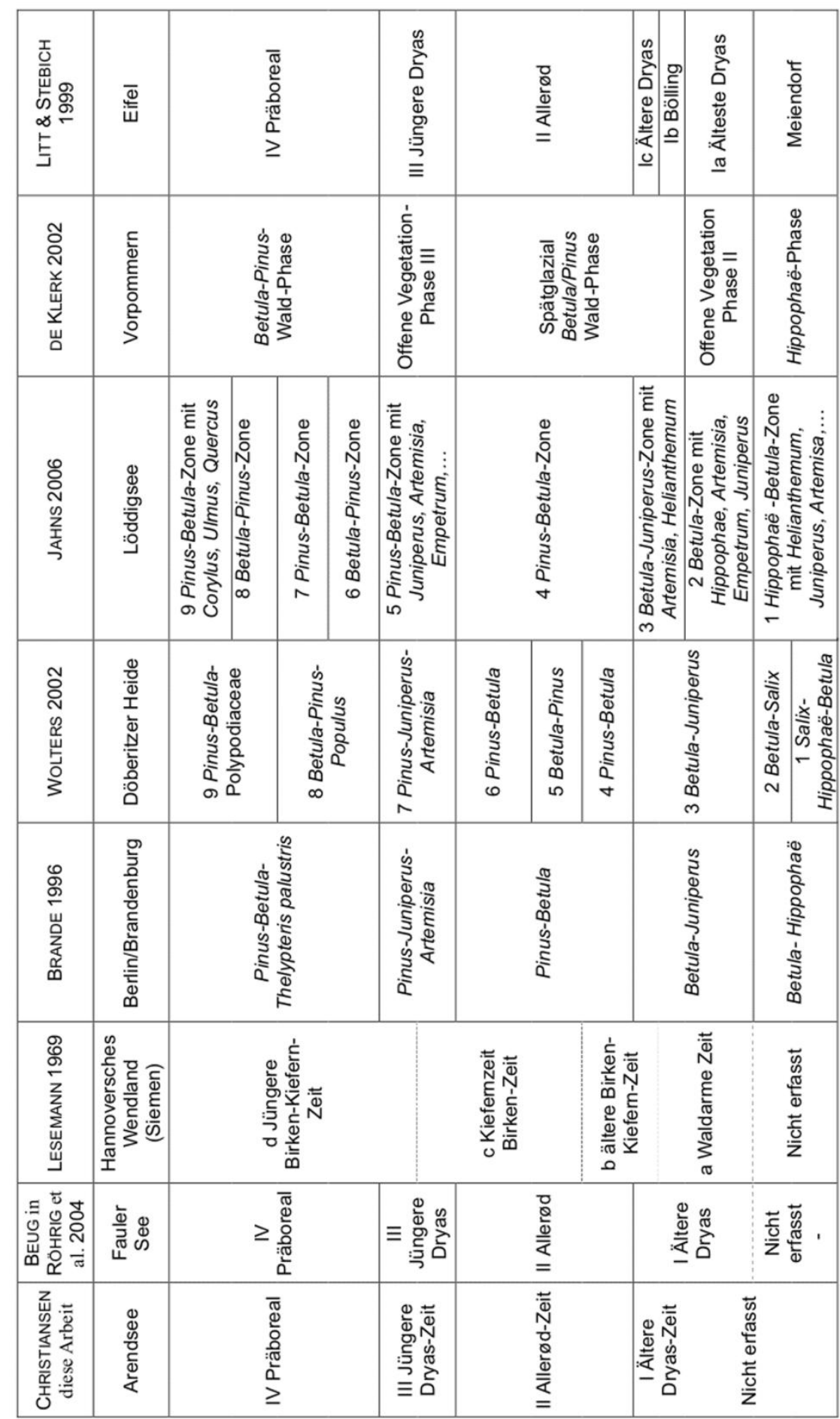




\subsubsection{Allerød-Zeit (Pollenzone II)}

Mit dem Allerød begann eine Waldzeit. Mit der zunehmenden Erwärmung breiteten sich Kiefern und Birken aus und bildeten Wälder. Der Rückgang der NBP und der Juniperus-Werte lässt als Folge der zunehmenden Bewaldung auch auf eine stärkere Beschattung schließen. Etwa in der Mitte der Allerød-Zeit erfolgte der Laacher See-Ausbruch. Die Laacher SeeTephra (LST) wurde im Kern ARS 1 mikroskopisch nachgewiesen, mit bloßem Auge war sie nicht erkennbar. Auch im benachbarten Faulen See konnte sie gefunden werden (RöHRIG et al. 2004). Über der Tephra des Laacher See-Ausbruchs zeigt sich bei ARS 1 am Ende des Allerøds ein Betula-Gipfel, während im Faulen See kein Birken-Maximum feststellbar ist. In 22 von 24 Diagrammen aus Brandenburg und Berlin wurde ebenfalls ein solches Maximum der Betula-Kurve gefunden (BRANDE \& WOLTERS 1997). Im Hannoverschen Wendland wurde weder der LST gefunden, noch ein Allerødzeitlicher Birken-Gipfel, der damit in Zusammenhang stehen kann. Nach diesem Betula-Maximum am Arendsee breitete sich die Kiefer nochmals aus, bevor mit der jüngeren Dryas-Zeit ein Klimarückschlag erfolgte.

\subsubsection{Jüngere Dryas-Zeit (Pollenzone III)}

Die Klimaverschlechterung dieser jüngeren subarktischen Zeit führte, wie in allen angrenzenden Teilen Mitteleuropas, zu einer Öffnung der Landschaft, was durch die Zunahme der Juniperus- und NBP-Werte angezeigt wird. Auch die Anteile von Artemisia und Rumex belegen dies. Für den Beginn der jüngeren Dryas-Zeit wurde in Laase von LESEMANN eine ${ }^{14} \mathrm{C}$ Datierung angegeben, welche neu kalibriert (CalPal-online) ein Alter von cal. BC: $10642 \pm 200$ ergibt. Dies fügt sich sehr gut in die Datierungen ein, wie sie für die Eifel, die Döberitzer Heide, Mittel- und Ostpolen sowie für den GRIP-Eisbohrkern von WOLTERS (2002) zusammengestellt wurden.

Im Vergleich mit Nordwestdeutschland, wo die Empetrum-Werte bis zu $14 \%$ erreichen (BEHRE 1966), sind sie hier mit maximal 5\% relativ niedrig. Wie in Siemen und Laase (LESEMANN 1969) liegen sie aber doch deutlich höher als in der östlich gelegenen Döberitzer Heide (WOLTERS 2002). Hier zeigt sich wohl ein deutlicher Gradient von West nach Ost, der eine zunehmende Kontinentalität widerspiegelt, wie er auch von BRANDE (1980) beschrieben wurde. 


\subsubsection{Präboreal (Pollenzone IV)}

Am Ende des Spätglazials setzen die Diagramme von Rambow (Beilage 5) und ARS 5 (Beilage 3) ein. Der starke Rückgang der NBP-Werte und der deutliche Anstieg bei den PinusWerten weisen auf das Einsetzen der endgültigen Wiederbewaldung hin. Während Kiefer und Birke mit ihren Pollenwerten deutlich vertreten sind, waren Pappeln die dritte in dieser Zeit bedeutende Baumgattung. Vermutlich handelte es sich hier um Populus tremula, da diese Art etwas geringere Wärmeansprüche hat als Populus alba und Populus nigra (ELLENBERG 1996). Bereits STEENSTRUP (1842 zit. nach FIRBAS 1949) bezeichnete aufgrund von Makrorestanalysen in dänischen Mooren das Präboreal als „Zitterpappelzeit““. Da Populus-Pollen in der Regel stark untervertreten ist (FIRBAS 1949), dürften die Pappeln, obwohl es für das Untersuchungsgebiet nur im Profil Rambow eine geschlossene Populus-Kurve gibt, einen nicht zu unterschätzenden Anteil am Waldbild gehabt haben. Auch in der Döberitzer Heide im Diagramm der Schwanengrabenrinne gibt es eine deutliche Populus-Kurve, dagegen sind im Kienfenn, dem Jungfernfenn und der Weidenkuhle die Werte deutlich niedriger (WOLTERS 2002). In einer Untersuchung im Vögelpohl (Ldkr. Friesland) fand MECKE (1995) maximale Werte von 4,6 \% für Populus bereits am Beginn des Präboreals. Später konnte MECKE dann kaum noch Populus-Pollen nachweisen, was sie auf die schlechteren Erhaltungsbedingungen zurückführte (vgl. UsINGER 1985). Im „Fenn im Wittenmoor“ (Altmark, LANGE 1986) und im Pechsee (Berlin, BRANDE 1980) erreichte die Pappel ihre stärkste Verbreitung ebenfalls im Präboreal.

Da es im Profil ARS 1 nur wenige Proben im Bereich des Präboreals gibt und in den anderen Profilen die Zone nicht vollständig erfasst wurde, ist eine Gliederung des Präboreals gemäß BEHRE (1966, 1967) relativ unsicher und daher in Beilage 1 auch nicht eingezeichnet. Man erkennt in Phase a (Abb. 15) einen beginnenden Anstieg der Baumpollenanteile, die in Phase b aber stagniert, verbunden mit einem Betula-Gipfel in einer Probe. In Phase c erfolgt dann wieder ein weiterer Rückgang der NBP-Werte, die dann erst unter anthropogenen Einfluss im Subboreal deutlich wieder ansteigen. Damit ist prinzipiell die Frieslandschwankung mit Phase a, die Piottino-/Rammelbeck-Phase in b und die endgültige Erwärmung in c auch für das Untersuchungsgebiet nachgewiesen. Allerdings lässt sich aufgrund der geringen Probenzahl nur schwer abschätzen, ob hier der klimatische Effekt auf die Vegetation weniger stark ausgeprägt war als in Nordwestdeutschland oder ob er sich im Diagramm nur nicht ganz so deutlich abzeichnet. 


\subsubsection{Boreal (Pollenzone V)}

Die Massenausbreitung der Hasel kennzeichnet diesen Abschnitt. Er zeigt den borealen Haselgipfel in einer für Altmoränengebiete typischen niedrigen Ausprägung. Bei den EMWArten erreicht Quercus die höchsten Werte. Alle anderen Arten spielen nur eine untergeordnete Rolle, auch dies ist typisch für ein östliches Altmoränengebiet.

Die Wälder bestanden zunächst im Wesentlichen aus Kiefern und Birken und zumindest östlich der Elbe auch aus einem sicher nicht zu vernachlässigenden Anteil an Pappeln. Obwohl die Pappel nach dem Präboreal nur im Profil Rambow vertreten ist, lässt sich nicht sicher sagen, ob sie am Arendsee und im Wendland wirklich gefehlt hat oder ob es sich hier, wie bereits ausgeführt, um eine Frage der Pollenerhaltung handelt. Nach der Einwanderung der Hasel kam es zur Bildung lichter Kiefern-Hasel-Wälder, in die dann die thermophilen Laubhölzer des Eichenmischwaldes vordrangen. Während die raschwüchsige Hasel sich bei zunehmender Erwärmung schnell in den lichten Kiefer-Birken-Espenwäldern ausbreitete, konnten die langsamer wachsenden Ulmen und Eichen sich nur allmählich gegen die jetzt im Wald herrschende und stark Schatten spendende Hasel durchsetzen. Andererseits ist die Ulme im Vergleich zu Kiefer, Birke, Eiche und Hasel nur mittelstarker Pollenproduzent, und ist daher prozentual in den Pollenspektren nicht so stark vertreten, wie im damaligen Waldbild (FIRBAS 1949, ANDERSEN 1970).

\subsubsection{Atlantikum (Pollenzone VI und VII)}

Gekennzeichnet ist diese Zeit durch die Massenausbreitung der Erle und den Rückgang der Hasel. Während am Arendsee die Ausbreitung der Erle schon erfolgte, bevor die Hasel an Bedeutung verlor, geschah dies in Rambow erst nach dem Rückgang der Hasel-Werte. Auch am Rugensee erfolgte die Ausbreitung der Erle schon vor dem deutlichen Rückgang der Hasel, während am Löddigsee ebenfalls der Alnus-Anstieg erst nach dem Haselrückgang erfolgte. Daraus lässt sich schließen, dass die Hasel zunächst einige Standorte besetzen konnte, die später von der Erle beansprucht wurden. Wobei dies aber nicht die alleinige Ursache für den Rückgang der Hasel war. Die Wälder wurden zunehmend dichter und die Konkurrenz durch Eiche und Ulme stärker.

Bei den Makroresten in Rambow fanden sich erstmals Früchte von Alnus glutinosa, was die Anwesenheit im Gebiet sicher belegt. Die Wälder an trockenen Standorten wurden wohl weiterhin von Kiefer und Eiche dominiert. Ihre Anteile im Wald dürften unter Berücksichtigung der unterschiedlichen Pollenproduktion, die bei Pinus etwa viermal so groß sein soll, wie bei 
Quercus (LANG 1994), in etwa vergleichbar gewesen sein. Auf den feuchten und vor allem auf den wechselfeuchten Standorten hielt die Erle Einzug.

Bei der Erle wird besonders deutlich, wie sich die Flächengröße des Moores bzw. des Sees auf die Pollenwerte im Diagramm auswirkt. JACOBSEN \& BRADSHAW (1981) weisen darauf hin, dass das Einzugsgebiet einer „Pollenfalle“, sei es nun ein See oder ein Moor, in einem engen Bezug zu der Flächengröße steht, welche den in der Luft befindlichen Pollen „einfängt“. Diesen Effekt sieht man besonders deutlich im Gebiet des Gartower Forsts, das mit dem Profil Heuweg 1 repräsentiert wird. Hier setzte im Atlantikum die Vermoorung ein. Corylus-Werte von über $200 \%$ und Alnus-Werte von bis zu $100 \%$ weisen auf eine starke lokale Überrepräsentation hin. Ein Vergleich mit dem Diagramm von LESEMANN (1969) zeigt für den Heuweg Corylus-Werte von nur maximal 60\%. Diese Diskrepanz erklärt sich, wie in Kapitel 4 beschrieben, mit der Moorentwicklung. Zunächst ist das Dünentälchen, in dem das Moor entstanden ist, vollständig bewaldet, und durch erhöhte Niederschläge und/oder einen ansteigenden Grundwasserspiegel kommt es zu kleinstflächigen Versumpfungen. Dicht am Rand gelegen erfasst das hier vorgestellte Diagramm mehr die lokale Vegetation, während das Profil von LESEMANN schon deutlich weniger lokalem Einfluss unterliegt. Mit zunehmendem Wachstum des Moores vergrößerte sich die baumfreie Oberfläche und der regionale Polleneintrag gewann an Bedeutung (vgl. Abb. 10).

Im Diagramm von Siemen erreicht die Erle maximal $71 \%$, aber auch die Werte vom Kern ARS 4 mit bis zu 150\%, zeigen, dass hier der lokale Pollenanteil sehr hoch war, was auf ein kleines Einzugsgebiet oder auf die relative Ufernähe der Bohrstelle hinweist.

Auch die Linde breitete sich aus, aber mit geringen Anteilen, wohl bedingt durch die relativ armen Böden, die im Untersuchungsgebiet vorherrschen. Nur im Diagramm vom Heuweg 1 erreicht Tilia Werte von bis zu 20\% während des Atlantikums. Dies lässt sich im Grunde nur mit einer lokalen Anwesenheit der Linde in unmittelbarer Nähe zum Bohrpunkt am Heuweg erklären. Ähnlich niedrige Tilia-Werte wie am Arendsee und im Rambower Moor finden sich in der Döberitzer Heide (WolTERs 2002) und am Löddigsee (JAHNS 2007). In den Diagrammen aus dem Hannoverschen Wendland von LESEMANN (1969) schwanken die Tilia-Werte meist um die 5\%, erreichen aber als Höchstwerte 10 bis $30 \%$ (Maujahn I, Zone VIII, LESEMANN 1969). Die Pollenfunde von Viscum und Hedera lassen weiterhin auf ein relativ warmes Klima schließen. Während die nahezu durchgängigen Nachweise von Artemisia und vom Rumex acetosa-Typ nicht zwingend an menschliche Tätigkeit gebunden sind, so lassen erste vereinzelte Funde von weiteren anthropogenen Siedlungszeigern (BEHRE 1981), wie 
dem Plantago lanceolata-Typ und erster Pollenkörner vom Getreide-Typ auf eine frühe Besiedlung schliessen.

\subsubsection{Subboreal (Pollenzone VIII)}

Der Übergang zum Subboreal (3448 - 700 bis 800 v. Chr.), oft durch einen starken Rückgang der Ulmen-Anteile gekennzeichnet, ist aufgrund der niedrigen Ulmus-Werte im Untersuchungsgebiet nicht sehr markant ausgeprägt. Eine am Profil Rambow durchgeführte Interpolation mit dem Ziel, Dauer und den Zeitpunkt des Ulmenfalls zu bestimmen (CHRISTIANSEN 1998), führte zu dem Ergebnis, dass hier in einem Zeitraum von ca. 150-200 Jahren der U1men-Anteil von 6,9 auf 1,9\% abfällt. Dies entspricht etwa den 180 Jahren, die DöRFLER (im Druck) für den Ulmenfall am Rugensee angibt. Die Dauer des Ulmenrückgangs spricht danach gegen eine Epidemie des durch den Ulmensplintkäfer übertragenen Pilzes Ceratocystus $u l m i$ als alleinige Ursache. Denkbar wäre allerdings, dass mögliche Verletzungen der Bäume durch Schneitelung sowie Viehverbiss erst allmählich zur Ausbreitung des Pilzes beigetragen haben (vgl. PEGLAR \& BiRKS 1993).

Die für den Ulmenfall durchgeführte Datierung am Arendsee ergab ein Alter von $3469 \pm 36 \mathrm{v}$. Chr. Damit liegt sie etwa 300 Jahre später als die üblicherweise für den Ulmenfall angenommene Datierung von 3800 v. Chr., die mittlerweile fast als Fixpunkt gilt (u. a. Wolters 2002). Andere Autoren (u.a. KIRLEIS 2002) weisen nicht zu unrecht darauf hin, das diese Datierung in Abhängigkeit von der Region um einige Jahrhunderte abweichen kann. Für das Elbaer Moor in der nördlichen Lüneburger Heide (KIRLEIS 2002) liegt eine Datierung auf ca. 3064 v. Chr. vor. Für das Melbecker Moor (KUBITZKI \& MÜNNICH 1960), ebenfalls Landkreis Lüneburg eine Datierung auf 3351 v. Chr., für den Bixbeerenbruch in Südostmecklenburg (MülLER \& KoHl 1966) eine auf 3580 v. Chr. Diese kurze Auflistung zeigt, dass es durchaus nicht legitim erscheint, den Ulmenfall als feste Zeitmarke zu werten, vielmehr kann er nur einen relativ guten Anhaltspunkt für eine zeitliche Einordnung geben.

Vom Ulmus-Rückgang profitierten am Arendsee insbesondere die Kiefern, aber auch Erlen und Eichen. Die Eiche hatte damit endgültig eine dominierende Rolle im Waldbild eingenommen. Das Profil aus Boberow zeigt dabei eine gute Übereinstimmung mit den Profilen des Arendsees. Das ist verständlich, weil hier die naturräumlichen Vorraussetzungen links und rechts der Elbe keine großen Unterschiede zeigen.

In den Diagrammen aus dem Hannoverschen Wendland schwanken die Tilia-Werte meist um die $5 \%$, erreichen aber als Höchstwerte 10 bis $30 \%$ (Maujahn I, Zone VIII, LESEMANN 1969). 
Ab der Grenze Atlantikum/Subboreal treten Pollenfunde von Acer und Fagus regelmäßig auf. Da der Pollen von Acer als insektenblütige Art sehr stark unterrepräsentiert ist, darf man sicher davon ausgehen, dass mit Auftreten des Pollens nun der Ahorn im Wald präsent war. Welche Art vertreten war, kann anhand des Pollens nicht bestimmt werden (FIRBAS 1949, BEUG 2004). Fagus-Pollen tritt nun häufiger auf, die Rotbuche kann aber zunächst noch keine bedeutende Rolle im Wald gespielt haben.

\subsubsection{Subatlantikum (Pollenzonen IX und X)}

Das Subatlantikum gliedert sich in einen älteren (IX) und jüngeren Teil (X), die jeweils in die zwei Abschnitte a und b gegliedert werden.

Mit dem beginnenden Anstieg der Fagus- und Carpinus-Werte und einem deutlichen Rückgang der Pinus-Werte beginnt das frühe Subatlantikum (Zone IXa, ca. 700-800 v. Chr. bis 0100 AD). Die Quercus-Kurve erreicht ihr höchstes Niveau, aber auch die Betula-Werte steigen an, während die ohnehin geringen Werte von Fraxinus und Tilia weiter zurückgehen. Dominiert werden die Spektren jedoch weiterhin von Alnus, während die Corylus-Werte stetig zurückgehen. Während auf den staunassen Böden der Niederungen weiterhin der Erlenwald vorherrschte, wurden die trockeneren und besseren Standorte von den Buchen besiedelt, was auf Kosten der Kiefer, aber auch der Esche und Linde ging. Die stark wechselfeuchten Standorte blieben den Eichen und Birken erhalten. Aufgrund des stark anthropogenen Einflusses auf die Vegetationsentwicklung in dieser Zeit kam es an den einzelnen Untersuchungspunkten zu unterschiedlichen Entwicklungen, auf die in Kapitel 6.2.4 näher eingegangen wird. Am Löddigsee erreichten die Buchen bereits in dieser Zeit ihre Höchstwerte, was wohl anthropogene Ursachen hatte (JAHNS 2007).

Mit der Massenausbreitung der Buchen beginnt der Abschnitt b des frühen Subatlantikums (Zone IXb, 0-100 AD bis 1140-1250 AD). Einen Rückgang in Besiedlungsintensität nutzten die Buchen möglicherweise zur Massenausbreitung, wobei gleichzeitig mit der Buchenausbreitung eine Zunahme der Siedlungsintensität erfolgte. Dies könnte auch auf einen klimatischen Effekt hinweisen. Diese Entwicklung ist stark von der Siedlungsgeschichte abhängig und wird in Kapitel 6.2.5 besprochen. In den Wäldern verdrängte die Buche die Eiche endgültig von den besseren Standorten und die Kiefer konnte sich wohl nur noch auf den ärmeren Sanderflächen und den Dünengebieten halten.

Mit der Ostkolonisation erreichte der Einfluss des Menschen auf die Vegetation einen Höhepunkt, und damit beginnt das jüngere Subatlantikum (Pollenzone Xa). Die Landschaft wurde großflächig entwaldet, was sich deutlich im Pollenniederschlag zeigt. Die Buchenkurven ge- 
hen zurück und die Kiefern-Werte steigen deutlich an. Dies ist zum Teil wohl ein mathematischer Effekt, da das Fehlen der Buchen rechnerisch einen Anstieg der Kiefern-Anteile bedingt.

Mit dem Beginn der zweiten Hälfte des jüngeren Subatlantikums (Pollenzone $\mathrm{Xb}$ ) begann die planmäßige Forstwirtschaft, was zu einer Förderung der Kiefer führte, die nun nicht nur auf einen rechnerischen Effekt beruht, sondern auf Aufforstungen in den Wäldern.

\subsection{Die Vegetationsentwicklung im Spiegel der Siedlungsgeschichte}

Die Siedlungsphasen in den Diagrammen sind anhand der Änderungen der Kurven der Siedlungszeiger ausgewiesen, das heißt, sie sind durch Änderungen der Pollenkurven definiert und nicht durch das Alter der archäologischen Phasen. Die Grenzen liegen in der Regel dort, wo eine Phase schwächerer Besiedlungsintensität mit einer Phase intensiverer Besiedlungsintensität wechselt oder umgekehrt. Das muss in den unterschiedlichen Diagrammen durchaus nicht synchron erfolgen. Daher stimmen die Buchstaben, mit denen die Siedlungsphasen bezeichnet wurden, nicht durchgängig überein. Es kommt vor, dass sich in einem Profil eine Zunahme der Besiedlungsintensität zeigt, während gleichzeitig in einem anderen Profil eine Abnahme der Besiedlungsintensität erfolgt.

\subsubsection{Das Mesolithikum}

Das Mesolithikum (ca. 9500 v. Chr. - 5500 v. Chr.), das sich über mehrere Jahrtausende erstreckte, ist eine Übergangszeit vom Ende der Eiszeit zum Holozän und somit die Zeit mit dem größten Wandel der Vegetation: Es reichte vom Präboreal mit seinen lichten KieferBirkenwäldern, über das Boreal mit seinen Kiefer-Hasel-Wäldern, bis ins Atlantikum, in dem Eichen-Kiefern-Wälder das Untersuchungsgebiet beherrschten.

Ein Einfluss der Mesolithiker auf die Vegetation ist anhand der Diagramme nicht nachweisbar. Dazu sind die Einflüsse des Menschen im Mesolithikum auf die Vegetation wohl zu gering gewesen. Um mesolithischen Einfluss direkt nachzuweisen, bedarf es einer sehr hohen zeitlichen Auflösung des Diagramms, und ein Siedlungsplatz muss in direkter Nachbarschaft zur Probenentnahmestelle gelegen haben, damit auch kleinste Einflüsse der Mesolithiker auf die Vegetation sichtbar werden können (BOS \& URZ 2003). Aber selbst bei idealen Voraussetzungen gelingt dies nicht immer (BEHLING \& STREET 1999). KUNES et al. (2007) versuchten sich der Problematik unter Zuhilfenahme mathematischer Methoden zu nähern, was aber zum gleichen Ergebnis führte: es kann im Pollendiagramm zu erkennbaren Signalen kommen, muss es aber nicht. 
Im Profil Rambow gibt es mehrere Funde von einzelnen Pollenkörnern, die dem Getreidetyp zugeordnet wurden. Dies kann jedoch nicht als Hinweis auf einen frühzeitigen mesolithischen Ackerbau gewertet werden, wie er in letzter Zeit öfter postuliert wurde. Dazu hat BEHRE (2007) ausführlich Stellung genommen und deutlich dargelegt, dass es für einen frühen mesolithischen Ackerbau derzeit keinen einzigen sicher belegbaren Nachweis gibt. Man muss damit rechnen, dass es bei Wildgräsern gelegentlich durch spontane Polyploidisierungen zur Bildung großer Pollenkörner kommen kann.

\subsubsection{Das Neolithikum}

Mit dem Übergang zum Neolithikum (ca. 5500 v. Chr. - 2200 v. Chr.) erfolgte der Wechsel vom Sammler und Jäger zum Ackerbauern und Viehzüchter. Im Untersuchungsgebiet scheint sich dieser Übergang im 4. Jahrtausends v. Chr. vollzogen zu haben. Ackerbau und Viehzucht hinterlassen Spuren in der Vegetation, die sich im Pollendiagramm abzeichnen.

Am Arendsee gibt es bereits vor dem Ulmenfall in Phase a im Diagramm ARS 5 erste vereinzelte Funde von Pollenkörnern vom Getreide-Typ und von Plantago lanceolata. Im Diagramm ARS 1 gibt es in dieser Zeit nur einen kleinen Gipfel der Siedlungszeiger-Werte, diese Funde sind so isoliert, dass auf eine erste länger dauernde neolithische Besiedlung nicht sicher geschlossen werden kann. Die vorliegende Datierung von $4205 \pm 98$ v. Chr. (vgl. Tabelle 4) ist deutlich jünger als die betrachtete Siedlungphase, eine einfache Interpolation ergab, eine gleichmäßige Sedimentationsrate vorrausgesetzt, ein ungefähres Alter von 4450 v. Chr. für die Phase a. Es bleibt also weiter eine Frage für die Archäologen, ob hier erste „Kolonisierungsversuche“ von Siedlern aus den südlich gelegenen Lössgebieten erfolgten oder ob die vor Ort lebenden Jäger und Sammler erste Versuche unternahmen, den im Süden praktizierten Ackerbau zu übernehmen.

Nach dieser ersten Phase mit erhöhten Siedlungszeigerwerten, schließt sich am Arendsee mit Phase $b$ eine Zeit geringerer Besiedlungsintensität an und Pollenkörner vom Getreide-Typ wurden nicht mehr nachgewiesen.

Die ersten deutlicheren Siedlungszeiger finden sich in fast allen Diagrammen kurz nach dem Ulmenfall, dessen Beginn am Arendsee mit ca. 3470 v. Chr. datiert wird (vgl. Tabelle 4). Damit beginnt auch die Zeit, die der Trichterbecherkultur zugeordnet wird (BEIER 1994) und im Diagramm ARS 1 beginnt die Kurve der Siedlungszeiger allmählich zu steigen.

Im Profil Rambow steigt nach dem Ulmenfall, im Diagramm-Abschnitt G, in der Siedlungsphase a, die Calluna-Kurve um das doppelte an, und zwar bei gleichzeitigem Rückgang der Pinus-Kurve und geringem Anstieg der Corylus-Werte. Zu dieser Zeit treten im Profil von 
Boberow (KIRLEIS 1998) schon erste Getreidepollenkörner in Verbindung mit Plantago lanceolata auf. Wahrscheinlich spiegelt sich in diesem Abschnitt die erste Siedlungsphase bei Boberow wider, was zeigt, dass zu dieser Zeit ein sehr kleinflächiger Anbau bei einer relativ geringen Besiedlungsintensität stattfand.

Am Arendsee beginnt mit Phase c eine Zeit, in der in Profil ARS 1 einige Pollenkörner vom Getreide-Typ auftreten, während die Kurve der Siedlungszeiger deutlich reagiert. Diesmal finden sich die Getreidepollenkörner am Südufer also bei ARS 1, den deutlicheren Ausschlag der SZ-Kurve findet man aber wieder in Profil ARS 5 aus der Seemitte. Das Ende der Phase c datiert auf ca. 2227 v. Chr. (vgl. Tabelle 4), somit erscheint es wahrscheinlich, dass diese stärkere Besiedlungsphase in Zusammenhang mit einer Besiedlung steht, während der auch ein Fischzaun errichtet wurde, von dem Teile auf 2671 v. Chr. datiert wurden (LEINEWEBER \& LÜBKE 2006).

In Rambow lässt sich diese Zeit wohl mit der Phase $\mathrm{c}$ und d gleichsetzen. Es finden sich Pollenkörner vom Getreide-Typ, die zusammen mit Pollenfunden von Plantago lanceolata auftreten. Die Anzeichen für menschliche Tätigkeiten erreichen damit hier ebenfalls einen ersten Höhepunkt. Die Schwankungen der Ulmen- und Eschen-Kurven deuten auf Viehhaltung hin, da beide Arten für die Laubheugewinnung geeignet sind. Der Anstieg der Picea- und der Pinus-Werte weist, genau wie die Zunahme des NBP, auf eine Auflichtung der Wälder am See hin.

\subsubsection{Die Bronzezeit}

In der Bronzezeit (2200 - 600 v. Chr.) nimmt am Arendsee nach der Phase c die Besiedlungsintensität wieder deutlich ab und erreicht am Beginn der Phase d ein deutliches Minimum, wenn man nach den Werten der SZ-Kurve urteilt. Allerdings finden sich in dieser Zeit Pollenkörner vom Triticum-Typ, was auf eine Fortführung des Getreideanbaus schließen lässt. Was die Ursache für den deutlichen Rückgang der SZ-Kurve sein kann, ob Abwanderung, Verlagerung der Anbauflächen oder ein Rückgang der Bevölkerungsdichte, ist nicht gewiss. Bereits wenige Proben nach dem Rückgang steigen die Werte der Siedlungszeiger wieder an. Die Werte der Siedlungszeiger sind wieder am Südufer, also im Profil ARS 1 ausgeprägter als in den übrigen Profilen vom Arendsee.

Die siedlungsgeschichtliche Phase $\mathrm{c}$ in Boberow ist eine Phase stärkerer Besiedlungsintensität, die der älteren Bronzezeit zugeordnet wird. Sie ist gekennzeichnet durch einen deutlichen Anstieg der Siedlungszeiger, sowie durch Pollenkörner vom Hordeum-Typ, genau wie in Phase e im Profil Rambow, das hier endet. 
Die Phase $b$ in Boberow ist wie am Arendsee eine Zeit schwächerer Besiedlung, sie wird der mittleren Bronzezeit zugeordnet. In der Phase c steigen die Werte der Siedlungszeiger wieder an, in Boberow treten erstmals Pollenkörner vom Triticum-Typ auf, hier wurde wohl die jüngere Bronzezeit erfasst. Phase d lässt in Boberow einen Rückgang der Anteile der Siedlungszeiger erkennen. Ein starker Anstieg der Betula-Werte deutet auf eine beginnende Wiederbewaldung hin.

\subsubsection{Die vorrömische Eisenzeit}

Die vorrömische Eisenzeit (600 v. Chr. - 0) beginnt am Arendsee etwa mit der Phase e, und hier zeichnet sich wieder eine Phase intensiverer Besiedlung ab. Sie ist sie gekennzeichnet durch einen weiteren Anstieg der Werte der Siedlungszeiger. Die Phase f ist eine Zeit abnehmender Besiedlungsintensität. Die Werte der Siedlungszeiger gehen deutlich zurück, und der starke Anstieg der Betula-Kurve zeigt die beginnende Wiederbewaldung der offen gelassenen und vormals landwirtschaftlich genutzten Flächen an. Es folgt ein Anstieg der Quercus-Werte, sowie am Ende der Phase ein deutlicher Anstieg der Buchen-Werte. Der Beginn der Phase f fällt vermutlich noch in die vorrömische Eisenzeit. Erste einzelne Pollenkörner vom Roggen gehen unter Umständen noch auf Unkrautroggen zurück.

\subsubsection{Die römische Kaiserzeit}

In Phase g beginnt im Untersuchungsgebiet die Massenausbreitung der Buchen. Die Rot- und Hainbuchen- Werte steigen stark an, auch die geschlossene Secale-Kurve setzt ein. Diese Phase wird in die römische Kaiserzeit datiert (vgl. BEHRE 1992). Ein Anstieg der übrigen Siedlungszeiger erfolgt aber nicht. Das weist darauf hin, dass die Einführung des Roggenanbaus nicht mit einer Zunahme der Besiedlungsintensität verbunden sein musste.

\subsubsection{Die Völkerwanderungszeit}

In Phase h geht die Roggen-Kurve zurück (Abb. 16), während die Werte der übrigen Siedlungszeiger auf das Niveau der mittleren Bronzezeit zurückfallen. Die Buchenkurven erreichen ihre Maxima und die NBP-Werte ein Minimum. Dies deutet auf eine Wiederbewaldung hin, die in Zusammenhang mit den demographischen Veränderungen der Völkerwanderungszeit stehen dürfte. Allerdings fällt auch der Seeeinbruch von 822 A.D. in die Phase h, so dass man davon ausgehen muss, dass sich diese Phase geringerer Besiedlung deutlich über die eigentliche Völkerwanderungszeit hinaus erstreckte. Damit erfährt auch die Anmerkung vom „...wüsten Ort Arnseo...“ in den fränkischen Annalen (RAU 1955) eine gewisse Bestätigung. Man darf also davon ausgehen, dass der Ackerbau deutlich zurückging und es auf den offen 
gelassenen Flächen zu einer Ausbreitung der Buchen kam. Die Werte der Pediastren lassen auch darauf schließen, dass die Eutrophierung des Sees zurückging.

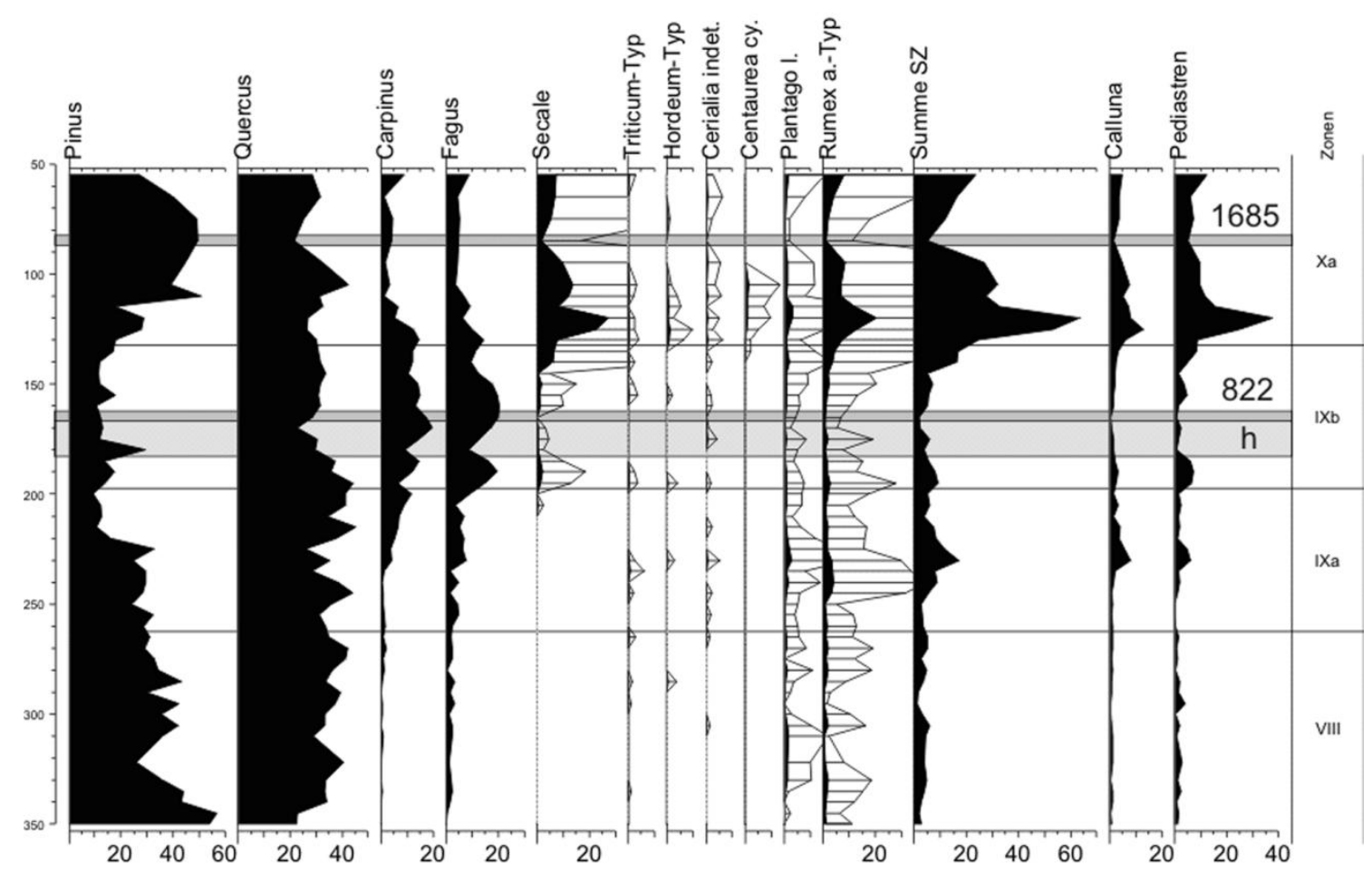

Abb. 16: Vereinfachtes Diagramm ARS 1, die Zeiten der Salzstock-/See-Einbrüche 822/1685 und die Phase h (Völkerwanderungszeit) sind hervorgehoben.

\subsubsection{Das frühe Mittelalter}

Wie beschrieben, fällt bereits das Ende der Phase $\mathrm{h}$ in die Zeit, in der der Beginn der Besiedlung durch die Slawen angenommen wird. In der Phase i zeigt sich am Arendsee ein deutlicher Anstieg bei den Siedlungszeigern. Die Rotbuche, die am Beginn der Phase ihre Höchstwerte erreichte, wird langsam zurückgedrängt und die Hainbuchenkurve geht deutlich zurück.

Phase $\mathrm{i}$ ist in Boberow gekennzeichnet durch eine deutliche Zunahme der Siedlungszeiger, einen starken Einbruch der Hainbuchen-Werte bei einem gleichzeitigen Steilanstieg der Birke, die auf Rodungen reagiert und auf den nun offenen Waldbeständen und an deren Rändern verstärkt auftritt.

\subsubsection{Das hohe und späte Mittelalter}

Mit der Belehnung der Askanier mit der Nordmark durch Kaiser Lothar III. begann die Kolonisation der Altmark. Nach erfolgreichen Eroberungsfeldzügen holte Albrecht der Bär unter Gewährung günstiger Siedlerrechte Rheinländer, Holländer und Flamen ins Land, und die Chronik der Stadt Arendsee beschreibt: „....Diese erhielten die wüsten Ländereien, und brach- 
ten durch ihre Fertigkeit im Ackerbau und ihren Gewerbefleiß blühende Zustände hervor.“ (FELCKE 1891). Diese „blühenden Zustände“ kommen in den Diagrammen ARS 1 und ARS 5 und in Boberow in der Phase j zum Ausdruck, mit einem starken Anstieg der Siedlungszeiger, vor allem der Anstieg der Secale-Kurve zeigt deutlich die Zunahme der landwirtschaftlichen Aktivitäten an. Da die übrigen Getreidearten im Gegensatz zum Roggen autogam sind, bedeutet der enorme Anstieg allerdings nicht, dass nun auf den Anbau anderer Getreidearten verzichtet wurde. Der Anstieg der Getreidewerte und die hohen Werte der NBP lassen darauf schließen, dass es zur großflächigen Entwaldung kam. Große Teile der Buchenwälder fielen den Siedlungsvorgängen dieser Zeit zum Opfer.

Der Wechsel der Phase j zu k markiert die Seuchenzüge im 15. Jahrhundert, mit einem deutlichen Rückgang der Siedlungszeiger, deren Hauptanteil der Roggen ausmacht. Nur die Kornblume und die Ackerwinde steigen deutlich an, was ein Hinweis darauf sein könnte, dass die Felder zwar zum Teil noch bestellt worden waren, aber infolge des Arbeitskräftemangels nicht mehr vom Unkraut frei gehalten werden konnten. Die Chronik der Stadt Arendsee (FELCKE 1891) gibt als Seuchenjahre 820, 1416, 1427, 1438, 1450, 1503, 1535, 1566, 1573 und 1578 an, wobei das Jahr 1438 als: „...(das große Sterben!)...“ und das Jahr 1450 mit der Bemerkung: „...(Starb der 3. Theil der Einwohner),... “ hervorgehoben wurden. In diese Zeit fällt ein deutlicher Anstieg der Pinus-Werte, bei einem gleichzeitigen Rückgang der Erle, was auf eine Trockenphase hinweisen könnte, von der besonders die Kiefer profitierte.

\subsubsection{Die Neuzeit}

Die Neuzeit ist nur im Diagramm ARS 1 erfasst. Die Phase 1, in der es zu einem deutlicheren Rückgang der Siedlungszeiger kommt, fällt in die Zeit des 30jährigen Krieges und erfasst den Einsturz der Mühle in den See im Jahre 1685. Es schließt sich die Phase m an, in der die Siedlungszeiger deutlich wieder zunehmen. Mit dem Wechsel der Phase m zu n ist wieder ein Kernwechsel verbunden, und es ist nicht sicher, wie groß die Lücke zwischen den Kernabschnitten ist, sie kann nicht länger als maximal 200 Jahre sein. Für die Zeit von 1750 bis 1850 geben REICHHOFF et al. (2001) eine Wüstungsperiode an, die im Zusammenhang mit ersten großen Meliorationsmaßnahmen stand. Der starke Rückgang der Alnus-Werte weist auf den Erfolg dieser Maßnahmen hin. Große Ackerflächen auf den armen Sandböden wurden aufgegeben und hauptsächlich mit Kiefern aufgeforstet, was sich deutlich im Diagramm zeigt. Auch nahe der Gegenwart erreicht die Kurve der Siedlungszeiger nicht mehr die mittelalterlichen Höchstwerte. Hierbei muss bedacht werden, dass die Landwirtschaft diese „Siedlungs- 
zeiger" in der Regel als Unkräuter betrachtet und entsprechend bekämpft. Mit der Einführung moderner chemischer Mittel wurde hier die Effektivität enorm gesteigert. Ein Blick auf die Pediastrum-Kurve belegt dies. Diese Kurve erreicht ihr Maximum in Phase n und wohl nur weil die Eutrophierung so stark ist, dass die Grünalgen von Blaualgen abgelöst wurden sinkt die Kurve am Ende wieder ab.

\section{$7 \quad$ Zusammenfassung}

In dieser Arbeit wird die vegetationsgeschichtliche Entwicklung des Spätglazials und des Holozäns der westlichen Prignitz, des östlichen Hannoverschen Wendlandes und der nördlichen Altmark vorgestellt. Dazu wurden pollenanalytische Untersuchungen an Bohrkernen aus dem Rambower Moor, dem Arendsee und einem kleinem Moor am Laascher Heuweg durchgeführt. Das Untersuchungsgebiet liegt am nördlichen Randbereich des lössfreien Altmoränengebietes, wo geeignete Ablagerungen für palynologische Untersuchungen allerdings selten sind und daher der vegetationsgeschichtliche Kenntnisstand bisher eher gering war.

Die durchgeführten Untersuchungen ermöglichten die Rekonstruktion des Verlaufs der vegetations- und siedlungsgeschichtlichen Entwicklung des Untersuchungsgebietes seit dem Ende der letzten Eiszeit und zeigten, dass die Entwicklung im gesamten Untersuchungsgebiet relativ ähnlich verlief.

\section{Die waldgeschichtliche Entwicklung}

Nur ein am Arendsee untersuchtes Profil reichte bis ans Ende der älteren Dryas-Zeit zurück. Es herrschte noch eine offene Tundren-Vegetation vor. Mit der Erwärmung in der Allerød-Zeit wurde sie von lichten Birkenwäldern abgelöst, in die die Kiefer vordrang und bald im Waldbild dominierte. Die Klimaverschlechterung der jüngeren Dryas-Zeit führte dann zu einer Öffnung der Waldbestände und zur Ausbreitung von Juniperus und von Empetrum-Heiden. Dieser Klima-Rückschlag konnte die in der Allerød-Zeit eingewanderten Bäume nicht vollständig verdrängen. Mit dem Präboreal begann dann die endgültige Wiederbewaldung, die aber von weiteren Klimaschwankungen begleitet wurde. Hier setzt das Pollendiagramm aus dem Rambower Moor aus der westlichen Prignitz ein.

Im Boreal wanderte die Hasel ein. Der boreale Haselgipfel ist in den Diagrammen nur gering ausgeprägt, wie es für eine lössfreie Altmoränenlandschaft zu erwarten war. Es entstanden Kiefer-Haselwälder, in denen sich etwas später auch andere wärmeliebende Gehölze wie U1me und Eiche allmählich ausbreiteten, während die lichtliebende Birke deutlich zurückgedrängt wurde. 
Im älteren Teil des Atlantikums verlor die Hasel an Bedeutung, und die Erle breitete sich an feuchten Standorten bevorzugt aus. Die Eiche gewann einen zunehmenden Einfluss im Waldbild und drängte gemeinsam mit Ulme und Linde nun auch die Kiefer zurück. Erst in dieser Zeit setzte am dem Kleinmoor am Laascher Heuweg im östlichen Hannoverschen Wendland ein kontinuierliches Torfwachstum ein. Das Pollendiagramm zeigt zunächst nur die lokale Vegetationsentwicklung aufgrund der geringen Ausdehnung des Moores.

Im jüngeren Teil des Atlantikums wandern Eschen und Ahorne in das Untersuchungsgebiet ein. Die Hauptbaumart war neben der Kiefer die Eiche.

Im Subboreal dann erreichte die Eiche ihre stärkste Verbreitung und drängte die Kiefer weiter zurück. Gleichzeitig begann die Einwanderung der Rotbuche und dann die der Hainbuche. Der Ulmenfall ist aufgrund der geringen Ulmen-Anteile nicht besonders deutlich ausgeprägt, und sein mit $3448 \pm 56$ cal. B.C. datiertes Alter ist über 300 Jahre jünger als das üblicherweise angenommen wird. Dies wirft die Frage auf, ob der Ulmenfall weiter als sichere Zeitmarke in Pollendiagrammen gelten darf.

Mit dem Übergang zum älteren Subatlantikum um etwa 800 v. Chr. begann dann die verstärkte Ausbreitung der beiden Buchen-Arten und außerdem nahm der anthropogene Einfluss auf die Vegetationsentwicklung deutlich zu. Ob die um Christi Geburt einsetzende Massenausbreitung der Buchen klimatische Ursachen hatte oder als Folge geringer werdenden menschlichen Einflusses zu werten ist, konnte nicht mit Sicherheit geklärt werden.

Im jüngsten Teil des Subatlantikums, in dem sich vor allem Kiefern und Eiche wieder ausbreiteten gingen im Gegenzug die Buchenwerte deutlich zurück. Es gab eine zunehmende anthropogene Entwaldung, und die Wälder wurden auf Standorte zurückgedrängt, die sich für eine landwirtschaftliche Nutzung nicht eigneten.

\section{Die siedlungsgeschichtliche Entwicklung}

Ein Einfluss der spätpaläolithischen und mesolithischen Menschen auf die Vegetation konnte nicht nachgewiesen werde. Erst am Ende des Atlantikums, um etwa 4500 v. Chr., zeigen die Pollendiagramme erste Spuren einer kurzfristigen neolithischen Besiedlungsphase am Arendsee.

Erst 1000 Jahre später, d.h. im Subboreal, gibt es dann am Arendsee in der Altmark und auch im Rambower Moor in der Prignitz wieder deutliche Spuren einer menschlichen Besiedlung, die aus Gründen der zeitlichen Einordnung der Trichterbecher-Kultur zuzuordnen sind. 
Am Übergang zur Bronzezeit um 2200 v. Chr. gibt es einen deutlichen Rückgang der Besiedlungsintensität und erst in der jüngeren Bronzezeit zeigt sich wieder eine deutliche Zunahme der Werte der Siedlungszeiger, die bis in die vorrömische Eisenzeit andauerte. In dieser Zeit spielte die Jastorf-Kultur im Untersuchungsgebiet eine wichtige Rolle.

Im Verlauf der römischen Kaiserzeit wurde der Roggenanbau eingeführt, der sehr schnell an Bedeutung gewann. In der darauf folgenden Völkerwanderungszeit zeigt sich ein deutlicher Rückgang der Besiedlungsintensität und damit auch des Roggenanbaus. Diese Phase geringer Besiedlung dauerte deutlich länger als man das für die Völkerwanderungszeit annimmt und erst im 9. Jahrhundert zeichnet sich eine erneute Zunahme der Besiedlungsintensität in den Diagrammen ab, die der Zeit der slawischen Besiedlung zuzuordnen ist.

Mit dem Beginn der deutschen Ostkolonisation im 11. Jahrhundert kam es zu einer starken Intensivierung des Getreideanbaus. Es endete auch die Buchendominanz in den Pollendiagrammen, und eine Kulturlandschaft trat an die Stelle noch weitgehend ursprünglicher Vegetation.

Es waren wohl die Seuchenzüge der Pest, die im 14. Jahrhundert den mittelalterlichen Ausbau der Kulturlandschaft beendeten. Noch schlimmer trafen die Verheerungen des 30jährigen Krieges das Untersuchungsgebiet mit der Folge, dass es zu einer gewissen Wiederbewaldung mit Kiefer und Eiche kam. Das Einsetzen einer geplanten Forstwirtschaft führte dann zu einer erneuten Förderung der Kiefer, die auch heute noch die dominierende Waldbaumart im Untersuchungsgebiet ist. 


\section{Literaturverzeichnis}

ANDERSEN, S. (1970): The relative pollen productivity and representation of North European trees, and correction for tree pollen spectra. Danm. Geol. Unders., II, 96, S. 1-99.

ANDERSEN, S. (1980): The relative pollen productivity of the common forest trees in the early Holocene in Denmark. Danmarks Geologiske Undersogelse, Arbog, 1979, S. 5-19.

BeHLing, H. und StreEt, M. (1999): Palaeoecological studies at the Mesolithic site at Bedburg-Königshov near Cologne, Germany. Vegetation History and Archaeobotany, Vol. 8, Nr. 4, S. $273-285$.

BEHRE, K.-E. (1966): Untersuchungen zur spätglazialen und frühpostglazialen Vegetationsgeschichte Ostfrieslands. Eiszeitalter und Gegenwart, 17, S. 69-84.

BEHRE, K.-E. (1967): The late glacial and early postglacial history of vegetation and climate in northwestern Germany. Review of Palaeobotany and Palynology, 4, S. 149-161.

BEHRE, K.-E. (1981): The interpretation of anthropogenic indicators in pollen diagrams. Pollen et spores, 23, 2, S. 225-245.

BEHRE, K.-E. und KuCAN, D. (1986): Die Reflektion archäologisch bekannter Siedlungen in Pollendiagrammen verschiedener Entfernung - Beispiele aus der Siedlungskammer Flögeln, Nordwestdeutschland, S. 95-114, In: BEHRE, K., (Hrsg.): Anthropogenic indicators in pollen diagrams, Balkema, Rotterdam.

BEHRE, K.-E. (1992): The history of rye cultivation in Europe. Vegetation History and Archaeobotany, Vol 1, Nr. 3, S. 141-156.

BEHRE, K.-E. (2007): Evidence for Mesolithic agriculture in and around central Europe? Vegetation History and Archaeobotany, 16, S. 203-219.

BEIER, H.-J. (1991): Die megalithischen, submegalithischen und pseudomegalithischen Bauten sowie die Menhire zwischen Ostsee und Thüringer Wald. Bd. 1 und 2. Beiträge zur Urund Frühgeschichte Mitteleuropas, 1, Halle, 238 S.

BEIER, H.-J. (1994): Das Neolithikum im Mittelelbe-Saale-Gebiet und in der Altmark. Beiträge zur Ur- und Frühgeschichte Mitteleuropas, 4, Beier und Beran, Wilkau-Hasslau, 363 S.

BENDIXEN, J. A. (1937): Verlagerung und Strukturwandel ländlicher Siedlungen. Ein Beitrag zur Siedlungsgeographie ausgehend von Untersuchungen in der südwestlichen Prignitz. Schriften des Geographischen Institus der Universität Kiel, 7, S. Heft 2. 
Beran, J. (2002): Das goldenene Metall verdrängt den Stein, Die Bronzezeit in der Altmark, S. 94 -101, In: BocK, H., (Hrsg.): Hünengräber - Siedlungen - Gräberfelder: von der Altsteinzeit bis zum Frühmittelalter, 1, Mittelland-Bücherei, Ziethen, Oschersleben.

BEUG, H.-J. (1957): Untersuchungen zur spätglazialen und frühpostglazialen Floren- und Vegetationsgeschichte einiger Mittelgebirge (Fichtelgebirge, Harz und Rhön). Flora, 145, S. 167-211.

Beug, H.-J. (2004): Leitfaden der Pollenbestimmung für Mitteleuropa und angrenzender Gebiete. Pfeil, München, 1. Aufl., 542 S.

BoHM, W. (1937): Die Vorgeschichte des Kreises Westprignitz. Leipzig,.

Bos, J. A. A. und URZ, R. (2003): Late Glacial and early Holocene environment in the middle Lahn river valley (Hessen, central-west Germany) and the local impact of early Mesolithic people - pollen and macrofossil evidence. Vegetation History and Archaeobotany, 12, 1, S. 19 $-36$.

BRANDE, A. (1980): Pollenanalytische Untersuchungen im Spätglazial und frühen Postglazial Berlins. Verhandlungen des Botanischen Vereins der Provinz Brandenburg, 115, S. 21-72.

Brande, A. (1996): Type region D-s, Berlin, S. 518-523, In: Berglund, B., BiRKS, H. J. B., Ralsk-Jasiewiczowa, M. und Wright, H. E., (Hrsg.): Palaeoecological events during the last 15000 years, Regional Syntheses of Palaeoeeological Studies of Lakes and Mires in Europe, John Wiley \& Sons, Chichester.

Brande, A. und Wolters, S. (1997): Zur Vegetationsgeschichte des Potsdamer Raumes. 7. Jahrestreffen AK Vegetationsgeschichte der RTG, Kurzfasung der Vorträge und Poster, Graz, $21 \mathrm{~S}$.

BREEST, K. (1997): Studien zur Mittleren Steinzeit in der Elbe-Jeetzel-Niederung (Landkreis Lüchow-Dannenberg), S. 389, Beiträge zur Steinzeit in Niedersachsen, Isensee, Oldenburg.

BrunN, W. A. v. (1959): Die Hortfunde der frühen Bronzezeit aus Sachsen-Anhalt, Sachsen und Thüringen. Schriften der Sektion für Vor- und Frühgeschichte / Deutsche Akademie der Wissenschaften zu Berlin, 7,1, 7,1, Akad.-Verl., Berlin, VIII, 84 S.

Capelle, T., Jankuhn, H. und Voelkel, G. (1962): Probegrabung auf einer slawischen Siedlung bei Rebenstorf, Kreis Lüchow-Dannenberg. Nachr. Niedersachsens Urgesch., 31, S. 58108. 
Christiansen, J. (1998): Vegetationsgeschichtliche Untersuchungen über die früh- und mittelholozänen Veränderungen der Umwelt im Gebiet des Rambower Moores, Landkreis Prignitz, Brandenburg. Unveröff. Diplomarbeit, Georg-August-Universität, Göttingen.

DE KLERK, P. (2002): Changing vegetation patterns in the Endinger Bruch area (Vorpommern, NE Germany) during the Weichselian Lateglacial and Early Holocene. Review of Palaeobotany and Palynology, 119, S. 275-309.

DÖRFLER, W. (im Druck): Pollenanalytische Untersuchungen zur Vegetations- und Siedlungsgeschichte im Einzugsbereich des Rugensee bei Schwerin, In: SchÜLKE, A., (Hrsg.): Landschaften - Eine archäologische Untersuchung der Region zwischen Schweriner See und Stepenitz, Mecklenburg-Vorpommern, vom Mesolithikum bis zur Frühslawischen Zeit. Beiträge zur Ur- und Frühgeschichte Mecklenburg-Vorpommerns, 49, Greifswald.

EllenberG, H. (1996): Vegetation Mitteleuropas mit den Alpen in ökologischer, dynamischer und historischer Sicht. Ulmer, Stuttgart, 5. stark veränd. und verb. Aufl., 1059 S.

FAEgRi, K., IVERSEN, J., KAlAND, P. E. und KRZYwinsKi, K. (1989): Textbook of pollen analysis. Wiley, Chichester [u.a.], 4. Aufl., 328 S.

FELCKE, A. F. L. (1891): Chronik der Stadt Arendsee in der Altmark. Könecke, Gardelegen,.

FINCK, P. (2002): Rahmenvorstellungen für das Nordostdeutsche Tiefland aus bundesweiter Sicht, S. 385 S., Bundesamt für Naturschutz, 50, Schriftenreihe für Landschaftspflege und Naturschutz, Bonn-Bad Godesberg.

FIRBAS, F. (1934): Über die Bestimmung der Walddichte und der Vegetation waldloser Gebiete mit Hilfe der Pollenanalyse. Planta, 22, S. 109-145.

FIRBAS, F. (1949): Spät- und nacheiszeitliche Waldgeschichte Mitteleuropas nördlich der Alpen Bd. 1: Allgemeine Waldgeschichte. Fischer, Jena, VIII, 480 S.

Fischer, W. (1958): Flora der Prignitz. Wiss. Z. Päd. Hochsch. Potsdam Math. Nat., 3, S. 181-243.

FUGMANN \& JANOTTA. (1995): Vorstudie zum Landschaftsrahmenplan Brandenburgische Elbtalaue. Büro für Ökologie und Landschaftsentwicklung, Berlin, S. 112 S.

GIESE, K. (1970): Das Dünenfeld auf der Langendorfer Geest-Insel. Hannoversches Wendland, 2, S. 99-104. 
GolomBeK, E. (1980): Pollenanalytische Untersuchungen zur spät- und postglazialen Vegetationsgeschichte im Drömling (Ostniedersachsen). Ber. naturhist. Ges. Hannover, 123, S. 79157.

GÖTZMANN, M. (1996): Vegetationsökologische Untersuchungen in Sandtrockenrasen am Rambower See. Unveröff. Magisterarbeit. Lüneburg.

GRIMM, E. C. (1990): TILIA and TILIA-GRAPH: PC spreadsheet and graphics software for pollen data. Inqua-Commission for the study of the Holocene. Working Group for DataHandling Methods - Newsletter 4, 5-7.

GRIMMEL, E. (1980): Warum der Salzstock Gorleben als Atommüllendlager ungeeignet ist. Z. Dt. Geol. Ges., 131, S. 487-519.

HalbFass, W. (1896): Der Arendsee in der Altmark. Petermanns Geogr. Mitteilungen, VII, S. 23-187.

Horst, F. (1985): Zedau: Eine jungbronze- u. eisenzeitliche Siedlung in der Altmark. Schriften zur Ur- und Frühgeschichte, 36, 36, Akademie Verlag, Berlin, 178 S. mit 18 Taf., 95 Abb. u. 6 Beil. S.

HurTiG, T. (1957): Physische Geographie von Mecklenburg. Dt. Verlag d. Wissensch., Berling, $252 \mathrm{~S}$.

Jacobson, G. L. J. und Bradshaw, R. H. (1981): The Selection of Sites for Paleovegetational Studies. Quaternary Research, 16, S. 80-96.

JÄGER, K. (2002): Zur Geologie und Geomorphologie topographischer Kleinsthohlformen in der brandenburgischen Prignitz, Diplomkartierung. Institut für Geowissenschaften, Johannes Gutenberg-Universität Mainz,.

JAHNS, S. (2007): Palynological investigations into the Late Pleistocene and Holocene history of vegetation and settlement at the Löddigsee, Mecklenburg, Germany. Vegetation History and Archaeobotany, 16, S. 157-169.

KEILING, H. (1982): Archäologische Funde vom Spätpaläolithikum bis zur vorrömischen Eisenzeit aus den mecklenburgischen Bezirken. MuSEUM FÜR UR- U. FRÜHGESCHICHTE, Archäologische Funde und Denkmale aus dem Norden der DDR. Museumskatalog ; 1, Schwerin, 95 S. 
KIRLEIS, W. (1998): Vegetationsgeschichtliche Untersuchungen über die spätholozäne Siedlungsgeschichte im Gebiet des Rambower Moores, Landkreis Prignitz, westliches Brandenburg. Unveröff. Diplomarbeit, Biologische Fakultät, Georg-August-Universität Göttingen.

KIRLEIS, W. (2002): Vegetationsgeschichtliche und archäobotanische Untersuchungen zur Landwirtschaft und Umwelt im Bereich der prähistorischen Siedlungen bei Rullstorf, Ldkr. Lüneburg. 83 S. Dissertation Biologische Fakultät, Georg-August-Universität Göttingen. In gedruckter Fassung ist diese Dissertationsschrift erschienen in: Probleme der Küstenforschung im südlichen Nordseegebiet 28, 2004

KöLlN, D. (2001): Erfassung und Bewertung des Rambower Moores, eines Durchströmungsmoores, am Rande des Mittleren Elbtales. unveröff. Diplomarbeit am Zoologischen Institut und Museum Hamburg, $71 \mathrm{~S}$.

KuBITZKI, K. und MÜNNICH, K. (1960): Neue 14C-Datierungen zur nacheiszeitlichen Waldgeschichte Nordwestdeutschlands. Berichte der Deutschen Botanischen Gesellschaft, 73, 4, S. 137-146.

Kunes, P., Pokorny, P. und SidA, P. (2008): Detection of the impact of early Holocene hunter-gatherers on vegetation in the Czech Republic, using multivariate analysis of pollen data. Vegetation History and Archaeobotany, Vol. 17, Nr. 3, S. 269 -287.

LANG, G. (1994): Quartäre Vegetationsgeschichte Europas. Fischer, Jena, 462 S.

LANGE, E. (1986): Vegetationsentwicklung im NSG "Fenn in Wittenmoor" und in dessen Umgebung. Arch. Nat.schutz Landsch.forsch. Berlin, 26, S. 243-252.

LAUX, F. (1996): „Aunjetitzer Fürstengräber“ im nordöstlichen Niedersachsen? Ein Beitrag zur Nordwestgrenze der Aunjetitzer Kultur in Niedersachsen. Die Kunde N. F., 47, S. $303-$ 323.

Leineweber. (2002): Es saßen die alten Germanen., Die Altmark während der ersten nachristlichen Jahrhunderte, In: BocK, H., (Hrsg.): Hünengräber - Siedlungen - Gräberfelder: von der Altsteinzeit bis zum Frühmittelalter, 1, Mittelland-Bücherei, Ziethen, Oschersleben.

LeINEWEBER, R. und LÜBKe, H. (2007): Der Fischzaun aus dem Arendsee. Archäologie in Sachsen-Anhalt, 13,.

LESEMANN, B. (1969): Pollenanalytische Untersuchungen zur Vegetationsgeschichte des Hannoverschen Wendlandes. Flora, Abt. B, 158, S. 480-519. 
LIEDTKE, H. (1994): Die Gliederung des Eiszeitalters in Norddeutschland und das Holozän, In: LiEDTKe, H. \&. M. J., (Hrsg.): Physische Geographie Deutschlands,.

LitT, T. und SteBich, M. (1999): Bio- and chronostratigraphy of the lateglacial in the Eifel region, Germany. Quaternary International, 61, 1, S. 5 - 16.

MECKE, A. (1995): Pollenanalytische Untersuchungen zur spät- und postglazialen Vegetations- und Klimageschichte im Landkreis Friesland. Probleme zur Küstenforschung im südlichen Nordseegebiet, 23, S. 11-49.

MitTAG, L. (2002): Verbrannt und begraben, Eisenzeitliche Gräberfelder in der Altmark, In:

Bock, H., (Hrsg.): Hünengräber - Siedlungen - Gräberfelder: von der Altsteinzeit bis zum Frühmittelalter, 1, Mittelland-Bücherei, Ziethen, Oschersleben.

Moore, P. D., WebB, J. A. und Collinson, M. E. (1991): Pollen analysis. Blackwell Scientific Publications, Oxford, 2. Aufl., 216 S.

MüLLER, H. und KOHL, G. (1966): Radiocarbondatierungen zur jüngeren Vegetationsentwicklung Südostmecklenburgs. Flora, Abt. B, 156, S. 408-418.

MÜLLER, R. (1985): Die Grabfunde der Jastorf- und Latènezeit an unterer Saale und Mittelelbe. Veröffentlichungen des Landesmuseums für Vorgeschichte in Halle, 38, 38, Dt. Verl. d. Wissenschaften, Berlin, 316 S., 27 Textabb., 113 Taf. S.

NÜsse, H. J. (2002): Untersuchungen zur Besiedlung des Hannoverschen Wendlands von der jüngeren vorrömischen Eisen- bis zur Völkerwanderungszeit. Philosphische Fakultät, Göttingen, $407 \mathrm{~S}$.

OELKE, E. (1997): Sachsen-Anhalt: mit einem Anhang Fakten - Zahlen - Übersichten. OELKE, E., Perthes Länderprofile, Perthes, Gotha, 1. Aufl., 423 S.

Peglar, S. M. und BiRKS, H. J. B. (1993): The mid-Holocene Ulmus fall at Diss Mere, South East England - disease and human impact? Vegetation History and Archaeobatany, 2, S. 6168.

PREuSS, J. (1980): Die altmärkische Gruppe der Tiefstichkeramik. Veröffentlichungen des Landesmuseums für Vorgeschichte in Halle, 33, 33, Dt. Verl. der Wiss., Berlin, 215 S.

PudelKo, A. und Voss, K. L. (1966): Eine Siedlungsstelle der Bernburger Kultur bei Kapern, Kreis Lüchow-Dannenberg. NNU, 35, S. 89-93.

PunT, W. (1976): The Northwest European Pollen Flora. - Bd. 1. Elsevier, Amsterdam. 
Punt, W. und Clarke, G. (1980): The Northwest European Pollen Flora. - Bd. 2. Elsevier, Amsterdam.

Punt, W. und Clarke, G. (1981): The Northwest European Pollen Flora. - Bd. 3. Elsevier, Amsterdam.

Punt, W. und Clarke, G. (1984): The Northwest European Pollen Flora. - Bd. 4. Elsevier, Amsterdam.

Punt, W., Blackmore, S. und Clarke, G. (1988): The Northwest European Pollen Flora. Bd. 5. Elsevier, Amsterdam.

PunT, W. \&. B. S. (. (1991): The Northwest European Pollen Flora - Bd. 6. Elsevier, Amsterdam.

PYRITZ, E. (1972): Binnendünen und Flugsandebenen im Niedersächsischen Tiefland. Göttinger Geographische Abhandlungen, 61.

RAU, R. (1955): Quellen zur karolingischen Reichsgeschichte T. 1: Die Reichsannalen. Ausgewählte Quellen zur deutschen Geschichte des Mittelalters, 5, 5, Wiss. Buchges., Darmstadt, $484 \mathrm{~S}$.

Reichhoff, L., Kugler, H., Refior, K. und Warthemann, G. (2001): Die Landschaftsgliederung Sachsen-Anhalts (Stand: 01.01.2001). Ein Beitrag zur Fortschreibung des Landschaftsprogramms des Landes Sachsen-Anhalt. Auftraggeber: Ministerium für Raumordnung, Landwirtschaft und Umwelt des Landes Sachsen-Anhalt. Landesamt für Umweltschutz Sachsen-Anhalt. Dessau.

ReIMER, P. J. et al., (2004): IntCal04 Terrestrial Radiocarbon Age Calibration, 0-26 Cal Kyr BP. Radiocarbon, Vol. 46, Issue 3, S. 1029-1058.

Richter, P. B., HeinEMANN, B. und KuCAN, D. (2002): Das neolithische Erdwerk von Walmstorf, Ldkr. Uelzen: Studien zur Besiedlungsgeschichte der Trichterbecherkultur im südlichen Ilmenautal. Veröffentlichungen der Urgeschichtlichen Sammlungen des Landesmuseums zu Hannover, 49, 49, Isensee, Oldenburg, VII, 383, 90 S.

Röhrig, R., Beug, H. J., Trettin, R. und Morgenstern, P. (2004): Subfossil chironomid assemblages as paleoenvironmental indicators in Lake Faulersee (Germany). Studia Quaternaria, 12, S. 117-127.

SAILE, T. (2004): Slawen und Franken am Höhbeck (Ldkr. Lüchow-Dannenberg). 
SAILE, T. (2007): Slawen in Niedersachsen: zur westlichen Peripherie der slawischen Ökumene vom 6.-12. Jahrhundert. Göttinger Schriften zur Vor- und Frühgeschichte, 30, 30, Wachholtz, Neumünster, Holst, 1. Aufl., 295 S.

SAILE, T.: DFG-Projektantrag „Slawen an der unteren Mittelelbe“, unveröffentlichter Projektantrag, basiert auf gleicher Datengrundlage wie Abb. 20 in SAILE 2007

SCHARF, B. W. (1998): Eutrophication history of Lake Arendsee (Germany). Palaeogeography, Palaeoclimatology, Palaeoecology, 140, S. 85-96.

SEYER, H. (2002): Das Eisen erobert die Altmark, In: BocK, H, (Hrsg.): Hünengräber - Siedlungen - Gräberfelder: von der Altsteinzeit bis zum Frühmittelalter, 1, Mittelland-Bücherei, Ziethen, Oschersleben.

Soepboer, W., Vervoort, J., Sugita, S. und Lotter, A. (2007): Evaluating Swiss pollen productivity estimates using a simulation approach. Vegetation History and Archaeobotany, 2008, online: DOI 10.1007/s00334-007-0128-4.

SPROCKHOFF, E. (1926): Die Kulturen der jüngeren Steinzeit in der Mark Brandenburg, In: EBERT, M., (Hrsg.): Vorgeschichtliche Forschungen, Berlin.

SPROCKHOFF, E. (1963): Das Hügelgräberfeld von Schnega. Prähistorische Zeitschrift, XLI, S. $1-50$.

STEFFAN, H. und DuPONT, L. (1988): Note on a program for plotting of pollen diagrams with an Atari ST Microcomputer. Pollen et Spores, 30, S. 125-130.

SteInMETZ, W. D. (1986): Jungsteinzeit. Die ersten Bauern, In: WACHTER, B., (Hrsg.): Führer zur archäologischen Denkmälern in Deutschland, 13, Stuttgart.

StockmarR, J. (1971): Tablets with Spores used in absolute Pollenanalysis. Pollen et Spores, 13, S. 615-621.

Stuiver, M. \&. R. P. (1993): Extended 14C Data Base, a revised Calib 3.9 14C Age Calibration Program. Radiocarbon, 35, S. 215-230.

Stuiver, M., Reimer, P. J., Bard, E., Beck, J. W., Burr, G. S., Hughen, K. A., Kromr, B., McCormack, F. G., VAn Der Plicht, J. und SPURK, M. (1998): INTCAL98 radicarbon age calibration, 24.000-0 cal BP. Radiocarbon, 40, S. 1041-1083.

UsINGER, H. (1985): Pollenstratigraphische, vegetations- und klimageschichtliche Gliederung des "Bölling-Alleröd-Komplexes" in Schleswig-Holstein und ihre Bedeutung für die Spätglazial-Stratigraphie in benachbarten Gebieten. Flora, 177, S. 1-43. 
VoelKel, G. (1965): Funde des Jahres 1964 im Kreise Lüchow-Dannenberg. NNU, 34, S. 103-105.

VoelKel, G. (1981): Aus der Urgeschichte, S. 47-55, In: Miest, P. und PAAsche, W., (Hrsg.): Hannoversches Wendland, Niedersächsische Landeszentrale für Polititsche Bildung, Hannover.

Voss, K. L. (1965): Bronzezeitliche Ackerflur über einem Kult- und Begräbnisplatz der Bernburger und Kugelamphorenkultur bei Pevestorf/Höhbeck, Kreis Lüchow Dannenberg. Germania, 43, S. 361-368.

Voss, K. L. (1970): Zum Stand der archäologischen Untersuchungen auf dem Hasenberg von Pevestorf, Kreis Lüchow-Dannenberg. Hannoversches Wendland. 2. Jh. d. Heimatkundl. Arbeitskreises Lüchow-Dannenberg, S. 7-12.

WACHTER, B. (. (1986): Hannoversches Wendland, S. 242, Führer zu archäologischen Denkmälern in Deutschland, Stuttgart.

WeTZEL, G. (1979): Die Schönfelder Kultur. Veröffentlichungen des Landesmuseums für Vorgeschichte in Halle, 31,

WolfF, B., Erhard, M., Holzhausen, M. und Kuhlow, T. (2003): Das Klima in den forstlichen Wuchsgebieten und Wuchsbezirken Deutschlands. Mitteilungen der Bundesforschungsanstalt für Forst- und Holzwirtschaft Hamburg, Nr. 211, 29 S.

WOLTERS, S. (2002): Vegetationsgeschichtliche Untersuchungen zur spätglazialen und holozänen Landschaftsentwicklung in der Döberitzer Heide (Brandenburg). Dissertationes botanicae, 366, Cramer, Berlin - Stuttgart, 157 S. 


\section{Verwendete Karten und Daten:}

CalPal-2007online (online version) Danzeglocke, U., Jöris, O., Weninger, B., 2007. CalPal2007online. http://www.calpal-online.de/, accessed 2007

Daten vom Deutschen Wetter Dienst 1961-1990, Klimadaten Deutschland, Mittelwerte, aus dem Internet: http://www.dwd.de, verwendet wurden die Niederschlags- und Temperaturdaten in der Fassung vom 21.10.2005

Mecklenburg-Vorpommern/Landesvermessungsamt. (2003): Mecklenburg-Vorpommern: [1:50.000]. Top 50, Die digitale Kartenserie der deutschen Landesvermessung, Schwerin, 1 CD-ROM.

Übersichtskarte der Böden, BÜK400d, Geologisches Landesamt Sachsen-Anhalt 1994

\section{Danksagung}

Herr Prof. Dr. Hans-Jürgen Beug und Herr Prof. Dr. Karl-Heinz Willroth gaben die Anregung zum Thema dieser Arbeit.

Herrn Prof. Dr. Hans-Jürgen Beug danke ich ganz besonders für die ständige Gesprächsbereitschaft, die Hilfe bei allen fachlichen Problemen, sein Interesse am Fortgang der Arbeit und natürlich auch die tatkräftige Unterstützung bei der Arbeit im Gelände.

Herrn Prof. Dr. Scharf danke ich für seine tatkräftige Unterstützung und die gute Zusammenarbeit.

Außerdem danke ich den Kollegen aus der Abteilung für Palynologie, insbesondere Frau Grothmann, die die Zeichnungen der Stratigraphie fertigte, sowie Frau Klammt, Frau Wittorf und Herrn PD Dr. Saile aus dem Seminar für Ur- und Frühgeschichte der Uni Göttingen.

Außerdem seien noch genannt Frau Dr. Jahns, Frau Dr. Leineweber, Frau Dipl.-Biol. Kölln, Herr Dr. Dörfler, Herr Dr. Gossler, Herr Dr. Wolters, und nicht zuletzt die DFG für die finanzielle Unterstützung.

Das Ministerium für Umwelt, Naturschutz und Raumordnung des Landes Brandenburg sowie die Naturparkverwaltung "Brandenburgische Elbtalaue" und die untere Naturschutzbehörde des Landkreises Prignitz gaben die Genehmigung zur Durchführung der Geländearbeiten im Naturschutzgebiet. 


\section{Anhang}

Tabelle 10: Gegenüberstellung der tatsächlichen Tiefen im Kern ARS 1, zu den im Diagramm angegebenen Tiefen.

\begin{tabular}{|c|c|c|c|c|c|c|c|c|c|c|}
\hline $\begin{array}{c}\text { Tiefe } \\
\text { im- } \\
\text { Kern }\end{array}$ & $\begin{array}{l}\text { im Diag- } \\
\text { ramm }\end{array}$ & Zonen & $\begin{array}{c}\text { Siedlungs- } \\
\text { phasen }\end{array}$ & $\begin{array}{c}\text { Tiefe } \\
\text { im } \\
\text { Kern }\end{array}$ & $\begin{array}{l}\text { im Diag- } \\
\text { ramm }\end{array}$ & Zonen & $\begin{array}{c}\text { Siedlungs- } \\
\text { phasen }\end{array}$ & $\begin{array}{c}\text { Tiefe } \\
\text { im } \\
\text { Kern }\end{array}$ & $\begin{array}{c}\text { Tiefe im } \\
\text { Diagramm }\end{array}$ & Zonen \\
\hline \multicolumn{2}{|c|}{$\begin{array}{c}\text { Mondsee-Core } \\
0-37 \mathrm{~cm}\end{array}$} & & \multirow{9}{*}{$\mathrm{n}$} & \multicolumn{2}{|c|}{ Kern ARS 1 2-3 m } & & & \multicolumn{2}{|c|}{ Kern ARS $14-5 \mathrm{~m}$} & \\
\hline 0 & 0 & \multirow{8}{*}{$\mathrm{Xb}$} & & 215 & 235 & \multirow{6}{*}{ IXa } & \multirow{3}{*}{$\mathrm{e}$} & 400 & 420 & \multirow{3}{*}{ VII } \\
\hline 2 & 2 & & & 220 & 240 & & & 410 & 430 & \\
\hline 12 & 12 & & & 225 & 245 & & & 421 & 441 & \\
\hline 16 & 16 & & & 230 & 250 & & \multirow{11}{*}{$\mathrm{d}$} & 430 & 450 & \multirow{6}{*}{ VI } \\
\hline 24 & 24 & & & 235 & 255 & & & 440 & 460 & \\
\hline 30 & 30 & & & 240 & 260 & & & 450 & 470 & \\
\hline 36 & 36 & & & 245 & 265 & \multirow{17}{*}{ VIII } & & 462 & 482 & \\
\hline \multicolumn{2}{|c|}{ Kern Ars 1A 0-2 m } & & & 250 & 270 & & & 470 & 490 & \\
\hline 10 & 45 & \multirow{12}{*}{ Xa } & \multirow{2}{*}{$\mathrm{m}$} & 255 & 275 & & & 480 & 500 & \\
\hline 20 & 55 & & & 260 & 280 & & & 490 & 510 & \multirow{4}{*}{ V } \\
\hline 30 & 65 & & \multirow{3}{*}{1} & 265 & 285 & & & 499 & 519 & \\
\hline 40 & 75 & & & 270 & 290 & & & \multicolumn{2}{|c|}{ Kern ARS 1 5-6 m } & \\
\hline 50 & 85 & & & 275 & 295 & & & 510 & 530 & \\
\hline 60 & 95 & & & 280 & 300 & & & 515 & 535 & \\
\hline 70 & 105 & & $\mathrm{k}$ & 285 & 305 & & & 525 & 545 & \\
\hline 75 & 110 & & & 290 & 310 & & & 530 & 550 & \\
\hline 80 & 115 & & & Kern & S 1 3-4 m & & $\mathrm{c}$ & 535 & 555 & 18 \\
\hline 85 & 120 & & & 308 & 328 & & & 540 & 560 & \\
\hline 90 & 125 & & $J$ & 310 & 330 & & & 545 & 565 & \\
\hline 95 & 130 & & & 315 & 335 & & & 550 & 570 & \\
\hline 100 & 135 & & & 320 & 340 & & & 560 & 580 & \\
\hline 105 & 140 & & & 325 & 345 & & & 570 & 590 & H \\
\hline 110 & 145 & & & 330 & 350 & & & 580 & 600 & 111 \\
\hline 115 & 150 & & 1 & 335 & 355 & & & 585 & 605 & \\
\hline 120 & 155 & & & 340 & 360 & & & 590 & 610 & \\
\hline 125 & 160 & & & 345 & 365 & & b & 595 & 615 & \\
\hline 130 & 165 & IXb & & 350 & 370 & & & Kerr & RS $16-7 \mathrm{~m}$ & \\
\hline 135 & 170 & & & 355 & 375 & & & 600 & 620 & \\
\hline 140 & 175 & & $\mathrm{~h}$ & 360 & 380 & & & 603 & 623 & \\
\hline 145 & 180 & & & 365 & 385 & VII & & 610 & 630 & \\
\hline 150 & 185 & & & 370 & 390 & & & 615 & 635 & II \\
\hline 155 & 190 & & & 375 & 395 & & & 620 & 640 & \\
\hline 160 & 195 & & $g$ & 380 & 400 & & & 625 & 645 & \\
\hline 165 & 200 & & & 385 & 405 & & $\mathrm{a}$ & 630 & 650 & \\
\hline 170 & 205 & & & 390 & 410 & & & 635 & 655 & \\
\hline 175 & 210 & & $\mathrm{~T}$ & 395 & 415 & & & 638 & 658 & \\
\hline 180 & 215 & IXa & & & & & & 645 & 665 & \\
\hline 185 & 220 & & & & & & & 650 & 670 & $\mathrm{r}$ \\
\hline 190 & 225 & & $\mathrm{e}$ & & & & & 656 & 676 & \\
\hline 195 & 230 & & & & & & & 660 & 680 & \\
\hline
\end{tabular}


Tabelle 11: Gegenüberstellung der tatsächlichen Tiefen im Kern ARS 5, zu den im Diagramm angegebenen Tiefen

\begin{tabular}{|c|c|c|c|c|c|c|c|}
\hline $\begin{array}{c}\text { Tiefe im } \\
\text { Diagramm }\end{array}$ & $\begin{array}{c}\text { Tiefe im } \\
\text { Kern }\end{array}$ & $\begin{array}{l}\text { Pollen- } \\
\text { zonen }\end{array}$ & $\begin{array}{c}\text { Siedlungs- } \\
\text { phasen }\end{array}$ & $\begin{array}{c}\text { Tiefe im } \\
\text { Diagramm }\end{array}$ & $\begin{array}{l}\text { Tiefe im } \\
\text { Kern }\end{array}$ & Pollenzonen & $\begin{array}{c}\text { Siedlungs- } \\
\text { phasen }\end{array}$ \\
\hline 3,0 & 3,0 & \multirow{9}{*}{$\mathrm{Xa}$} & \multirow{9}{*}{$\mathrm{j}$} & 76,0 & 76,0 & \multirow{11}{*}{ VIII } & \multirow{5}{*}{ d } \\
\hline 4,0 & 4,0 & & & 78,0 & 78,0 & & \\
\hline 6,0 & 6,0 & & & 80,0 & 80,0 & & \\
\hline 7,0 & 7,0 & & & 82,0 & 82,0 & & \\
\hline 8,0 & 8,0 & & & 84,0 & 84,0 & & \\
\hline 10,0 & 10,0 & & & 86,0 & 86,0 & & \multirow{3}{*}{$\mathrm{c}$} \\
\hline 11,0 & 11,0 & & & 88,0 & 88,0 & & \\
\hline 11,5 & 11,5 & & & 90,0 & 90,0 & & \\
\hline 12,0 & 12,0 & & & 92,0 & 92,0 & & \multirow{6}{*}{$\mathrm{b}$} \\
\hline 14,0 & 14,0 & \multirow{14}{*}{$\mathrm{IXb}$} & \multirow{4}{*}{$\mathrm{i}$} & 94,0 & 94,0 & & \\
\hline 16,0 & 16,0 & & & 96,0 & 96,0 & & \\
\hline 18,0 & 18,0 & & & 98,0 & 98,0 & \multirow{7}{*}{ VII } & \\
\hline 20,0 & 20,0 & & & 100,0 & 132,5 & & \\
\hline 22,0 & 22,0 & & \multirow{5}{*}{$\mathrm{h}$} & 102,5 & 135 & & \\
\hline 24,0 & 24,0 & & & 105,0 & 137,5 & & \multirow{3}{*}{$\mathrm{a}$} \\
\hline 26,0 & 26,0 & & & 107,5 & 140 & & \\
\hline 28,0 & 28,0 & & & 110,0 & 142,5 & & \\
\hline 30,0 & 30,0 & & & 112,5 & 145 & & \\
\hline 32,0 & 32,0 & & \multirow{5}{*}{$\mathrm{g}$} & 115,0 & 147,5 & \multirow{10}{*}{ VI } & \\
\hline 34,0 & 34,0 & & & 117,5 & 150 & & \\
\hline 36,0 & 36,0 & & & 120,0 & 152,5 & & \\
\hline 38,0 & 38,0 & & & 122,5 & 155 & & \\
\hline 39,0 & 39,0 & & & 125,0 & 157,5 & & \\
\hline 40,0 & 40,0 & \multirow{18}{*}{ IXa } & \multirow{3}{*}{$\mathrm{f}$} & 127,5 & 160 & & \\
\hline 42,0 & 42,0 & & & 130,0 & 162,5 & & \\
\hline 44,0 & 44,0 & & & 132,5 & 165 & & \\
\hline 46,0 & 46,0 & & \multirow{12}{*}{$\mathrm{e}$} & 137,5 & 170 & & \\
\hline 48,0 & 48,0 & & & 143,5 & 176 & & \\
\hline 50,0 & 50,0 & & & 147,5 & 180 & \multirow{5}{*}{$\mathrm{Vb}$} & \\
\hline 52,0 & 52,0 & & & 153,5 & 186 & & \\
\hline 54,0 & 54,0 & & & 157,5 & 190 & & \\
\hline 56,0 & 56,0 & & & 162,5 & 195 & & \\
\hline 58,0 & 58,0 & & & 167,5 & 200 & & \\
\hline 60,0 & 60,0 & & & 172,5 & 205 & \multirow{7}{*}{$\mathrm{Va}$} & \\
\hline 62,0 & 62,0 & & & 177,5 & 210 & & \\
\hline 64,0 & 64,0 & & & 182,5 & 215 & & \\
\hline 66,0 & 66,0 & & & 187,5 & 220 & & \\
\hline 68,0 & 68,0 & & & 192,5 & 225 & & \\
\hline 70,0 & 70,0 & & \multirow{3}{*}{$\mathrm{d}$} & 197,5 & 230 & & \\
\hline 72,0 & 72,0 & & & 202,5 & 235 & & \\
\hline 74,0 & 74,0 & & & 207,5 & 240 & IV & \\
\hline
\end{tabular}


Tabelle 12: Stratigraphie des Profils Heuweg 1

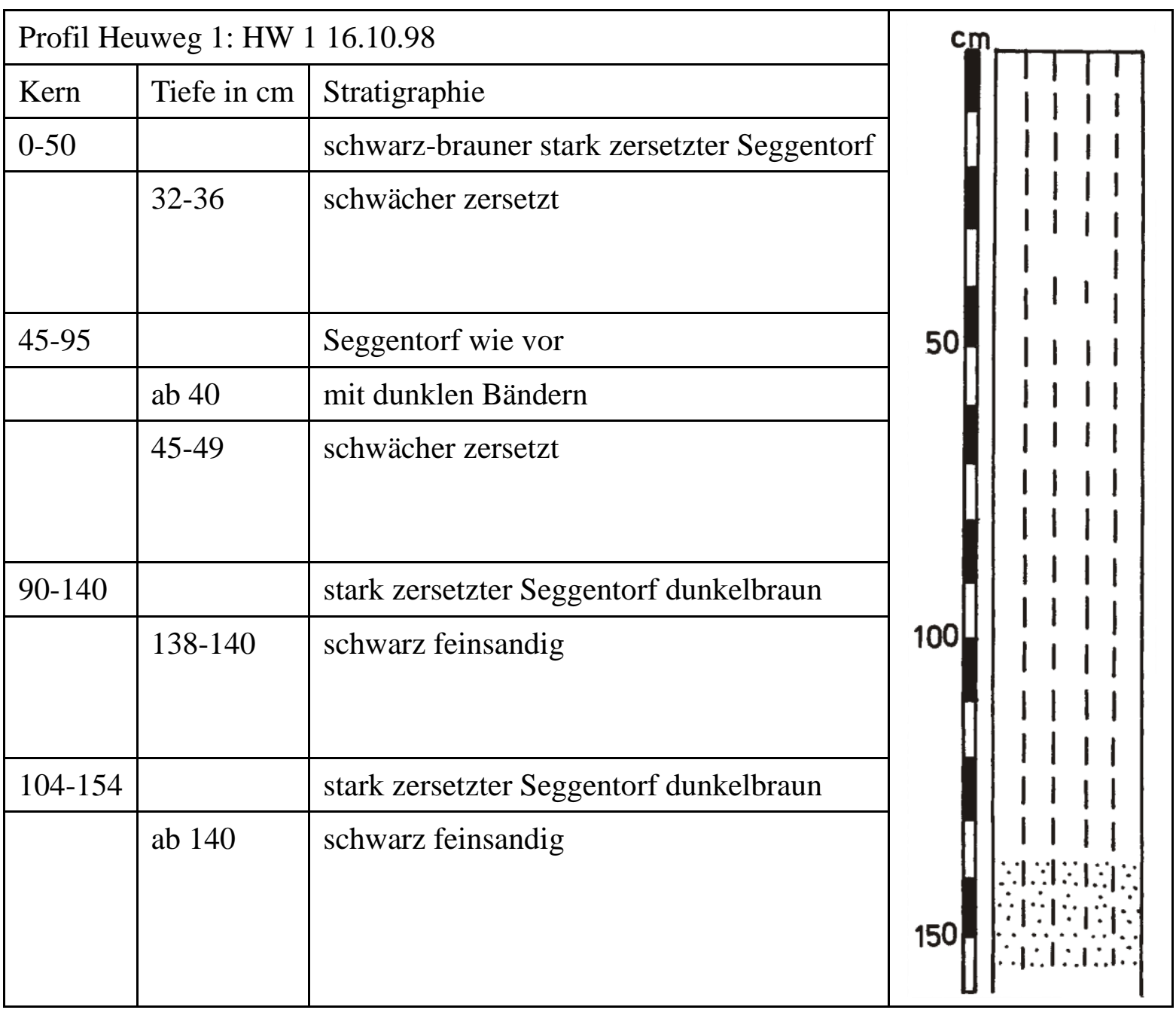

Legende

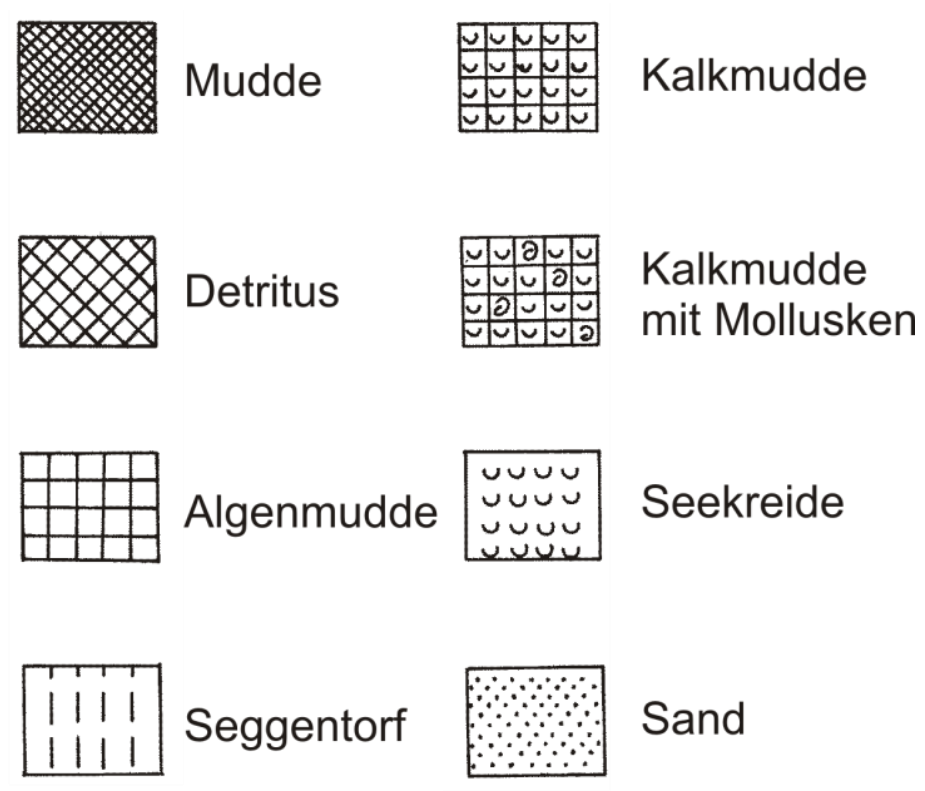


Tabelle 13: Stratigraphie des Profils Boberow

\begin{tabular}{|c|c|c|c|c|}
\hline Profil Bob & 13.10 .98 & & & \\
\hline Kern & Tiefe in $\mathrm{cm}$ & Stratigraphie & & \\
\hline $34-70 \mathrm{~cm}$ & $0-34$ & Wasser & & \\
\hline & $34-42$ & lockerer Seggentorf & 50 & \\
\hline & $42-48$ & dunkelbraune Mudde & & \\
\hline & $48-52$ & Sand & & \\
\hline & $52-64$ & dunkler Torf & & \\
\hline & $64-70$ & mittelbraune Detritusmudde & & \\
\hline $65-115$ & & hellbraune kalkige Feindetritusmudde & & \\
\hline & $70-77$ & heller & 100 & \\
\hline & $92-102$ & dunkler & & \\
\hline $110-160$ & & & & \\
\hline & $110-146$ & $\begin{array}{l}\text { hellbraune kalkige Feindetritusmudde, } \\
\text { nach unten dunkler werdend }\end{array}$ & & \\
\hline & $146-160$ & weißgraue Kalkmudde & & \\
\hline $155-205$ & & weißgraue Kalkmudde & & \\
\hline & 176-186 & etwas bräunlicher & & \\
\hline $200-250$ & & & & \\
\hline & 200-208 & weißgraue Kalkmudde & & \\
\hline & 208-215 & hellbraune Kalkmudde & & \\
\hline & $215-250$ & $\begin{array}{l}\text { mittelbraune Feindetritus-Kalkmudde, } \\
\text { ab } 246 \text { heller }\end{array}$ & 200 & \\
\hline 245-295 & & Feindetritus-Kalkmudde & & \\
\hline & $245-253$ & mittelbraun & & \\
\hline & $253-273$ & gelbbraune & & \\
\hline & $273-286$ & hellgraubraun & & \\
\hline & $286-288$ & weißgrau & & 本 \\
\hline & $288-289$ & grobkörnig, weißgrau & & \\
\hline & 289-295 & weißgrau & & \\
\hline 290-340 & & Feindetritus-Kalkmudde & & \\
\hline & 290-296 & weißgrau & & \\
\hline & 296-300 & graubraun & & \\
\hline & $300-314$ & grauweiß & & \\
\hline & $314-316$ & weiß-rötlich & 300 & \\
\hline & 316-330 & grau-rötlich & & en \\
\hline & 330-333 & grauweiß & & un \\
\hline & $333-340$ & graubraun & & \\
\hline
\end{tabular}


Tabelle 14: Stratigraphie vom Profil Rambow

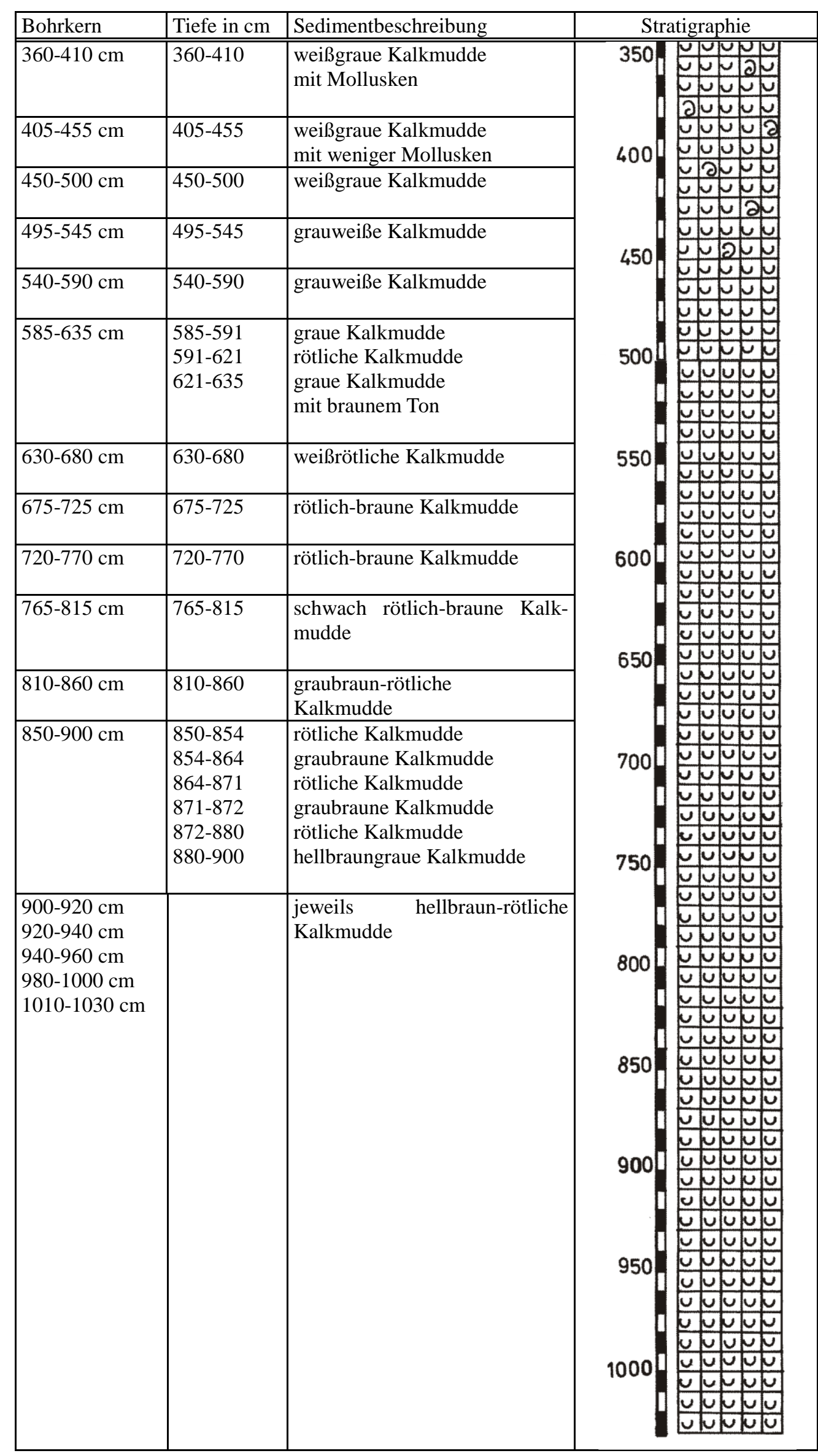


Tabelle 15 Stratigraphie des Profils Arendsee 5 (UFZ-Magdeburg)

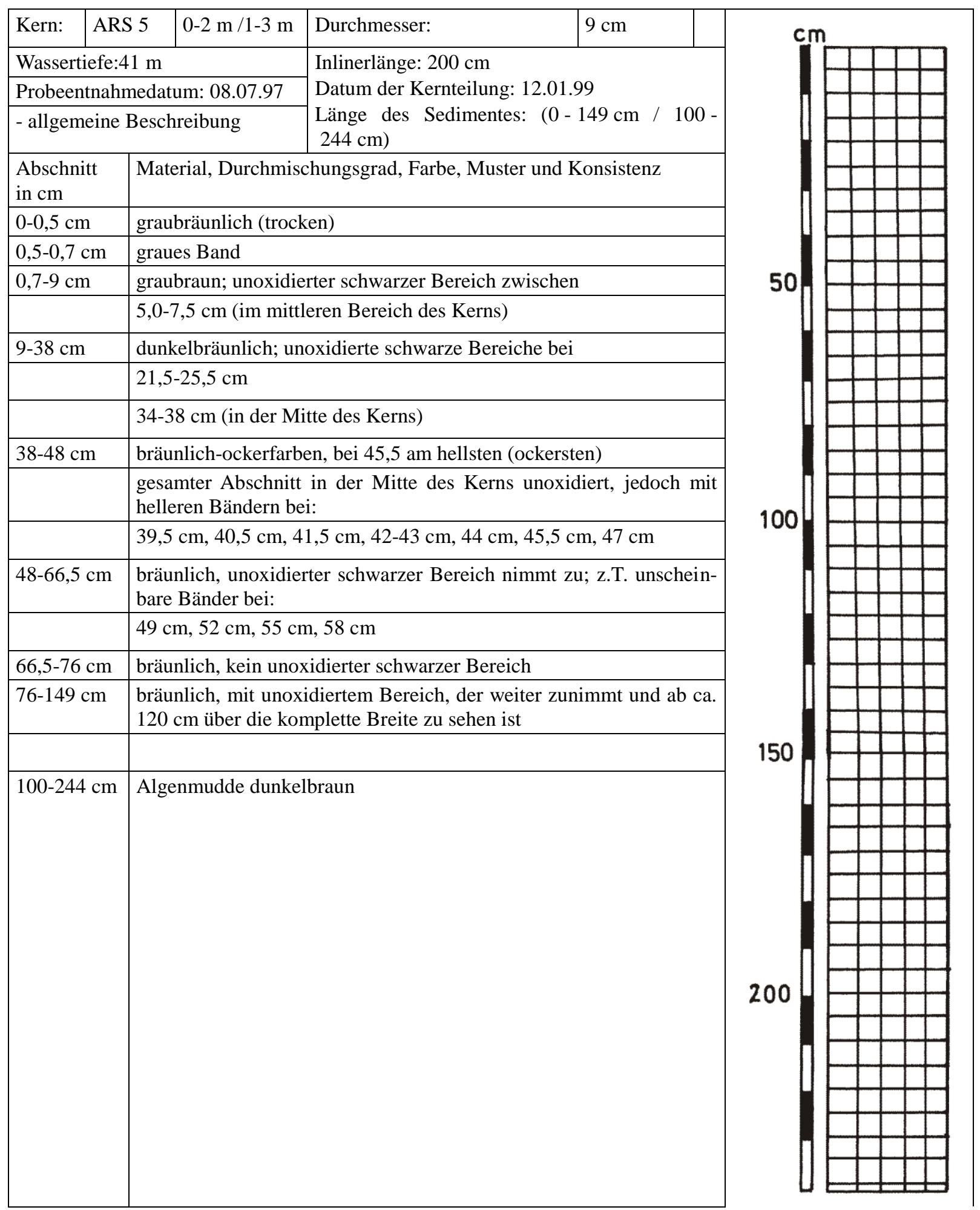


Tabelle 16 Stratigraphie des Profils Arendsee 4 (UFZ-Magdeburg)

\begin{tabular}{|c|c|c|c|c|}
\hline \multicolumn{2}{|c|}{ Kern: ARS $40-2 \mathrm{~m}$} & \multicolumn{3}{|l|}{ Durchmesser: $9 \mathrm{~cm}$} \\
\hline \multicolumn{2}{|c|}{ Wassertiefe: $6,30 \mathrm{~m}$} & \multicolumn{3}{|l|}{ Inlinerlänge: $200 \mathrm{~cm}$} \\
\hline \multicolumn{2}{|c|}{ Probenentnahmedatum: 08.09.98 } & \multicolumn{3}{|l|}{ Datum der Kernteilung: 15.12 .98} \\
\hline \multicolumn{2}{|c|}{ Position: N: $52^{\circ} 53^{\prime} 81^{\prime \prime} \mathrm{E}: 11^{\circ} 28^{\prime} 81^{\prime \prime}$} & \multicolumn{3}{|l|}{ gegenüber der schilffreien Bucht } \\
\hline \multicolumn{2}{|c|}{ Länge des Sedimentes: $178,5 \mathrm{~cm}$} & \multicolumn{3}{|l|}{ Sedimenttiefe: $0-200 \mathrm{~cm}$} \\
\hline $\begin{array}{l}\text { Abschnitte } \\
\text { in } \mathrm{cm}\end{array}$ & \multicolumn{2}{|c|}{$\begin{array}{l}\text { Abschnitt in cm, Material, Durchmischungsgrad, Farbe, Mus- } \\
\text { ter und Konsistenz }\end{array}$} & & \\
\hline $0-3 \mathrm{~cm}$ & \multicolumn{2}{|c|}{ Sand mit Seekreidebereichen unstrukturiert } & & \\
\hline $3-8 \mathrm{~cm}$ & \multicolumn{2}{|c|}{ Seekreide, braun } & & \\
\hline $8-10 \mathrm{~cm}$ & \multicolumn{2}{|c|}{ Seekreide, angedeutete Streifen } & & \\
\hline $10-11 \mathrm{~cm}$ & \multicolumn{2}{|c|}{ helle Seekreide } & & \\
\hline $11-12,5 \mathrm{~cm}$ & \multicolumn{2}{|l|}{ Seekreide, olivgrün } & & \\
\hline $12,5-16 \mathrm{~cm}$ & \multicolumn{2}{|l|}{ Seekreide, hellbraun } & & \\
\hline $16-18 \mathrm{~cm}$ & \multicolumn{2}{|c|}{ laminierter gräulicher Bereich, grüner werdend } & & $\cup \cup \cup \cup$ \\
\hline \multirow[t]{2}{*}{$18-25 \mathrm{~cm}$} & \multicolumn{2}{|c|}{ Seekreide, braune Bänder bei } & & $\cup \cup \cup \cup$ \\
\hline & \multicolumn{2}{|c|}{$18,5-19,5 \mathrm{~cm}, 20-21 \mathrm{~cm}, 21,5-22 \mathrm{~cm}, 23,5-24 \mathrm{~cm}$ und $25 \mathrm{~cm}$} & & \\
\hline $25-29 \mathrm{~cm}$ & \multicolumn{2}{|c|}{ Seekreide, laminiert, grün bräunlicher werdend } & & $\cup \cup \cup \cup$ \\
\hline $29-36 \mathrm{~cm}$ & \multicolumn{2}{|c|}{ Seekreide mit viel grober organischer Substanz } & & \\
\hline $36-37 \mathrm{~cm}$ & \multicolumn{2}{|c|}{ Seekreide, unstrukturiert } & & ن \\
\hline $37-39,5 \mathrm{~cm}$ & \multicolumn{2}{|c|}{ Seekreide, beigefarben } & & $\cup \cup \cup \cup$ \\
\hline $39,5-56,5 \mathrm{~cm}$ & \multicolumn{2}{|c|}{ Seekreide z. T. laminiert mit vereinzelten org. Bestandteilen } & & $\cup \cup \cup \cup$ \\
\hline $56,5-57,5 \mathrm{~cm}$ & \multicolumn{2}{|c|}{ org. Band } & & \\
\hline $57,5-61 \mathrm{~cm}$ & \multicolumn{2}{|c|}{ Seekreide, unstrukturiert } & 100 & $\cup \cup \cup \cup$ \\
\hline $61-70 \mathrm{~cm}$ & \multicolumn{2}{|c|}{ org. Bestandteile nehmen zu } & & $\cup \cup \cup \cup$ \\
\hline $70-85 \mathrm{~cm}$ & \multicolumn{2}{|c|}{ Seekreide, beigefarben, vereinzelte org. Bestandteile } & & \\
\hline $85-91 \mathrm{~cm}$ & $\begin{array}{l}\text { durchgehend gestr } \\
\text { Band bei } 90-91 \mathrm{~cm}\end{array}$ & Bereich mit einem deutlichen braunen & & $\cup \cup \cup \cup$ \\
\hline $91-101 \mathrm{~cm}$ & grün-gräulicher $\mathrm{Be}$ & heller & & \\
\hline $101-104,5 \mathrm{~cm}$ & dunkelgrün-bräunl & Bereich & & $\cup \cup \cup \cup$ \\
\hline $104,5-105 \mathrm{~cm}$ & helle Bande & & & $\cup \cup \cup \cup$ \\
\hline $105-107 \mathrm{~cm}$ & grün-gräulicher $\mathrm{Be}$ & , hell & & $\smile \cup \cup \cup$ \\
\hline $107-162 \mathrm{~cm}$ & Seekreide, beige-b & lich mit dunklen Bändern bei & 150 & ชuv \\
\hline & $121,5 \mathrm{~cm}, 123 \mathrm{~cm}$ & & & $\cup \cup \cup \cup$ \\
\hline & und heller-dunkler & inierung zwischen: & & $\smile \cup \cup u$ \\
\hline & $136,5-139,5 \mathrm{~cm}, 15$ & $152 \mathrm{~cm}$ & & \\
\hline $162-178,5 \mathrm{~cm}$ & gräulicher Bereich & r wenig strukturiert & & \\
\hline
\end{tabular}


Tabelle 17 Stratigraphie des Profils Arendsee 4 Freezecore (UFZ-Magdeburg)

\begin{tabular}{|c|c|c|}
\hline Probennummer: ARS 4 & Freeze-Corer & \\
\hline Wassertiefe: $6,10 \mathrm{~m}$ & Sedimenttiefe: $0-2 \mathrm{~m}$ & \\
\hline Probenahmedatum: 07.09.1998 & Datum der Kernteilung: 07.09.1998 & \\
\hline Position: N: 52॰53'81 & \begin{tabular}{|l|l|} 
& E: $11^{\circ} 28^{\prime} 81$ \\
\end{tabular} & \\
\hline Abschnitte in $\mathrm{cm}$ & $\begin{array}{l}\text { Material, Durchmischungsgrad, Farbe, Muster und Konsis- } \\
\text { tenz }\end{array}$ & \\
\hline $1-5 \mathrm{~cm}$ & Sand & \\
\hline $5-9 \mathrm{~cm}$ & Seekreide unstrukturiert & نंنंن: \\
\hline $9-12 \mathrm{~cm}$ & Seekreide mit dicken bräunlichen Streifen & $\cup \cup \cup \cup$ \\
\hline $12-17 \mathrm{~cm}$ & Seekreide mit angedeuteten Streifen & $\cup \cup \cup \cup$ \\
\hline $17-27 \mathrm{~cm}$ & helle Seekreide & $\cup \cup \cup \cup$ \\
\hline $27-34 \mathrm{~cm}$ & bräunliche Streifen dominieren & $\cup \cup \cup \cup$ \\
\hline $34-36 \mathrm{~cm}$ & gräulicher Bereich & $\cup \cup \cup \cup$ \\
\hline $36-37 \mathrm{~cm}$ & helle Seekreide & $\cup \cup \cup \cup$ \\
\hline $37-38,5 \mathrm{~cm}$ & gräulicher Bereich & $\cup \cup \cup \cup$ \\
\hline $38,5-40 \mathrm{~cm}$ & Seekreide & $\cup \cup \cup \cup$ \\
\hline $40-43 \mathrm{~cm}$ & bräunliche Einlagerungen z.T. streifig & ソ৩ソ \\
\hline $43-47 \mathrm{~cm}$ & bräunlich-gräuliche Streifen dominieren & (u) \\
\hline $47-51 \mathrm{~cm}$ & Seekreide mit deutlichem braunen Streifen ca. in der Mitte & yu \\
\hline $51-55,5 \mathrm{~cm}$ & bräunlich-gräulicher Bereich deutlich dunkel gestreift & צบบ \\
\hline $55,5-59,5 \mathrm{~cm}$ & Seekreide relativ unstrukturiert & $\cup \cup \cup \cup$ \\
\hline $60-63 \mathrm{~cm}$ & deutliche hell-dunkel Streifung & $\cup \cup \cup \cup$ \\
\hline $63-69 \mathrm{~cm}$ & Seekreide mit angedeuteten Streifen & $\cup \cup \cup \cup$ \\
\hline $69-72 \mathrm{~cm}$ & helle Seekreide & ソ৩レレ \\
\hline $72-78 \mathrm{~cm}$ & Seekreide mit deutlichen Streifen & $\cup \cup \cup \cup$ \\
\hline $78-83,5 \mathrm{~cm}$ & helle Seekreide wenig strukturiert & $\cup \cup \cup \cup$ \\
\hline $83,5-84 \mathrm{~cm}$ & deutliche helle und braune Streifen & $\cup \cup \cup \cup$ \\
\hline $84-86 \mathrm{~cm}$ & gräulicher Bereich & $\checkmark \cup \cup \cup$ \\
\hline $86-95 \mathrm{~cm}$ & deutliche Streifung in diesem Bereich & $\cup \cup \cup \cup$ \\
\hline & extrem braune Streifen bei: 87,$5 ; 89,5$ und $90 \mathrm{~cm}$ & $\cup \cup \cup \cup$ \\
\hline $95-96 \mathrm{~cm}$ & heller Bereich & $\cup \cup \cup \cup$ \\
\hline $96-97 \mathrm{~cm}$ & gräulicher Bereich & ouv \\
\hline $97-104 \mathrm{~cm}$ & $\begin{array}{l}\text { homogener gräulicher Bereich von jeweils helleren Zonen } \\
\text { eingeschlossen }\end{array}$ & $\begin{array}{l}\cup \cup \cup \cup \\
\cup \cup \cup \cup \\
\cup \cup \cup \cup\end{array}$ \\
\hline $104-135 \mathrm{~cm}$ & $\begin{array}{l}\text { durchgehend gestreifter Bereich mit deutlichen braunen } \\
\text { Streifen bei: }\end{array}$ & 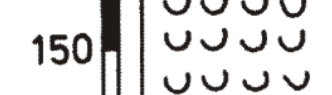 \\
\hline & $107,114,121,124,5 ; 125,5 ; 127$ und $128 \mathrm{~cm}$ & $\cup \cup \cup \cup$ \\
\hline $135-146 \mathrm{~cm}$ & gräulicher Bereich heller beginnend & $\cup \cup \cup \cup$ \\
\hline $146-147,5 \mathrm{~cm}$ & dunkelgräulicher Bereich & $\cup \cup \cup \cup$ \\
\hline $147,5.148,5 \mathrm{~cm}$ & heller Bereich & $\cup \cup \cup \cup$ \\
\hline $148,5-160 \mathrm{~cm}$ & hellbräunlich-gräulicher Bereich, wenig strukturiert & $\cup \cup \cup \cup$ \\
\hline $160-164 \mathrm{~cm}$ & hellbräunlich-gräulicher Bereich, teilweise streifig & $\cup \cup \cup \cup$ \\
\hline $164-168 \mathrm{~cm}$ & hellbräunlich-gräulicher Bereich, wenig strukturiert & \\
\hline $168-180 \mathrm{~cm}$ & hellbräunlich-gräulicher Bereich, teilweise streifig & ৩ \\
\hline $180-194 \mathrm{~cm}$ & $\begin{array}{l}\begin{array}{l}\text { hellbräunlich-gräulicher } \text { Bereich, wenig strukturiert im } \\
\text { unteren Bereich dunkler }\end{array} \\
\end{array}$ & \\
\hline
\end{tabular}


Tabelle 18: Am Kern ARS 4 durchgeführte ${ }^{14} \mathrm{C}$-AMS-Datierungen (UFZ-Magdeburg).

\begin{tabular}{|c|c|c|c|}
\hline $\begin{array}{c}\text { Sedimenttiefe } \\
{[\mathrm{cm}]}\end{array}$ & Fraktion & $\begin{array}{l}\text { Alter } \\
{[\text { cal BP }]}\end{array}$ & $\begin{array}{c}\text { Standard- } \\
\text { Abweichung }\end{array}$ \\
\hline $10-12$ & $\begin{array}{c}\text { Sediment, Pflanzenreste, } \\
\text { Samenschalen }\end{array}$ & 1.799 & \pm 62 \\
\hline $30-32$ & Sediment & 2.230 & \pm 79 \\
\hline $48-51$ & Sediment & 2.281 & \pm 68 \\
\hline $70-72$ & Sediment & 2.533 & \pm 174 \\
\hline $90-92$ & Sediment & 2.538 & \pm 175 \\
\hline $98-100$ & Pflanzenreste & 2.684 & \pm 61 \\
\hline $104-106$ & Pflanzenreste & 2.765 & \pm 14 \\
\hline $110-112$ & Sediment & 3.403 & \pm 42 \\
\hline $130-132$ & Sediment & 3.430 & \pm 38 \\
\hline $150-152$ & Sediment & 3.652 & \pm 39 \\
\hline $170-172$ & Sediment & 3.897 & \pm 64 \\
\hline
\end{tabular}

Tabelle 19: Am Kern ARS 5 durchgeführte ${ }^{14} \mathrm{C}$-AMS-Datierungen (UFZ-Magdeburg).

\begin{tabular}{|c|l|l|c|}
\hline $\begin{array}{c}\text { Sedimenttiefe } \\
{[\mathrm{cm}]}\end{array}$ & \multicolumn{1}{|c|}{ Fraktion } & $\begin{array}{l}\text { Alter } \\
{[\text { cal BP] }]}\end{array}$ & $\begin{array}{l}\text { Standard- } \\
\text { Abweich. }\end{array}$ \\
\hline $12,5-15$ & Sediment, Algenmudde & 1.361 & \pm 46 \\
\hline $55-60$ & Sediment, Algenmudde & 1.945 & \pm 45 \\
\hline $75-80$ & Sediment, Algenmudde & 2.240 & \pm 105 \\
\hline $168-170$ & Sediment, Algenmudde & 7.052 & \pm 68 \\
\hline $181-183$ & Sediment, Algenmudde & 8.797 & \pm 183 \\
\hline $269-271$ & Moosreste & 12.089 & \pm 511 \\
\hline $269-271$ & Sediment, Algenmudde & 13.479 & \pm 297 \\
\hline $297-299$ & Pflanzenreste & 14.733 & \pm 588 \\
\hline
\end{tabular}


Beilage 1 Pollendiagramm Arendsee, Profil ARS 1, Baumpollen (excl. Alnus und Corylus) = $100 \%$

Beilage 2 Pollendiagramm Arendsee, Profil ARS 4, Baumpollen (excl. Alnus und Corylus) = $100 \%$

Beilage 3 Pollendiagramm Arendsee, Profil ARS 5, Baumpollen (excl. Alnus und Corylus) $=$ $100 \%$

Beilage 4 Pollendiagramm Rambower Moor, Profil Boberow 1, Baumpollen (excl. Alnus und Corylus $)=100 \%$

Beilage 5 Pollendiagramm Rambower Moor, Profil Rambow 1, Baumpollen (excl. Alnus und Corylus) $=100 \%$ 


\section{Lebenslauf}

\section{Persönliche Daten}

Name:

Jörg Christiansen

Anschrift:

Hannoversche Str. 39

37176 Nörten-Hardenberg

Geburtsdatum:

29.05.1966

Geburtsort:

Risum-Lindholm

Familienstand:

ledig, keine Kinder

Staatsangehörigkeit:

deutsch

Werdegang

1987 - 1990

Besuch des Fachgymnasiums in Niebüll

Abschluss:

allgemeine Hochschulreife

$1991-1998$

Studium der Biologie

an der Georg-August-Universität Göttingen

Studienrichtung:

Botanik, Schwerpunkt Vegetationsgeschichte

Nebenfächer Anthropologie, physikalische Chemie

Abschluss:

Diplom-Biologe

1998-2000

wissenschaftlicher Mitarbeiter an der Universität Göttingen im DFG-Projekt „Wandel der Geo/Biosphäre der letzen 15.000 Jahre"

2000-2004

verschiedene Kurzeitprojekte und Vorbereitung der Antragstellung eines DFG-Projekts

2004-2008

wissenschaftlicher Mitarbeiter an der Universität Göttingen im DFG-Projekt „Paläoökologische Untersuchungen über die Entwicklung der Pflanzendecke zur Slawenzeit."

Göttingen, den 17.03.08 
